QUANTUM-MECHANICAL FEW-BODY SCATTERING EQUATIONS

WITH HALF-ON-SHELL ENERGYY-INDEPENDENT SUBSYSTEM INPUT*

ENRIQUE M, ZEIGER

STANFORD LINEAR ACCELERATOR CENTER

STANEORD UNIVERSITY

Stanford, Calfforn1a 94305

PREPARED FOR THE DEPARTMENT OF FNERGY

UNDER CONTRACT No. EY--76-C-03-05I5

\section{May 1978}

Printed in the Uniled Stales of America, Mvallable from Nactunal Technical Information Service. V.S. Department of Commerce. 5285 Port Royal Road. springfield, Virgtnia 2261 . Pricr: Printed Copy \$n.D0; Microfiche $\$ 3.00$

*Ph, D, Dissertation

\section{ABSTFACT}

We present new equations for three- and four-body scattering. within the context of non-relativistic quantum mechanics and a Hamilconlan scattering theory,

For the three-body case we present Faddeev-type equations which, al though obtained from the rignrous faddeev theory. only require twobody bound state wavefunctions and half-off-shell transition amplicudes as input. In addition, their "effective pocencials" are independent of the three-body energy, and can easily be made real after an angular momentum decomposition. The equations are formulated in terms of physical transition amplitudes for three-body processes, cxcept that in the breakup case che partial-wave amplitules differ from the corresponding full amplitudes by a Watson final-state-interaction factur.

We also present new equations for four-body scattering, ohtaincd by generalizing our three-body formalism to the four-body case. These equations, although equivalent to those of Faddeev-Yakubovski1, are expressed in terms of singularity-free transition amplicudes, and their corgy-independent effective potentials require only half-on-shell subsystem transicion amplitudes (and bound state wavefunctions) as input. However, due to the detailed index structure of tha Eaddeev-Yakubovsk1f formalisp, the result of our generalization is considerably more compli rated than in the threc-body case.

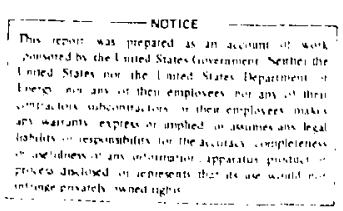




\section{Acknowledgement}

The ma1n results of this work were obtained in close collaboration with Dr. Bengt R. Karlsson, to whom I would like to express my appreciation for exclting collaborations and a much-valued frtendship.

I would like to express my gratitude to Prof. H. Plerre Noyes, for his consistent support and encouragement, for atimulating me to continually broader the perimeters of my work, and for providing a continuously evolving statement of a personal balance between the academic and social responsibilities of a scientist.

I am grateful to the Theory Group at SLAC for support, and for the stimulating nature of 1 ts ambience. I am also Indebted to the Physics repartment for continued support and genuine understanding during my graduate student pertod.

Finally, I would like to thank the Institute of Theoreticai Physics in Goiteborg, Sweden, for their hospitality during several visits.
Chapter One: Intraduction

Chapter Two: Two-Body Scattering

Chapter Three: The Three-Body Problem,

$$
\text { and Faddeev's Solution }
$$

ค. 22

Chapter Four: Three-Body Equations With Half-On-Shell Inout

Chapter Five: Three-Body Unitarlty

Chapter S1x: Four-Bodv Equatiox, with Hatf-On-Shell Input

Chapter Seven: Conclusions 
Chapter One

INTRODUCTION

Our understanding of physical processes in the microscuplc realm is largely based on quantum theory, developed in the 1920's and 1) 30 's by Bohr, Schrbdinger, Heisenberg and others.

In the decades that followed, as mast ry of the new theory and the amount of relevant experfmental data 1ncreased, attention was turned to the problem of undersianding the nature of the interactions among subatomic. (or nuclear) particles. The physical process that was then studied more and more cxtensively was that of scattering, in which a beam of particles of one klnd is made to hit a target (usually stationary in the laboratory) composed of one or more kinde of particles.

The theory that was developed to describe such a process was quantum scatrering theory. 'During the 1940's and 1950's this theory was developed in great mathematical detail Eor the caee of two-body scattering, that is a scattering in which the bexm and the target are each composed of a single kind of particle. For such physical processes, the theory was developed to a very satisfactory scate, espectally after the Introduction of the Lippmann-Schwinger (LS) equation, ${ }^{2}$ which marked the transition from a theory based on differential equations to one based on integral equations.

In the late 1950's, attempts were made at generalizing scatterIng theory to the case of three-body scattering, first with great confidence in the power of the already-developed two-body thecry, and then more haltingly as serious difficulties were encountered repeated $1 y$. These difficulties, related to a basic difference in the asymptotic nature of the two- and three-body scattering descriptions, were evencually pinpointed as arising Erom the non-uniqueness of the solutions of the three-body LS equations. ${ }^{3}$

In the late 1950's and early 1960's many successful special. models for the three-body problem were presented, weeting these difficulties withtn the restrictions of each model: A zero-range model by Skornyakov and Ter-Martirosyan, ${ }^{4}$ separable models by Mitra, 5 Sitenko and kharchenko, 5 and a non-relativistic : teld-theory model by Amado. ${ }^{7}$

A rigorous mathenatical solution to the general problem of threebody scattering within a Hanlltonian theory was finally presented in the early 1960's by Faddeev, ${ }^{\theta}$ who was able to solve the abovementioned difficultles by introducing different three-body entities and the new set of coupled integral equations they satisfy. Faddeev's work was recast Into a form more suftable to meet the practical requirements of scattering data by Lovelace, ${ }^{9}$ who first used the concept of pole dominance, and later by Alt, Grassberger and Sandhas, 10 with their quasi-particle approach. Extensive calculations applying these equations to spectfic physical systems were carried out in the last two decades. ${ }^{11}$

One of the most characteristic features of the Faddeev equations 1s that they are expressed in terms of amplitude components, 1.e. In terms of splittings of the three-body entities considered in the LS equations. This is a consequence of the fact that to properly handle the asymptotic structure of the three-body problem. Faddeev intro- 


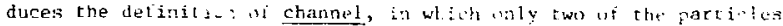

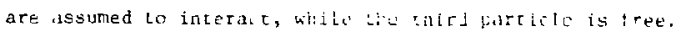

As a tesult, the Faddeev tuluations have as irput the cheranel two-body tranaition matrices of all rwo-body subsystem. Becrise n the kinematics involved, these twi-body t-matrices ulpear in the kernels of the energy hell; that is, the energy parataeter corresponds to netther of tive momenta arguments in the two-bury t-matrix. In this way, the three-boty encrgy parameter appears in the kernel not unly through the physical singularicies (Creen's functions), but also chrough the ewo-body subsystem t-matrices. Thus the $k$ ind of analytic structure that appears in the $L S$ equations is signdficantly cnanged when going into the Faddeev theory. Furthermore, since the experimental phase shifts of the two-body subsystems are connected only to the fully-on-shell two-body t-matrices, the input to the Faddeev equations is far removed from the experimental data, and thus highly model-dependent.

Usiag a general reprosentation of the utf-shell twi-body $t-$ matrices that separates the on-shall from the off-shell pieces, 2 voves deals with this problem by tntraducing a further deconposition inf the three-body amplitudes into "interibr" and "excerior" parrs. su chat only the "Interior" amplitudes invilve of $f$-sheill pleses af the twobody t-matrices. 13 However, since the interiur and extertor ampititudes remain coupled to each other fn this formula: ion, the off-sheli character of the kernel is not complecely eliminated.

In this work, we deal with this difflculty in Faddenv's work hy focusing on a different uspect of the three-body problem that is :eeminglu discunnected trom the one rentioned ab ve. Host of the approacics se referied to wetre the amplitudes of the theory by using dn dpprotriate ulane-wave basis in which to expund the relevant state vertors of tho theor. Thi; !: understandable, as hiscerically this choire is row most firect zencruifation of the rwo-budy case: In twa-bed: scattring. the oniy nat a 1 basis that ex: its is of ruuree that of : hw higenstates of the free Hantionians, f.e. the plane-wave bisis wrosponiting ic a stugie free partirit. obviously,

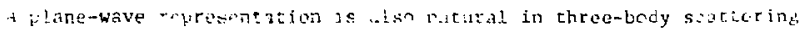

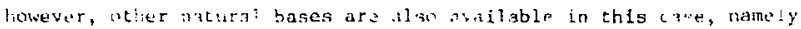

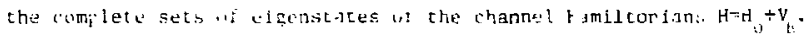
$8=1,2,3$. (An analogcus freedor af choice of course holds in the fuurbudy case.) Such projections of the three-body wavilunction compenents ont" channel eigenfunctions were first ec.11sidered hy Woyes.

L. is by exploiting tints freedum of choice for the three- and

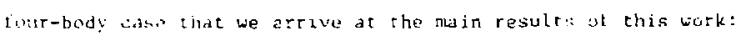

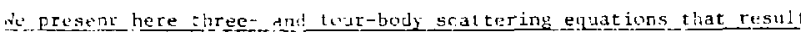

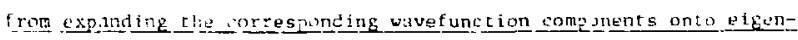
ingetions of the appropriate channei Hamiltonions, rather Lhan consi dering the nlane-wat projections of such components.

For the three-hidy rase, we expand the threc-boty Faddeov wavefuart ion compunents cnto the two-body channel eigamstaces, " and show the chis representation $i s$ actually more natural than $t^{\prime}$ ب plane-wave representation, ani leads to a considerably stmplified formulation of the chree-bondy theory.

This three-body appronci leads to a new pair of ampliturles . 


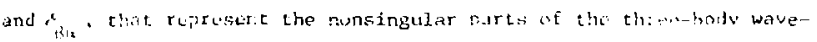
function in a kimplor way than the amplitwes intridured by Faddecv do. Ilw min advantage of this formulation, however, lins in the Eact that the integral equations far the new set of amplitudes: $\mathscr{H}^{\prime}$ and Car: signiticantly simpler in structure: thetr effoctive potentiuls arc independent of the three-body energy, and they unly ruquire twobody lalf-uon-sithll crinsition amplitudes and bound state wavefunctions as input. Niditional convenient features become apparent after an

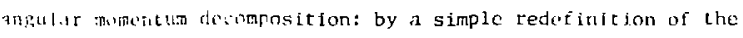
Fartial wive components of the amplitude 8 , the effective potentials con be molde $z 0.01$, and the breakup scattating amplitude is seen to cxhiblt waplichly a hatson final-state-inieraction factor in each channel.

The reasons for these simpleficotions can be physically understood as follows: mutit of the complicated scructure of the plono wave projections of the three-body wavefunction is not due to truc threeLody dynanics, but is simply a reflection of the "spectiator" two-hody channel dynamics. By considering thesc plane wive profoctions, che channel dynaming are mixed with the erue threa-horly dynamis"s in $n$ cumplicated way. If however we expand each Faddeev component of the full wavifunction into the complete set of eigenfunctions of the spectator Hamilemian in its own channel, the twombedy cbannel Jynamics are automatically treated in a natural way hy these epercator comicte sets; as a consequence, the threchody entities and is Left to consider when solving the three-body problem get appreciahly simpl if led.

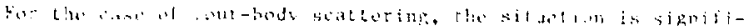

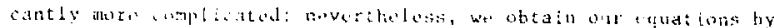

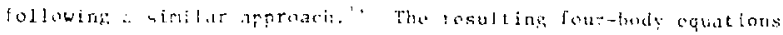

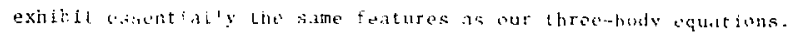

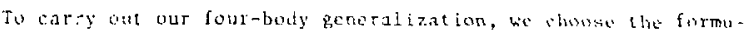

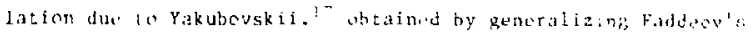

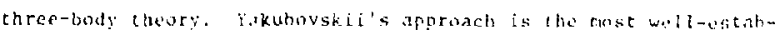
ished fort-jodv throry, in particular because its lquivalence with the schrödinger eguation nas becin demonstrated, for the passibility of spurlous ablations can be ruled out.

The mast inaracteristic jeature ot this formalisw, and atwe its

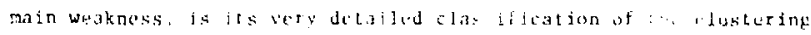
propertice at the tidur-bujy syster.

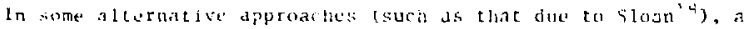
less detailed fidex structure is onsidered, for instance usiag only a two-cluster lassiftedion of the ioar particles. As compared to Yakuhovskij's, the resulting equations pxhibit in :yencral a mire

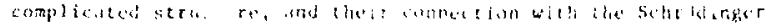

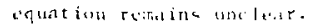

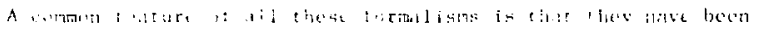

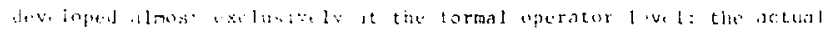

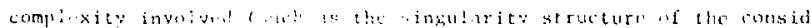

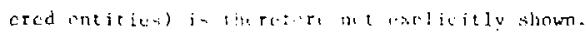

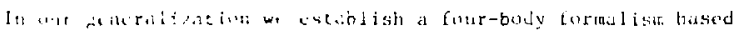

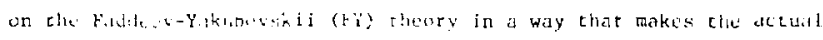

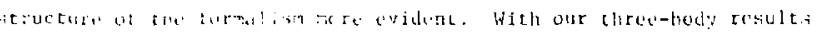


in mind, we carry out a similar singularity analysis of the Eourbody kernel. As in the three-body case, this task is considernuly simplified by using the complete sets of eigenstates of the channe Hamiltonians. The analysis turns out to be particularly straightforward for FY encicies labeled by two-cluster indices only - such is the wavefunction components $\psi^{\circ}=\sum_{B} \psi_{R}^{J}$, $\psi_{j}^{\sigma}$ being the conventional fourbody FY component - and leads very naturally to new singularity-free amplitudes for lour-body scattering.

In order to obtain equations for such amplitudes, however, the FY formalism requires that we also analyze the wavefunction conponent $\psi_{\beta}^{\sigma}$ itseif; i.e., it requires that the singularity analysis be made taking into account the Eull index structure of the Eormalism, Unfortunately, this more detailed analysis turns out to be less straightforward than the first; in addition to the physical transition amplitudes, wo ure forced to introduce a nonphysical amplitude. whici, alcheugh not present in the tuil four-body wavefunctions, still appears in the dyramical equations.

Nevertheles:;, the set of equations wi ure 1, " 1 xhlbit essentilly the samie features as our corresponding three-budy equations: namely, a multi-chanul Lipponan-Schwinger structure with energyindependent effective potentials that tellire a simplified subsystem input (i.e., unly halt-1"1-s' "! subsystem scattering amplitudes and bounc state wavefunctions).

In Chapter 2 we present a brief sumary of the relevant wo-body operators and cigorstates, as well as the relations and equations that will be useful in later chapters.
In Chap. 3 we review the difficulties faced be the direct gencralization of two-body thory to the case of threo-body scotcoring,

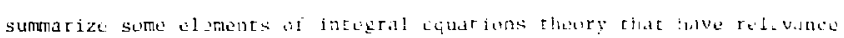

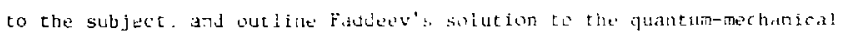
three-body probien.

In Chap. 4 we present one of the main results ot this werk, namely our hat t-o -shell chres-body equations. Wis watain the halt-

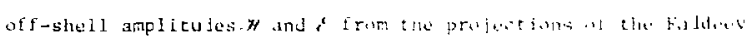
components into clannel igentatus, generalia to tine correspuming fully-oft-shell anpticuces, and derive the equat iuns they sal isly.

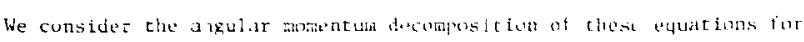

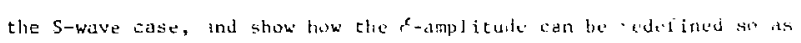

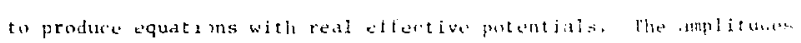

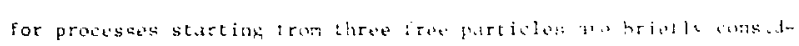

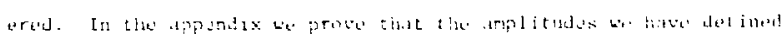

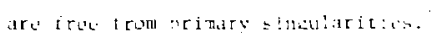

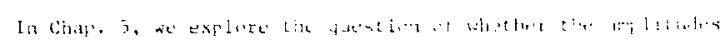

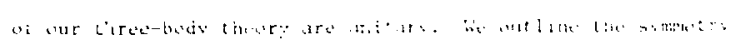

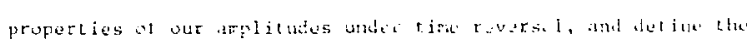

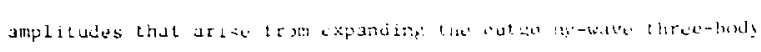

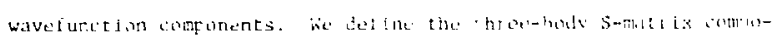

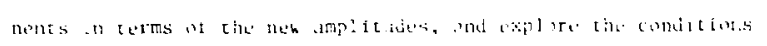

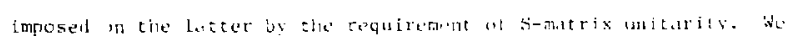

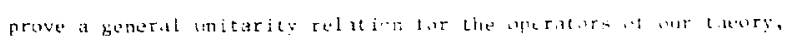

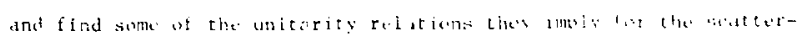

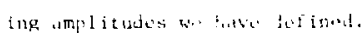




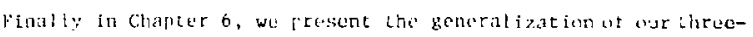
body ajproach to the four-body caso. We bripfly presunt it atraightforward ronte to deriv: che FY equations, and introduce che four-body channel eigenstates. Wo and yae bic singularitibs of the partiallysumed wavefunc:-1on comp litents, and identify the physiral scattering amplitudes. The fully-spltt Fir componenrs are then analyzed, and we find the equations they sidtisfy- Finally, we generalize cur amplitudes to the fuliy-off-shell case, connect our amplitudes to the operator formulation, and disedssi ite complicatiuns encountered. In the appendis we prove that our anplitules yield the physical scatering amplitudes.
Chapter Two

TWO-BODY SCATTERINC,

[. Tille two-budy scatcering problem

In cilis chipter we outline the main rejults of two-body scattering cheury thet are relevant to the material presented in later chapters, and write down some results that wil] become useful later.

For cte case of two-particle scatcering, the machemacical dificulties ruferred to in Chip. I can be easily handled by appropriate specialized techniques, inrronuced durings the early development of sratering thenry. The starting foint for these techniques is stationary scatceting theory, in which it is required that we find s.luluturs af the two-body Schradinger equaticn,

$$
\text { " } e^{\prime}=\left(h_{0}+v\right)^{\prime} \|_{e}=e_{i}
$$

where $h=h_{0}+v$ s the cwo-bedy Haniltonian oparator for the system. In momenturn spile: Eq. $(1.1)$ has a represenzation

$$
\vec{p} \cdot(\vec{p})+\rho_{v}(\vec{p}-\vec{p}) \psi_{\vec{k}}(\vec{p}) d^{3} p=\vec{k}^{2} \psi_{\vec{k}}(\vec{p})
$$

while, if wis assume local potentials, it has a coordinate-space i.preseritiatian

$$
-\frac{\dot{1}}{\therefore} \dot{k}(\dot{x})+v(\dot{x}) v_{k}(\dot{x})=\dot{k} v_{k}(x) \text {. }
$$

In rhe the tertercinns, 2 is the reduced mass of the two-body wask. $k$ in the ralative mumentun correspronding to an energy eigenvitulu wek $23, \dot{x}$ is the vectur diatance between the two particles in

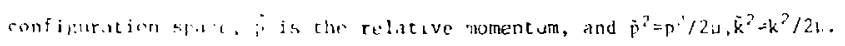
The interaction inetwen the partities is usually represented by a

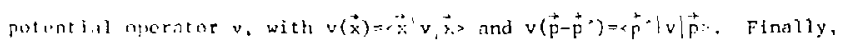




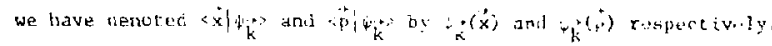

Within this lamework, the arprobejale bunklry conditiors artsing from a generai time-dependent scattwi ixg theory :" suchporated into the st itionary formulation by requireng thut clue sulution $\ldots(\vec{x})$ be of the frirm

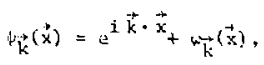

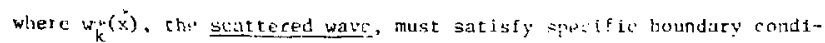
tions for $\{x \mid>\infty$, namely the radiation

$$
w_{k} \cdot(\dot{x}) \cdot E_{k} \cdot(\vec{i}) \frac{e^{i k} \cdot x}{x}, \mid \overrightarrow{x_{1}}
$$

For the problem ulitined abrve, a tigorous formulation has been developed by several autiors; in jarticuliar, a curmplete rathematical description of the soiution to the two-iody problem has been given by

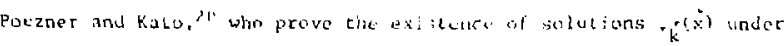

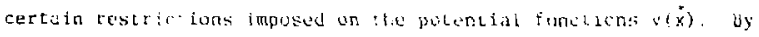

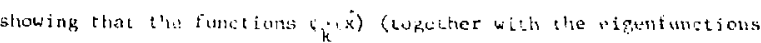
correspontings to the discrete spertrum of the operater h), (onstitute a complete set of tiptenfuncliols, they make it, asistble to expund an

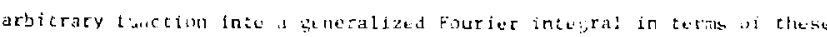

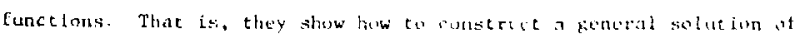

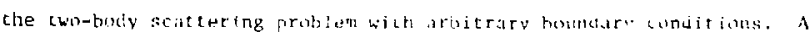

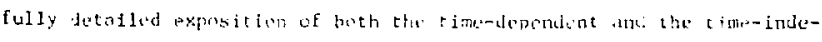

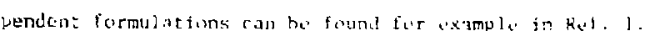

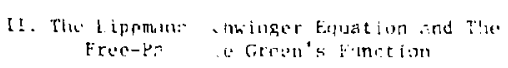

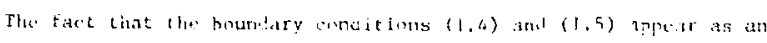

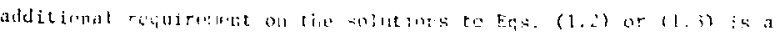

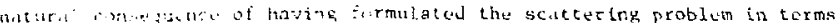

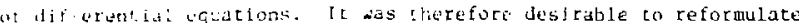
the theory in such a way so as te have those boundary conditions "built-ia" into cine ner foraliation. This was acconglishod in the 1950': Oy suveral atuthors, notably with the introduction of the LippmannSchwluger (1.S) integral Equation," which greatly Eacllitaced further progress af scuttering theory.

The change $\mathrm{f} z \mathrm{om}$ a differential e'cuation to ar integral equation with bulf-in boundary conditions can be accomplished th the following way: Consider aquin Eq. ( 2.1$)$, rearranged as follows:

$$
\left(h_{0}-e\right) \therefore=-v \cdot u \text {. }
$$

Mulciptying hath aides ty the invarme operator $\left(h_{0}-2\right)^{-1}$, we imediately obtain the 1.5 equation for rlie two-body wiacfunction,

$$
f=t_{3}=\left(h_{0}-e\right)^{-1} v ! \cdots .
$$

where $-\cdots$ is a solution of the cquation

$$
\left(i_{i},+i\right) \geqslant=u_{\text {. }}
$$

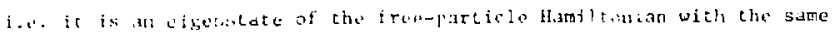

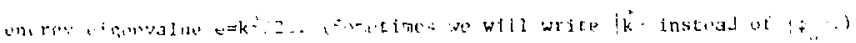

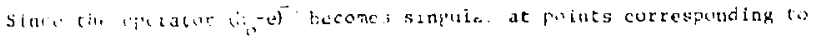
the apurulues of $b_{0}$, it is recessary o generallet its definition by

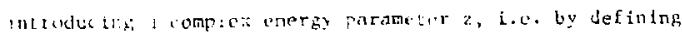

$$
\xi_{0}(z)=(h,-s)^{-i} \text {. }
$$

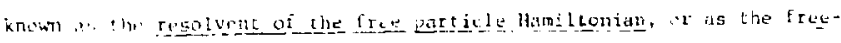

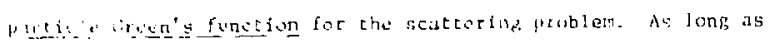

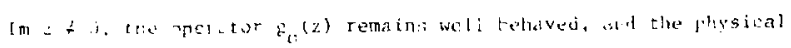

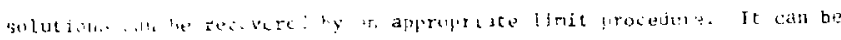


show that once $\left.\right|_{0}{ }^{\prime}$ is chosen and a specific prescription for the limit Im $2+0$ is given, the efgenfunctions are completely detsminad ly Eis.

(2.2); i.e., the buundary conditions hase beten successfuity incurpardtent into the dynamical equat fons to be solves.

The nature of the limit prescription can we seen as tollows: It 1

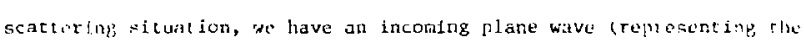

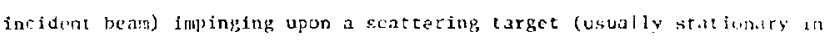
the lab transe). The scattering of proiectile aat taget produce i spheriral wave: centered at the target's posteton, so that we end tip with a siatcering solution of the cype given in Eq. (1.4), i.c.

$$
p_{k}(\vec{k})=e^{i \vec{k} \cdot \dot{x}}+f \vec{k}(\vec{x}) \frac{e^{t i k x}}{x}
$$

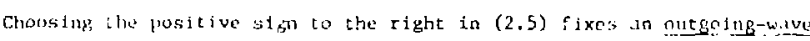

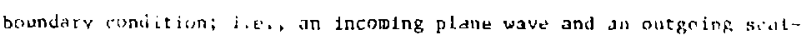

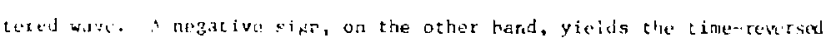

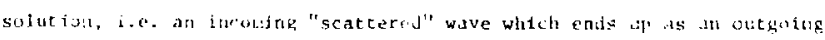
pl.inir *itue.

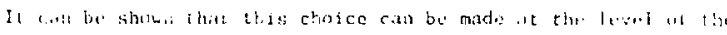

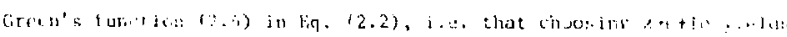

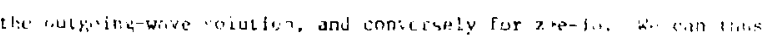

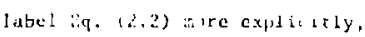

$$
i t^{2} \cdots \omega_{0}, B_{0}(e+10) v \mid \psi^{+} \text {. }
$$

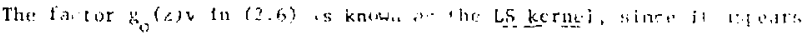

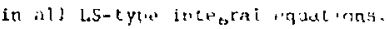

: With appropriats enstrectas on the ketnel, this L.S. type it:teptit

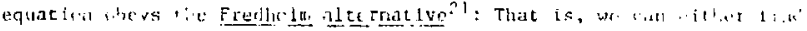

sratturing wavetunctions $/ \mathrm{k}^{-(p)}$ is solutions of (2.6) with a nonzero

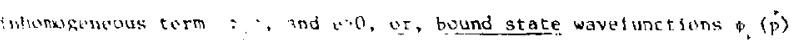

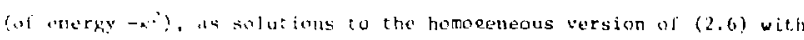
end. But we ban nuver ind the two kinas o solutions cooxisting at a iven inurgy.

Hore explicitly, that the Fredholm alcernative eximl: tor Eq. (2.6)

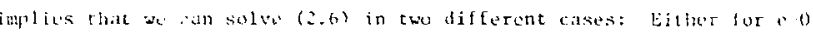

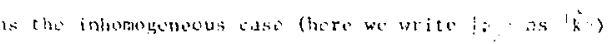

$$
i_{k} \hat{k}=\dot{k}-q_{n}(\dot{k} \cdot \operatorname{in}) \cup i \dot{k}
$$

It is the homogene ous case for pan,

$$
\because-x_{0}(-x-2) 0 ; 0,
$$

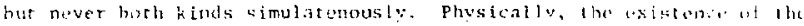

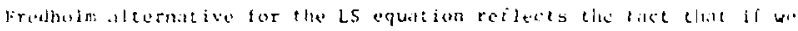

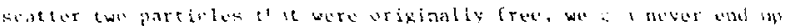

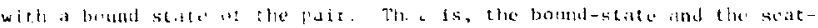

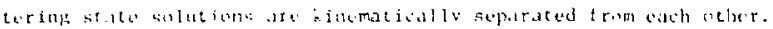

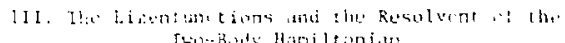

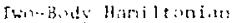

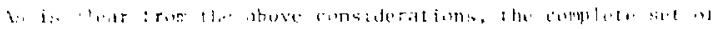

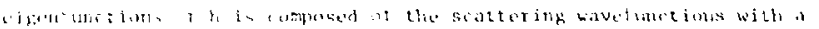

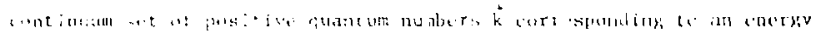

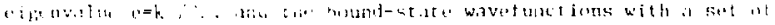

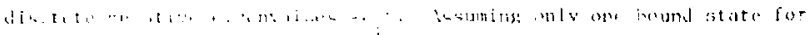

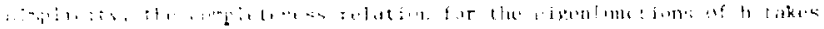
i'l 1 r.

$$
\therefore \quad \ddots_{i}+\int !+\infty \dot{k}_{k} \quad 1
$$


where it will be recalled that for plane-wave states the correspunding completeness relations is given simply by

$$
\int_{\mathrm{d}^{3} \mathrm{k}} \mathrm{k}|\overrightarrow{\mathrm{k}} \times \overrightarrow{\mathrm{k}}|=1
$$

The actual solutions to Eqs. (2.7), however, are usually obtained tn terms of other operators that are more conventent and also more central to scattering theory. One of them is the resolvent of the full two-body Hamil conian, 1,e.

$$
g(z)=(h-z)^{-1}=\left(h_{0}+y \cdot i^{-1} .\right.
$$

From the definicion (3.3), it is cleat that, for real potentials,

$$
g^{+}(z)=g\left(z^{\star}\right)
$$

(wh:re implies the hermitian adjoint operation, and the asterisk * imbltes complex conjugation), and also tha.

$$
g\left(z_{1}\right)-\varepsilon\left(z_{2}\right)=\left(z_{1}-z_{2}\right) g\left(z_{1}\right) g\left(z_{2}\right) .
$$

Eq. (3.5) is known as Hilbert's idemelty, or as the first resolvent

\section{equation.}

The importance of the operacor $g_{3}(z)$ is that, onre it is known, the elgenfunctions of , can be obtained by a jirect limit procedure (instead of finding it by solving (2.6)). To see this we manipulate' Ee, (2,6) agatn, "solving" for las:

$$
i \psi=\left[1+\varepsilon_{10}(z) v^{-1} \mid \psi .\right.
$$

Buc

$$
k_{0}^{-!}\left(1+g_{0} v\right)=B_{0}^{-1}+v=h_{0}+v-z=b^{-1},
$$

so that

$$
\left|\psi=\left(1+g_{0} v\right)^{-4} \psi_{0}=0,8_{0}^{-1}\right| \phi_{0} \times
$$

Furthermore, $\left.g_{0}^{-1}\right|_{0}=\left.\left(h_{0}-e+i t\right)\right|_{0}=t i \phi_{0}{ }_{0}$, so we flrislly find that

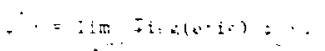

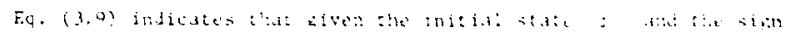

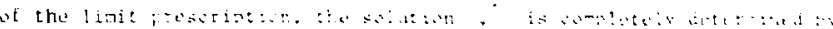

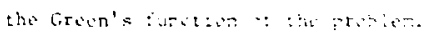

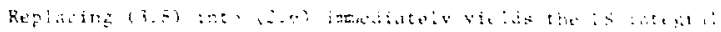
aquarion for sas?

$$
\therefore=z_{0}-2, \cdots
$$

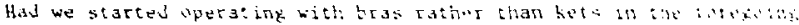

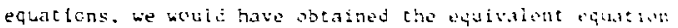

$$
\Sigma=s_{0}-s^{2} \sum_{2}
$$

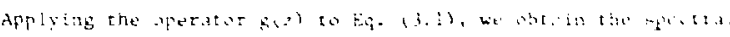

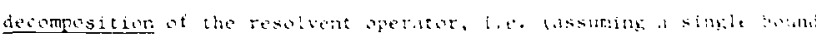
state at energy - 1

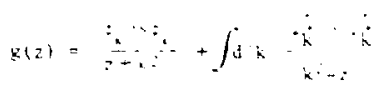

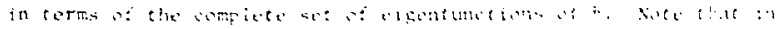

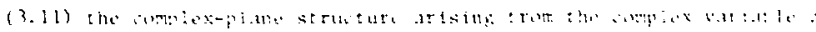
is asplicits a d a bitat.

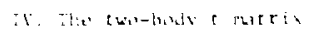

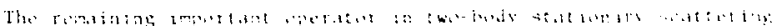

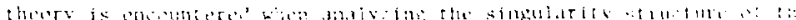

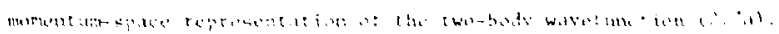

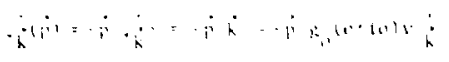

lsing (1, 3), we cin writo

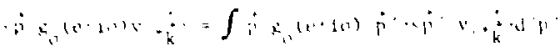




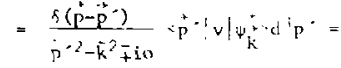

$$
\begin{aligned}
& -\frac{p+v \mid q k}{p^{2}-k^{2}+i n}
\end{aligned}
$$

(since the frec-particle Green's function is diagonal in a plane-wave repres.ntation). Thus

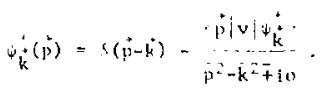

The matrix element pilvilin is directly connected with the siatturing amplitude $i_{k}$ of Eq. (2.5), as can be seen by btaining the fourier transform of (4.3) to reproduce (2.5). Because of this, plane-wave motrix clements of a transition operacor ${ }^{\prime}$ are defined through

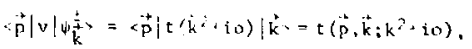

such thit

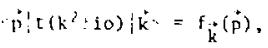

thus relited th the differential cross-scction by

$$
\frac{d n}{d 2} \cdot|-\vec{k}| t(\vec{k}+10)|\vec{k}|^{2} .
$$

Now from the dofinition $(4.4)$ we see that

$$
t\left(k^{2}+i_{0}\right) ; \vec{k}=v \mid \psi_{k}^{*}
$$

fur:hernore, since replacing (3.10b) into (3.8) yields

$$
\left|\psi_{\vec{k}}=(1-g v)\right| \vec{k},
$$

wo obtain, replacing (4.7) into (4.8),

$$
t=v-v g v \text {, }
$$

which de'ines the transition nperator $t$ in terms of the (ircen's function g. Replacing (4.9) into (3.10a) right-multiplied by v, and into (3.10t) left-multiplied by $v$, wo obtain the identities

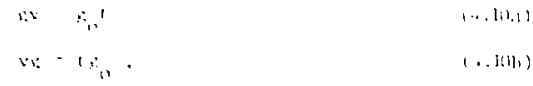

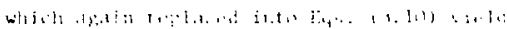

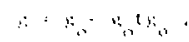

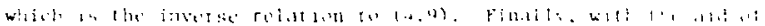

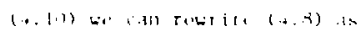

$$
\text { in }-(1-1,1) \dot{b}
$$

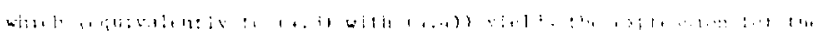

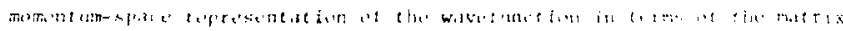
oliments w the tramsition werater t:

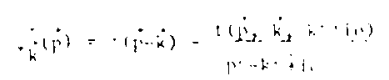

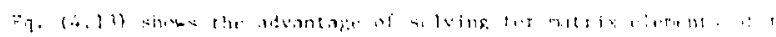

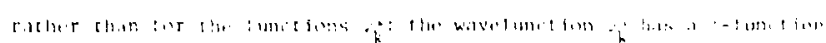

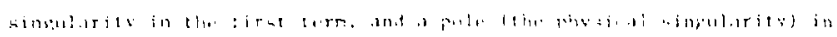

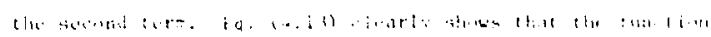

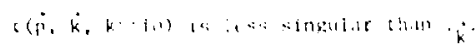

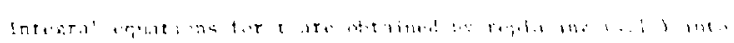
$(-1)$. Bivin:

$$
\begin{aligned}
& \text { 1 : } \forall-\cdots, \\
& t=v-t s x \text {. }
\end{aligned}
$$$$
\ldots(\cdot . .1)
$$

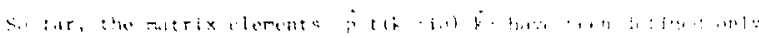

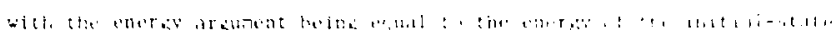

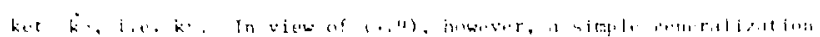

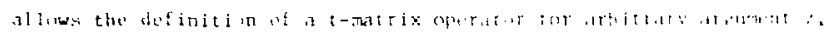
i.

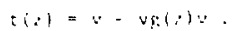


The functions

$$
t\{\vec{p}, \vec{k} ; z)=\vec{p} ! t(a), \vec{k}
$$

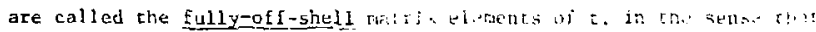

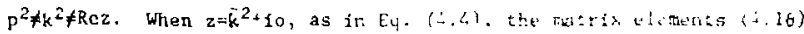

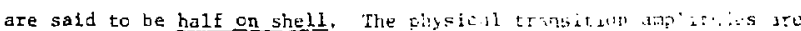

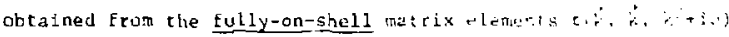
$=<\vec{k}\left|t\left(\vec{k}^{2}+10\right)\right| \vec{k}>$, as in Eq. (4.6).

Using (3.4) and (4.9), we see that

$$
t^{+}(x)=t\left(z^{\star}\right) \text {, }
$$

which forplies that

$$
t *(\vec{p}, \vec{k}, z)=\left\{\left(\vec{k}, \overrightarrow{p^{*}}, z^{*}\right) .\right.
$$

In the stevations that ate usually encomected, in whatid time-revetall Invartance and detalled balance are conerved, wh also how evidesily.

$$
t(\vec{p}, \vec{k} ; z)=t(\vec{k}, \vec{p} ; z)
$$

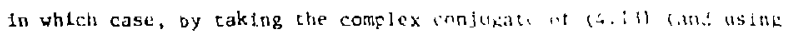
$(4.18))$ we obtain

$$
[\underset{\mathrm{k}}{+}(\dot{\mathrm{p}})]^{*}=\stackrel{\overline{\mathrm{k}}}{\overline{\mathrm{k}}}(\overrightarrow{\mathrm{p}}) \text {. }
$$

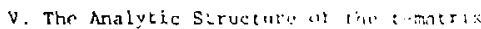

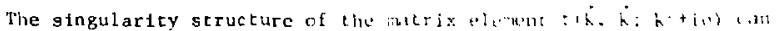

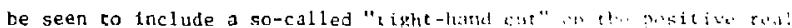

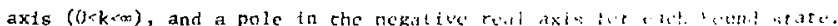

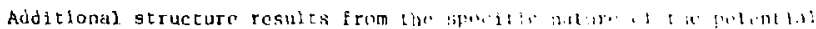

\section{functions $v$ ( $x$ ).}

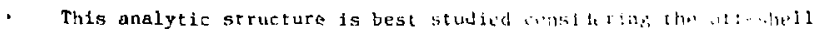
matr: $x$ elements (4.16); using Hilbert's ldent ty tor g(:) (F.q. (3.5))

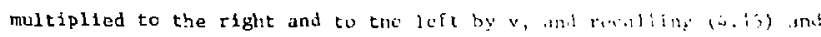
$(4.10)$, we can write

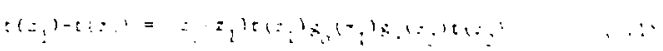

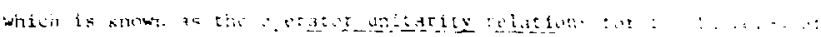

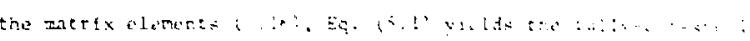

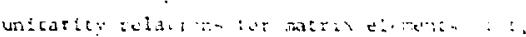

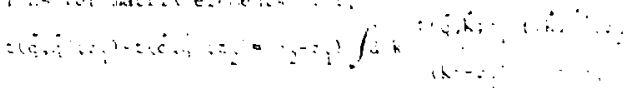

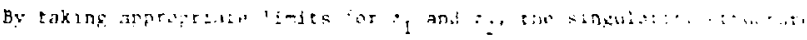

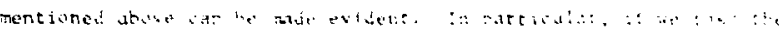

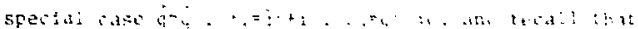

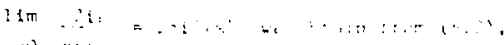

in $x \cdot+$

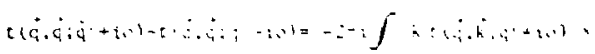

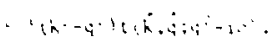

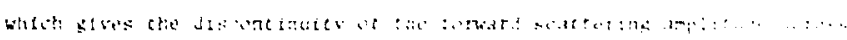

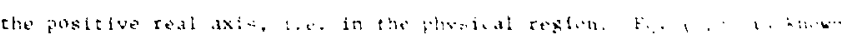

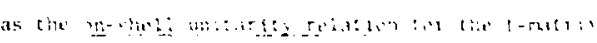

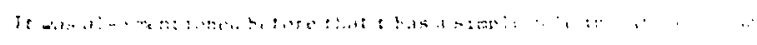

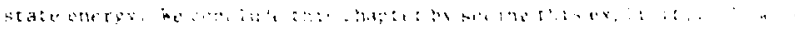

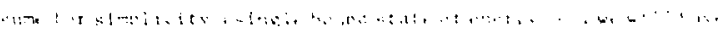

$$
\therefore, \ldots+1, \ldots+
$$

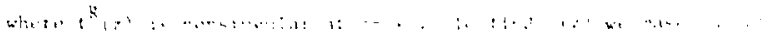

"

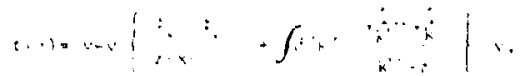

$\therefore$ th.st

$$
\cdots \quad \therefore \quad \because \quad \because .
$$




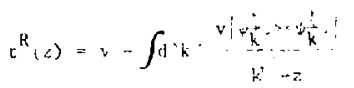

Takits, matrix elements of $(3,-1)$, we se:

$$
v(\dot{p}, \vec{k}, 2)=\vec{p}|v|: \cdots, \cdots v \dot{k}
$$

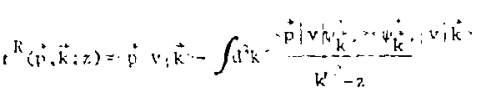

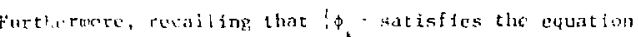

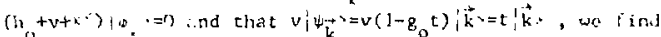

$$
r(\dot{r}, \dot{n} ; z)=\frac{\dot{k}(\vec{p}) \phi_{k}^{*}(k)}{z+k^{2}}+t^{k}(\dot{p}, \dot{k} ; z)
$$

wher

$$
S_{k}(\dot{p})=-\left(p^{2}+x\right)+(p)
$$

is known as the gertex function for the bound state, and the rainder is given by

$$
t^{R}(\vec{\Gamma}, \vec{k} ; z)=v(\vec{p}-\vec{k})-\int d^{3} k \cdot \frac{t\left(\vec{p}, \vec{k}^{\prime}+\vec{k}^{-2} \pm 10\right) L\left(\vec{k} \cdot \vec{k}_{i} \vec{k}^{-3}+\mathbf{i} 0\right)}{\vec{k}^{-2}-z}
$$

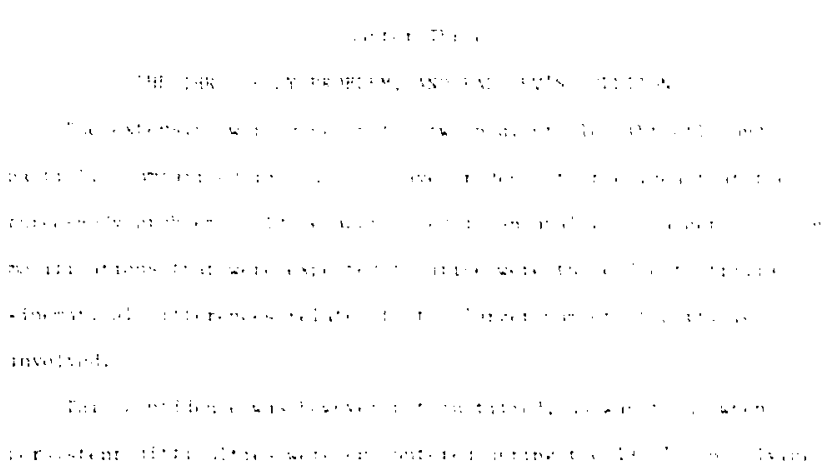

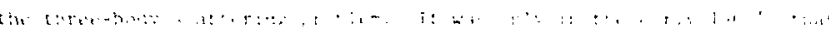

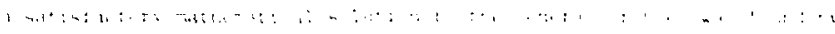

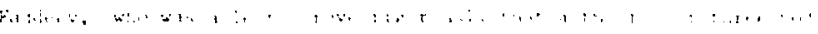

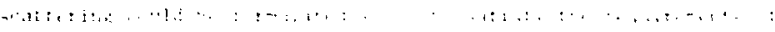

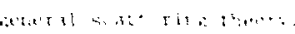

$$
\text { : A + A }
$$

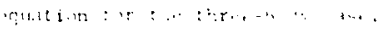

$$
11,+\because-\cdots)
$$

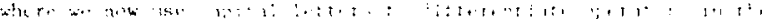

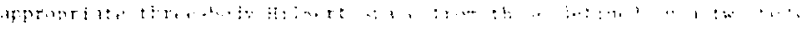
4) i1.11.

$$
\because-\because+x+\because \quad 11,1
$$

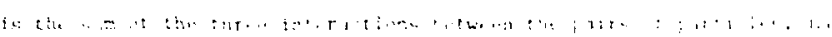

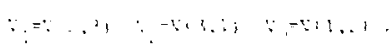

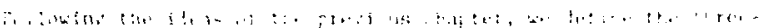


body Eree-particle Green's function as

$$
G_{0}(z)-\left(H_{0}-z\right)^{-1}
$$

and the corresponding full creen's iunction as

$$
C(a)=\left(H_{0}+v-z\right)^{-1}
$$

The three-body transicion operator $T(z)$ is dufined th be, also in analogy to che two-body" rase,

$$
T(z)=v-V C(z) v
$$

and obeys the equations

$$
\begin{aligned}
& T(z)=V-V G_{0}(z) T(x) \\
& T(z)=V-T(z) G_{0}(z) V .
\end{aligned}
$$

known as the thres-body LS equations for $T$.

Inspired by the cinfidence with which the well-dweloned twin-bind seattering formalism was generally held, it was assuma that, by meinit

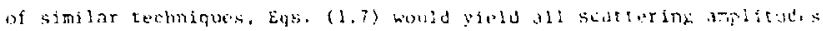

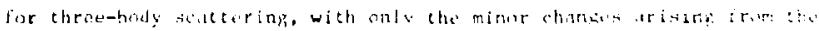

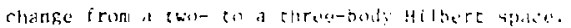

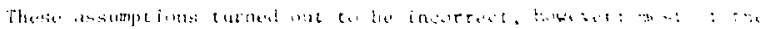

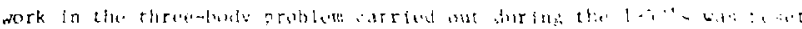

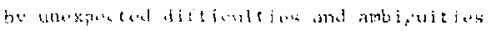

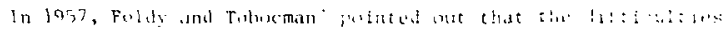

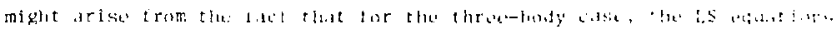

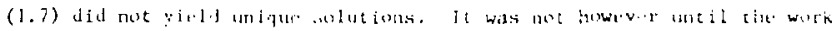

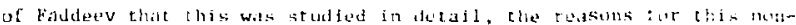

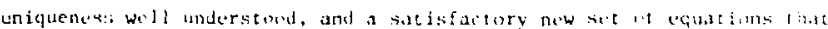
yiched torrect scatrering amplitudes was hend

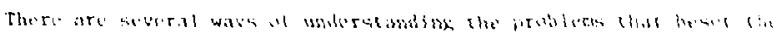

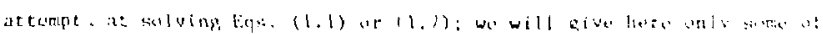

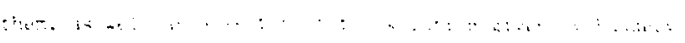

$$
\therefore \quad \therefore \quad \ldots \quad \therefore, \cdots, \cdots
$$

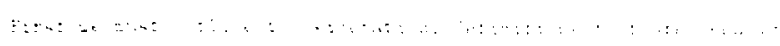

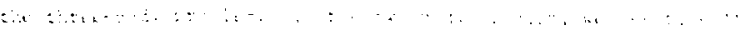

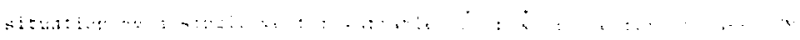

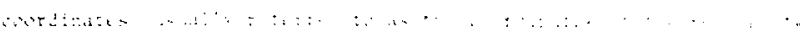

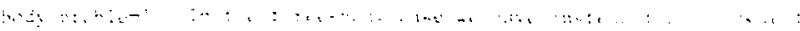

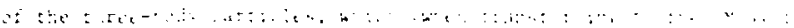

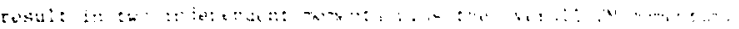

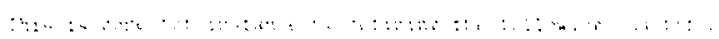


body ent ity hoins: j,itrit, :.

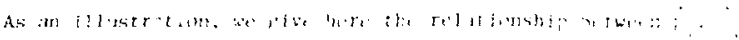

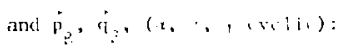

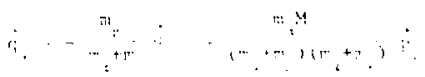

$$
\begin{aligned}
& P=i-\therefore \quad \therefore .
\end{aligned}
$$

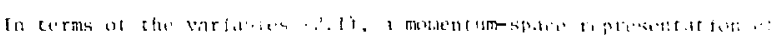

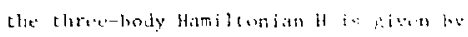

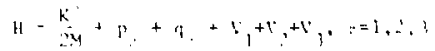

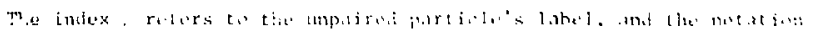

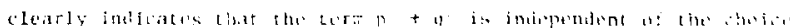
of $\therefore \ln \{\therefore 3\rangle$,

$$
\dot{r}=\frac{n}{\because y}=\frac{1}{y}
$$

with

$$
\begin{aligned}
& 11=-\cdots(m+m) \\
& u=\frac{m, n}{a+n},
\end{aligned}
$$

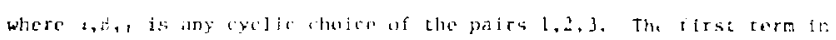
(2.3) can of course always be decoupled frum the tnterna nution of the system.

The kind of kimematio variables wo have jest desertned leads ver

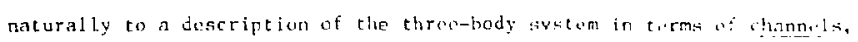
which as we will see are a central feacure of Faddeev's artition. A channel is defined as a corfiguration of the three partiles in which

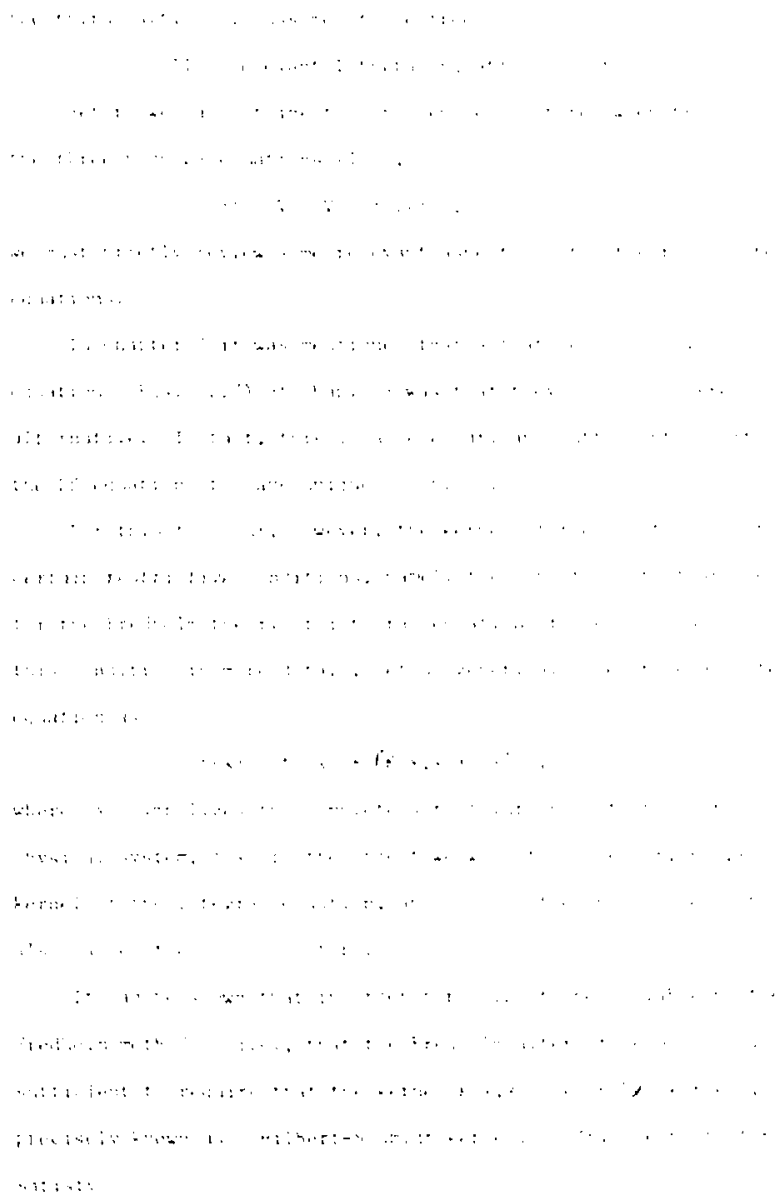




$$
\| k !_{s}=\int k\left(x, x-\cdots \text { dix } 1 x^{\cdots}\right. \text {. }
$$

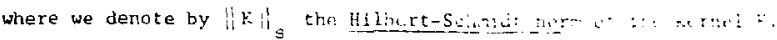

This should be compared to che ususi inerizter m r: "

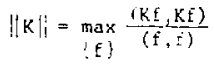

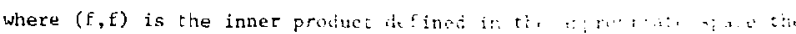

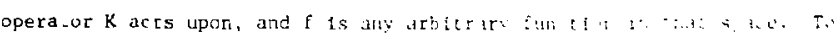

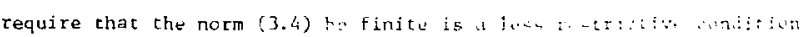
than (3.3), since it can be shown tha:

$$
\mid k i_{s} \geq 1, K i i^{2}
$$

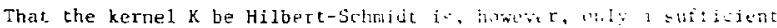

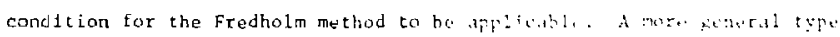

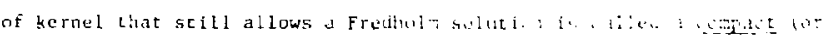
compietely continuos) kernel.

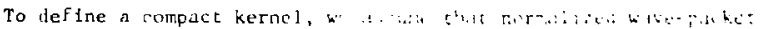

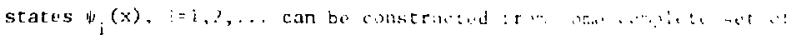

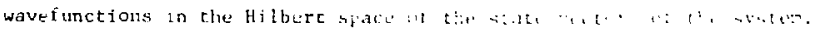

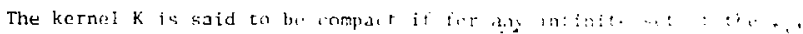

$$
k_{i}: \int k\left(x, x^{\prime}\right) n_{i}(x) d x
$$

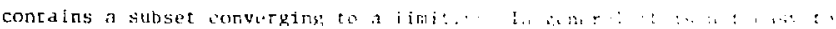

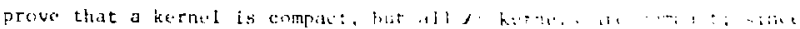

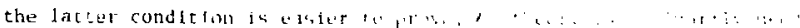
when applicoshle.

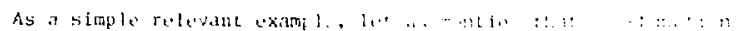

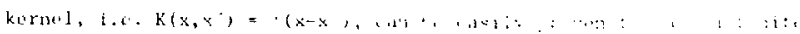

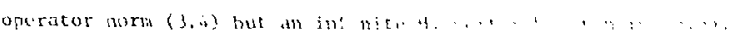

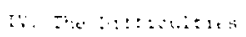

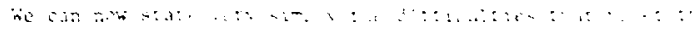

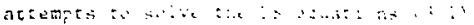

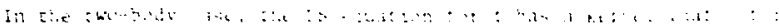

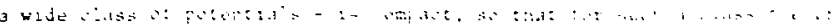

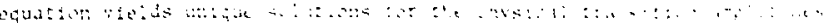

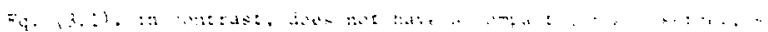

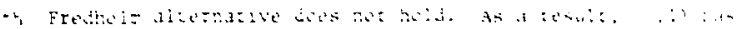

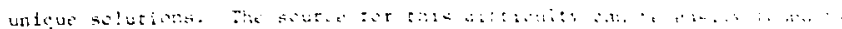

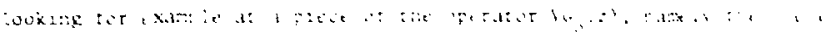

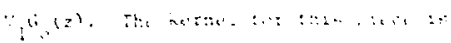

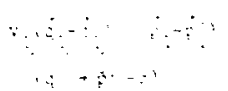


intriasically difterent from that of the two-budy problim, an! in: different structure must be dealt with appropriataly.

To fllustrate this, we show how a ditferent vlew at the torme difficulty becomes apparent when we consider the three-budy sthriting.t. equation (Eq. (1.1)),

$$
\left(H_{1}+\sum_{i 2=:}^{3} V_{1}-E\right) i H^{+}=0
$$

which we rearrange (for an arbitrary index $x$ ) to redd

$$
\left(H_{0}+v_{a}-E\right)\left(r^{+}\right)=-\left(v_{i}+v_{v}\right)+t^{+} \cdot 1=1,2,3
$$

Defining the chamel tuo-bndy Green's function de

$$
G_{1}(z)=\left(H_{0}+v_{1}-z\right)^{-1}
$$

we can invort (i. 2) Es abtain

$$
14^{+}=c_{x} i_{x}-c_{11}(E+i o)\left(v_{z^{2}}+v_{y}\right) \psi^{+} \cdot x=1,2,3
$$

where l $_{\text {is }}$ is a solution of

$$
\left(H_{0}+v^{x}-E\right) \mid x_{i x}=0 \text {. }
$$

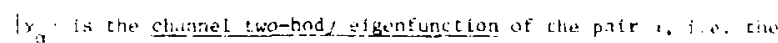
efgenfunctions of the a subsystem, in whteh partirles is a spectacn

obviously, we can carry ouc this procedure in chee different wiy (one for each channo1), so there is no way to deteruine how mucit of each of the $\left\{x_{a}\right.$ goes into the full aolution $\mid t^{t}$. (1.t. che values of the $C_{u}$ ) until one has sol-ed the problem tia ? different way. ${ }^{2} A_{i}$ thori, any of the equations (4.4) has a bufle- In ambigulty in its hourdar: conditions.

In yel anothet way, we can express the difficuley by sayne thit, again due to the nature of tt:s kerne?, the hoangenenus verston if if, i) will also have solut 1 n:s in the scattering region. This helps to

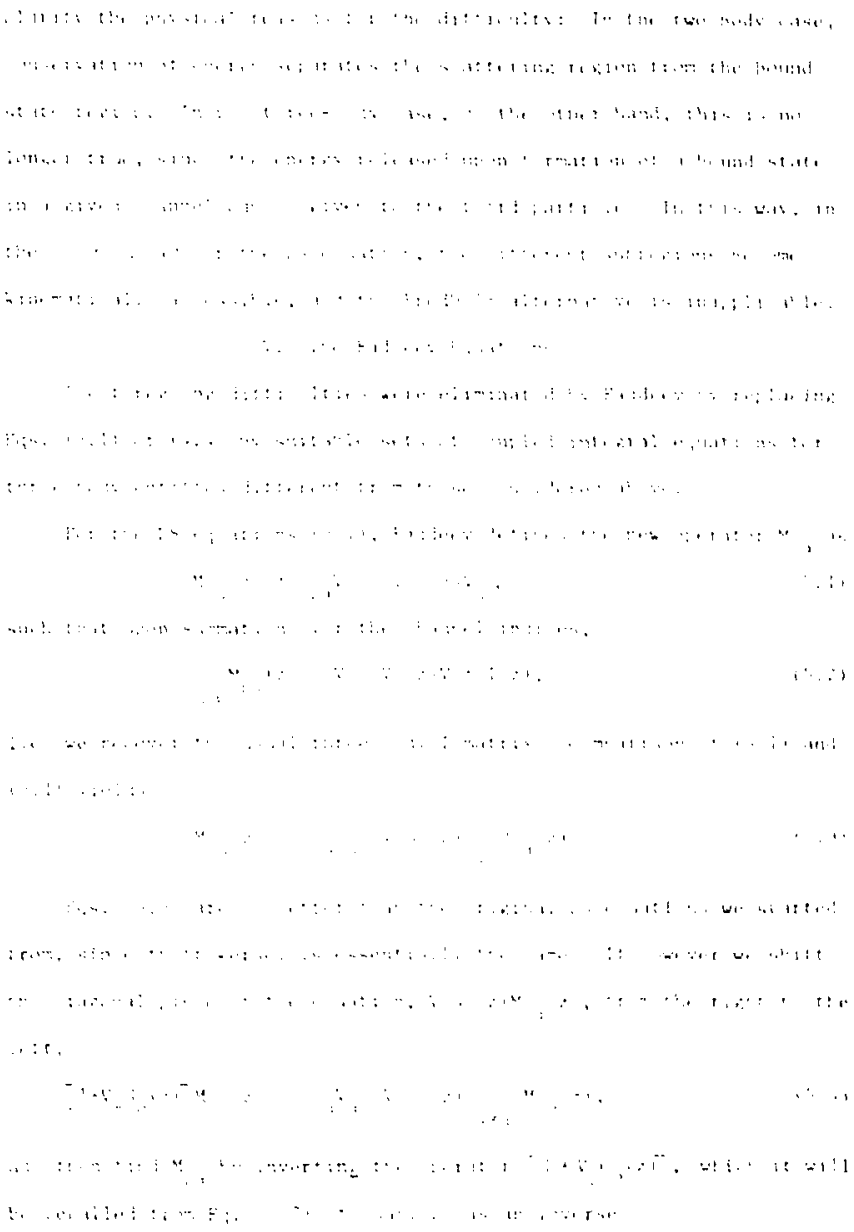




$$
I+v_{0} G_{0}(2)^{-1}=\sigma_{0}^{-1}(z) \sigma_{0}(z)
$$

we obtain the equations

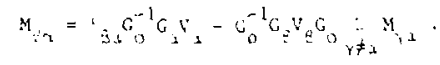

where we have omittoil writing the z-dependence of the operators in

$(5,6)$. Recialling now $E_{q}$. (4.10) irom chap. 2, 1.e. that

$$
G_{b}=G_{0} E_{z} \text {. }
$$

where $t_{\beta}$ is the two-body t-matrix in channel $E$ suitably defined in the three-hody Hilbert space, we can write (5.6) as

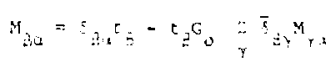

or equivalentiy,

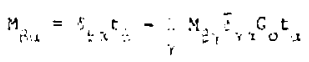

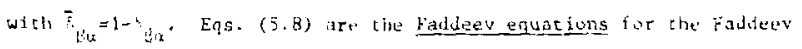
operater $\mathrm{M}_{\mathrm{S}}$.

The kernei of Els. (5.8) is differine from the 25 kernel, Jue :-

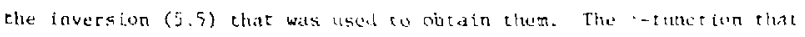
survives al all orders in the Le kngnel disappears after one fleration

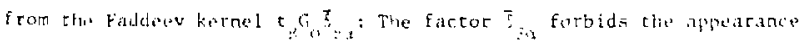

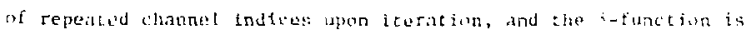

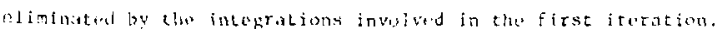

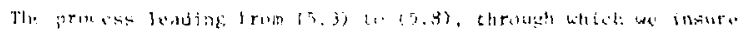
that the new kerred has the desired shuracteristics, is atled rimeving discomected pieces iron the kernel. The name arises from rite fact that. as opposed to the three-body t.s equations, no disconnerted processes

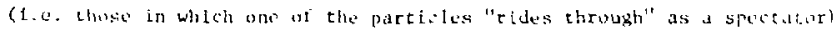

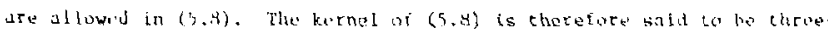

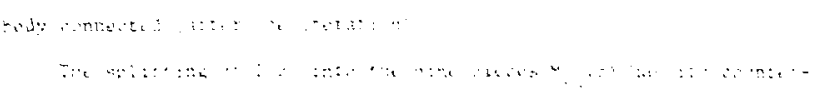

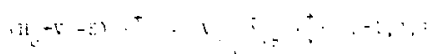

so that intersion ant wits

$$
\therefore=-\therefore \quad \because \because \because \because \because \because
$$

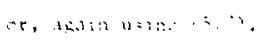

$$
\because, \quad, \because, \cdots, \cdots, \ldots, \ldots, \ldots
$$

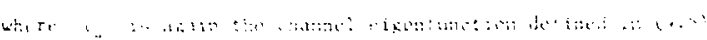

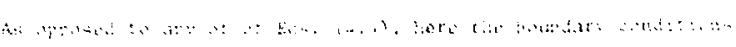

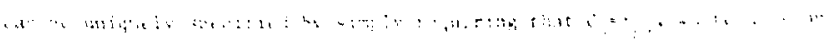

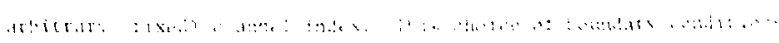

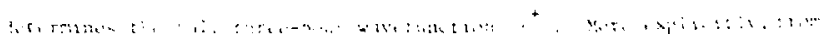

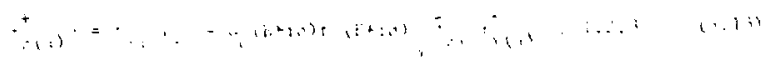

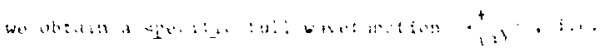

$$
\therefore \quad \therefore, \quad \ldots i, 1
$$


as that threr-body scattering solut ion that arises from an initial stace of an interasting pair a and a third free particle. Eqs. (5.13)

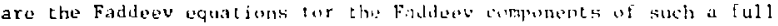
three-body waverunct ion.

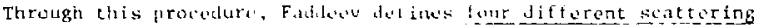
solutions, according. to the initial state trom which each arise (a bound state in eath channel with the currespinding third fres particle, and the state of three trece partiallas):

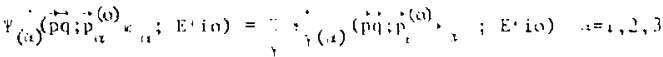

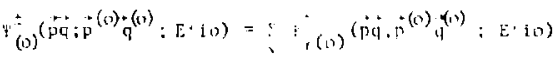

In the second line "fi (b.l(s), the ind hal stace of three tree partictes has an energy $E=p(0) \cdot+\gamma(0)$, while the chand 1 initial state in $t$ ? first line has energy $E=p_{1}(0)_{-} \cdot$, corresponding to a bound state in chanuel o whth energy - $\therefore$ and a third free particle of menentum $p_{i}(0)$.

The Fadieev approith in fact sulves the thret-body problem by successfully constructing the Hilbert spite corresponding to the continusus spectrum of $\mathrm{H}$ from four ditferent pieces,

$$
x^{\prime} x_{1}+x_{1}+x_{2}+x_{3}
$$

so that each of the wiverunctions ( 5.15 ) are the eigenfunctions of $H$ in the proper subspace. In addition, we of course alsn have the (kinematically inaccessible) discrete spectrum of $H$, corresponding to threetoody bound staces, with a Hilhort spare, $\boldsymbol{x}_{\text {.l }}$ "

Returning to the faddesv uquations ( 5.8 ) for $M_{30}$, we obtain equations for the corresponding amplttude: by taking plane-wave matrix elements of (5.8). In the two-body case, such plane-wave bra and kets whr a

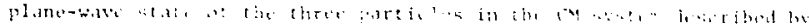

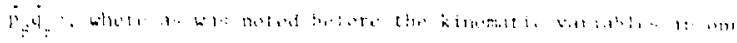

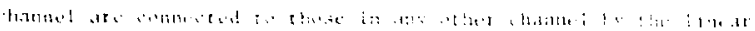

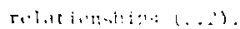

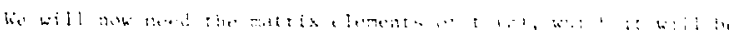

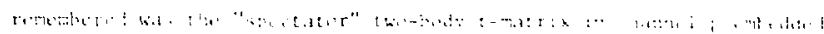

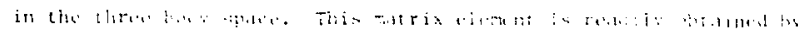

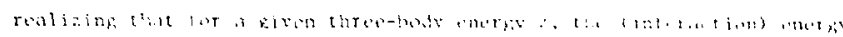

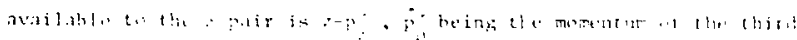

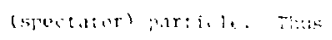

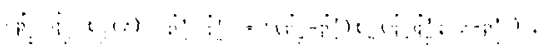

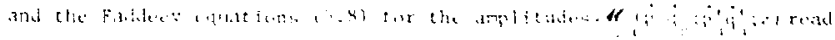

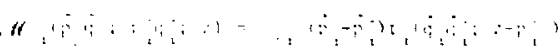

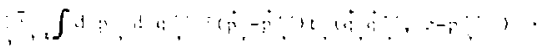

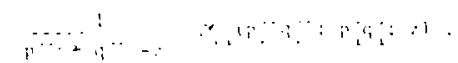

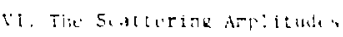

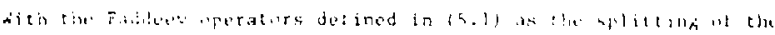

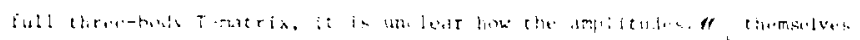

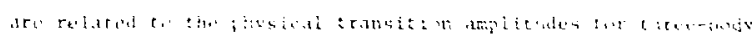
sithloting.

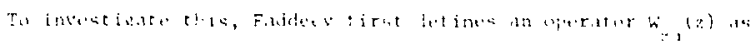

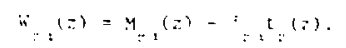

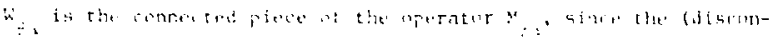




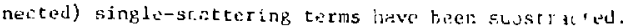

It is in fact fer the operater bi chat raddew catrig: out his

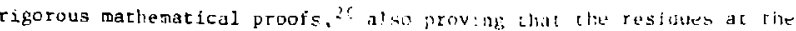
phystcal stngulartetes in $w_{d a}$ yleld the physical tiatis:tion impittudes, 25,2: Explicitly, it is proven that we cun write for cise amplitudes $\alpha /$

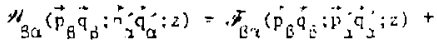

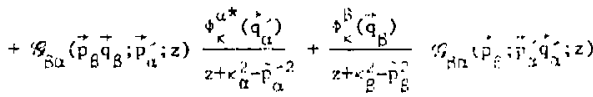

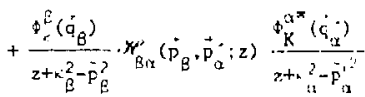

where the vertex functions s have been deilned in Eq. (5.9) of Chap. 2 and the functions. 4 , 8 and have no primary singularities 19,27

Thus, in Faddeev's approach, the scattering amplitudes dre ubtained as the residues of the operator $W_{B a}$. if is showr to be related to the

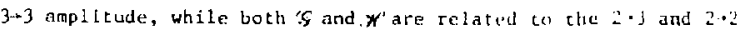
amplitudes.

For the case of most phystcal interest, i.e. an initial state conslsting of a bound state plus a third frew particis, $f$ and whe the relevant quantities. Instead of wrjtinxi equat inus for $\because \ldots$, Usions and

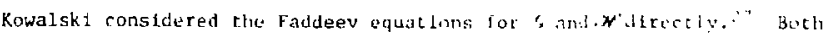
Eqs. (6.2) and the Osborn-Kowalskl (ok) coguarions folinw froli -ijh Ing use of Eqs. (5.B) rif chap. 2, i.e. of a splitting af the two-bordy thatrix Into a term $c^{p}$ containing the bound-state polp. and a reandinder $t^{R}$.

A differene approach, presented by Alt, lirassborger Jul Sandhas (ACS), 10 introduces a different Faddeev operator $U_{b i 1}(z)$ that yiclds the

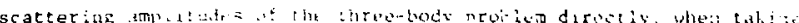

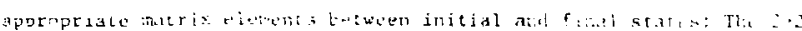

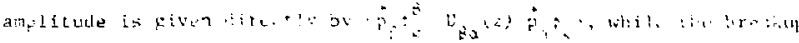

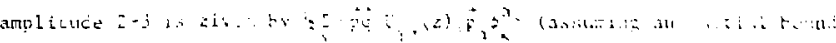
seat it: thancel :

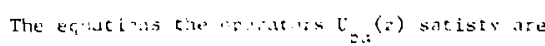

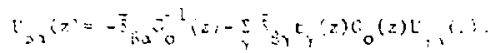

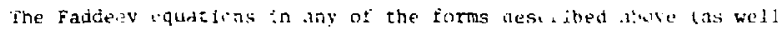

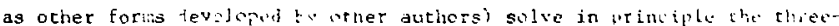

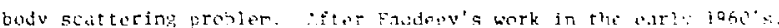

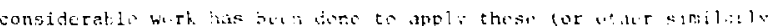

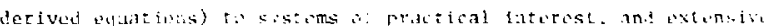

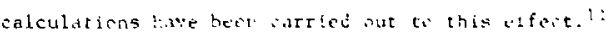

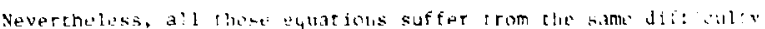

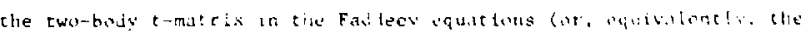

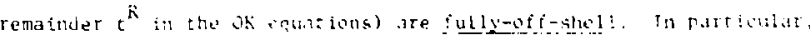

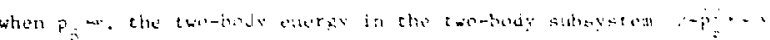

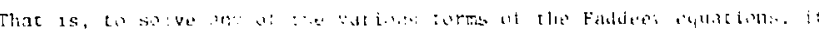

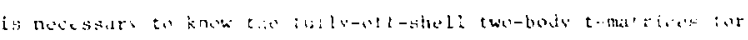

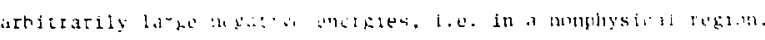

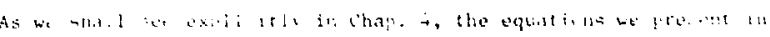

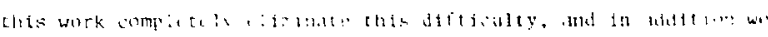

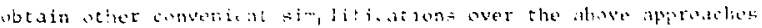




\section{Chapter Four}

THREE-.BOOY EOLATTONS WTTH HALF-IN-SHEC.i. I:ITLT

I, Incroduction

We present in this chapter sue of the two main results or this wurk, namely a niw spet ot equations for three-body scatrerang. The remaining main result is the corresponding generalization to thur-body swattring, presented in litapter 6.

In two-budy scatcring theory, as mentioned before, the only natitil bas is is the elgenstates of the free Hadllontan $h_{0}$, i.e., the

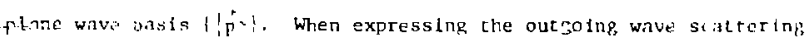
state veccor $\mid \psi_{\vec{k}}^{+}$in such a basis, $\psi_{\vec{k}}^{+}(\vec{p})=\langle\vec{p}| \psi_{\vec{k}}^{+}$, , one is naturally ivi Lo n repros,ontation in terms of a less singular amplitude, suct. as is found in Eu. (4.13) of Chap. 2 :

$$
\psi_{\vec{k}}^{+}(\vec{p})=\delta(\vec{p}-\vec{k})-\frac{t\left(\vec{p}, \vec{k}, \vec{k}^{2}+i 0\right)}{\vec{p}^{2}-\vec{k}^{2}-i 0} .
$$

where $\vec{k}^{2}=\frac{k^{3}}{2, i}$, and where $t\left(\vec{p}, \vec{k}, \dot{k}^{2}+10\right)$ is just the plane wave natrix element of the transition operator $c(2)$ (its on-shell value, $1 . p$., the residue at the scactering polc $\tilde{\mathrm{p}}^{2}=\overline{\mathrm{k}}^{2}$ in (1.1) yields the physieal transllion almplitude).

In chrea-body scattering theory the situation is more complfcated. Also in thi:i case a plane wave representation (corresponding to the eigenstate $\mid \overrightarrow{p q}$ of $\left.H_{0}\right)$ is natural. A detalied analysis of the sinpularfty structure of such a representation for the three-body wavefunction, $\left\langle\overrightarrow{p q} i u^{+}\right.$, has been carried out by Faddeev, as referred to th the previous chapter, and leads to an expression similar to (1-1), but now in terms of a pat of amplitudes $\psi_{g \alpha}$ and $f_{B(t}$ (descrtbed in the Appendix). Susc as In the two-body case, these amplitudes are closely related to the

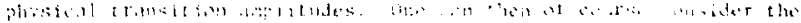

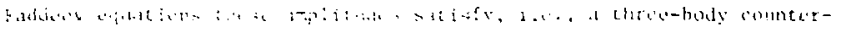

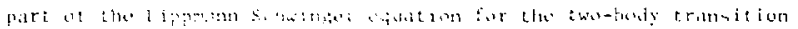

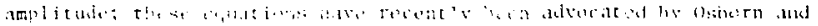

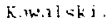

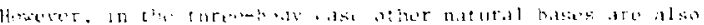

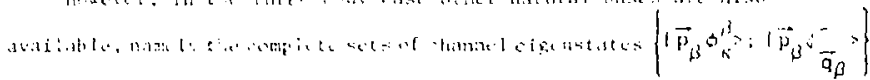

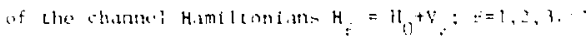

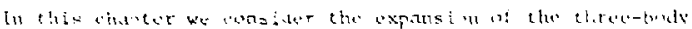

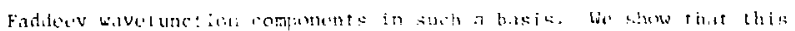

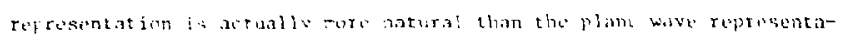

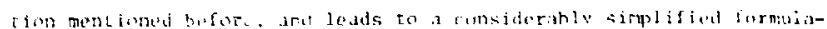
tion of the threw-horig theory.

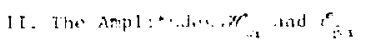

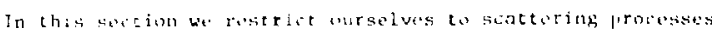

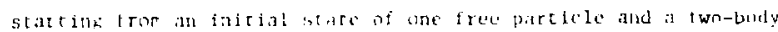
bould state. For this a a we consider the Faddery ariation for the s-component of llik threr-bod: wavefunction:

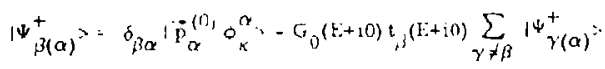

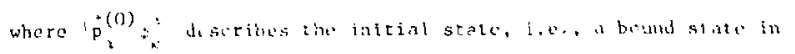

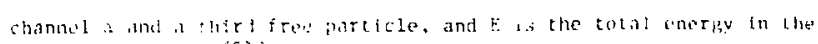

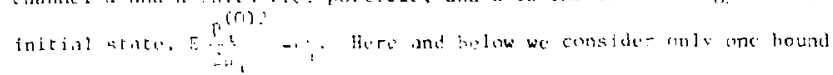

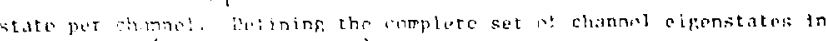

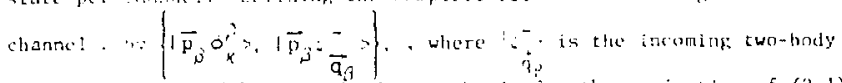

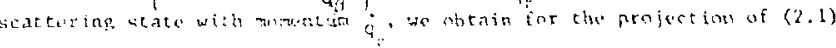

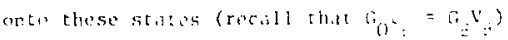




$$
\begin{aligned}
& \left\langle\overrightarrow{\mathrm{p}}_{\beta}{ }^{\beta}{ }_{\kappa}^{\beta} \mid \Psi_{\beta(\alpha)}^{+}\right\rangle=\delta_{\beta \alpha} \delta^{3}\left(\overrightarrow{\mathrm{p}}_{\gamma}-\overrightarrow{\mathrm{p}}_{\alpha}^{(0)}\right)-\frac{w_{3 \alpha}^{\prime}\left(\overrightarrow{\mathrm{p}}_{\beta} \cdot \overrightarrow{\mathrm{p}}_{\alpha}^{(0)}: \mathrm{E}+\mathrm{i} 0\right)}{\widetilde{\mathrm{p}}_{\beta}^{2}-\kappa_{\beta}^{2}-\mathrm{E}-\mathrm{i} 0} \\
& \left\langle\overrightarrow{\mathrm{p}}_{\beta^{\psi}}{ }^{-} \overrightarrow{\mathrm{q}}_{\beta} \mid \psi_{\beta(\alpha)}^{+}\right\rangle=\frac{\varepsilon_{\beta \alpha}\left(\overrightarrow{\mathrm{p}}_{\beta}, \overrightarrow{\mathrm{q}}_{\beta}, \overline{\mathrm{p}}_{\alpha}^{(0)}: \mathrm{E}+\mathrm{i} 0 \mid\right.}{\overrightarrow{\mathrm{p}}_{\beta}^{2}+\overrightarrow{\mathrm{q}}_{\beta}^{2}-\mathrm{F}-\mathrm{i} 0}
\end{aligned}
$$

where

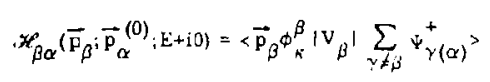

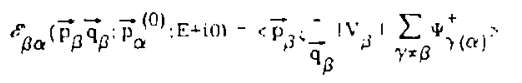

In (2.3), $\tilde{p}_{\beta}^{2}=\frac{p_{\beta}^{2}}{2 n_{\beta}}$, and $\tilde{q}_{\beta}^{2}-\frac{q_{3}^{2}}{2 \mu_{\beta}}$ with $n_{\beta}-\frac{m_{\beta}\left(m_{\gamma}+m_{\alpha}\right)}{\left(m_{\alpha}+m_{\beta}+m_{\gamma}\right)}$ and $\mu_{\beta}-\frac{m_{\alpha} m_{\gamma}}{m_{\alpha}+m_{\gamma}}$

Lising (2.2), the expansion of the plane wave projections of the

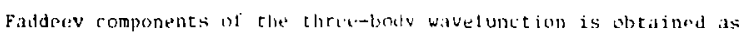

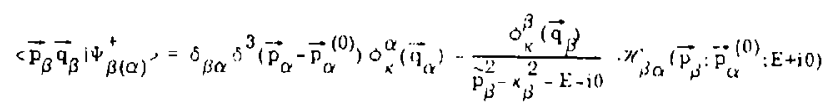

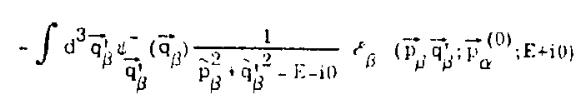

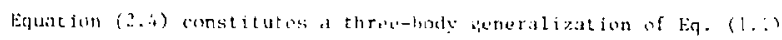

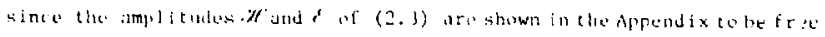
from elastic, rearrangetnent and breskup pules: l.e.. thes are the anplitudes in terms of whith we will now tormulate the threp-bady theory.

Wa first note how these anplitubes are rolated to the phosi al transition amplitudes: recalling that the residues of the wavetunctions

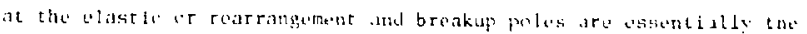

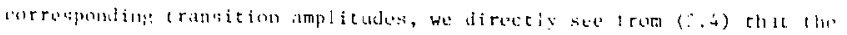

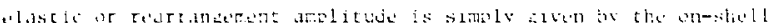

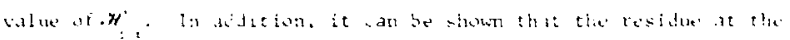

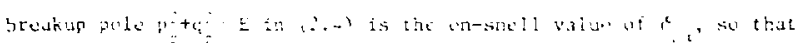

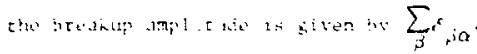

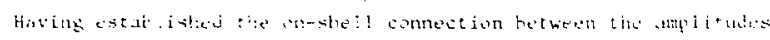

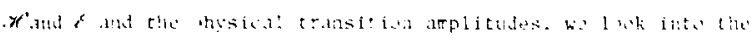

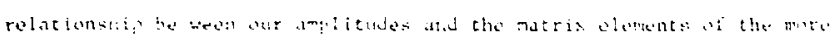

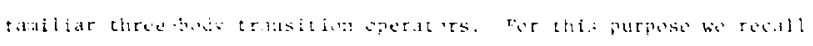

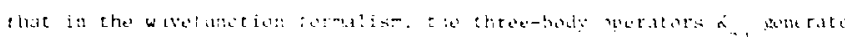

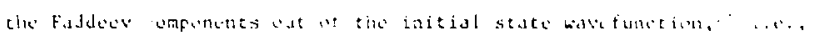

$$
\left|\Psi_{\partial(a)}^{+}\right\rangle=\left[s_{j \alpha}-G_{0}\left(E+i n k_{j \alpha}(E+10)\right]\left|\vec{F}_{\alpha}^{(1)} a_{a}^{\alpha}\right\rangle\right.
$$

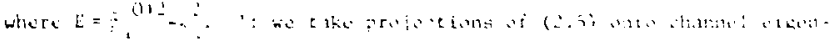

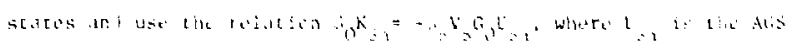

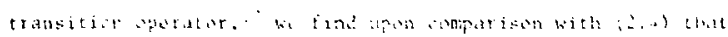

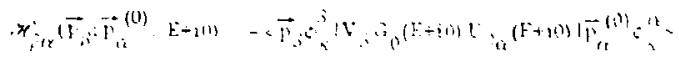

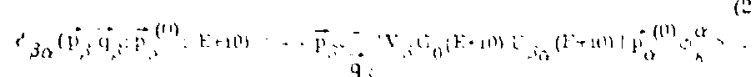

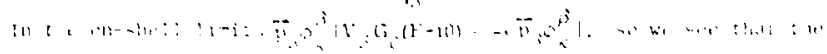

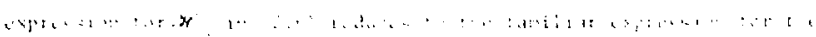

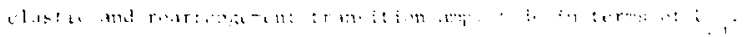

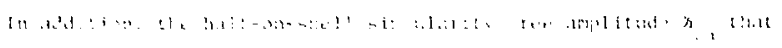

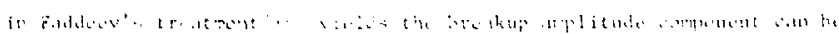

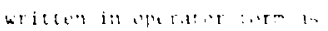

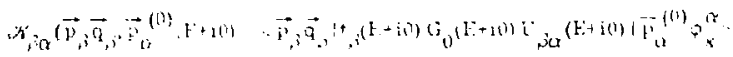

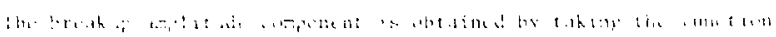

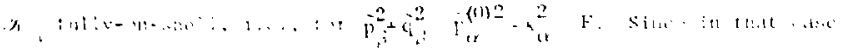




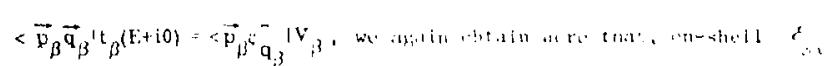

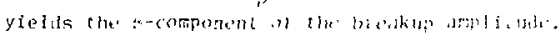

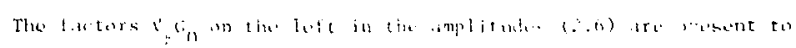

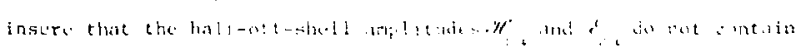

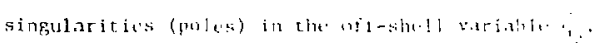

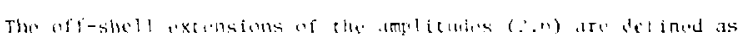

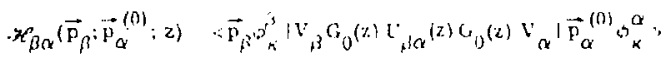

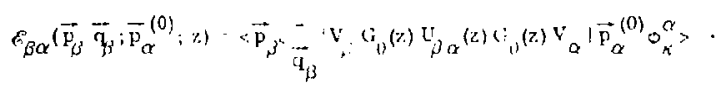

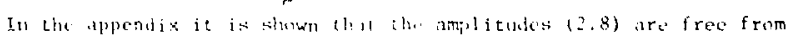

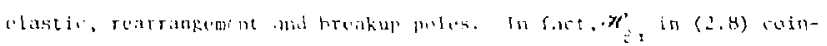

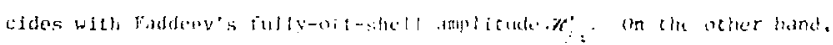

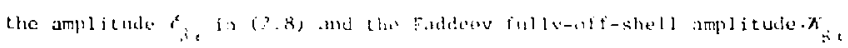

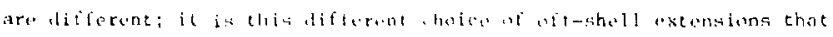

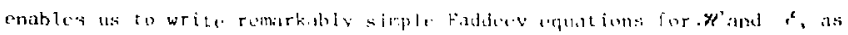
we show in the any surtinn.

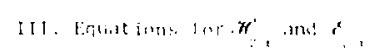

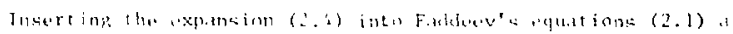

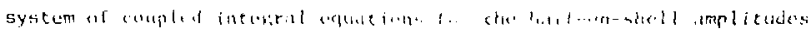

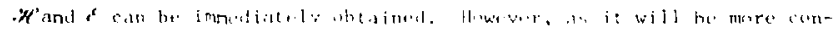

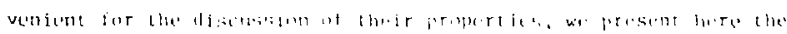

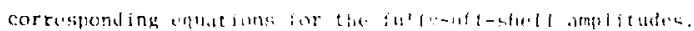

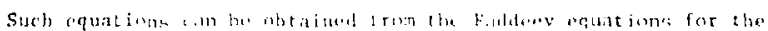
operaturs $"::^{\circ}$

$$
\mathrm{U}_{\beta \alpha}(z)=-\bar{\delta}_{\beta \alpha} G_{0}^{-1}(x)-\sum_{\gamma} \bar{j}_{j \gamma \gamma} \mathrm{t}_{\gamma}(x) \mathrm{G}_{0}(\alpha) \mathrm{C}_{\gamma \alpha}\left(\beta_{\alpha}\right)
$$

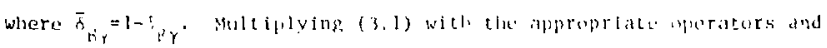

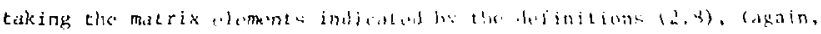

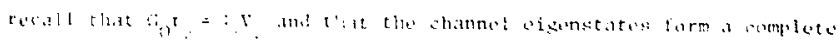

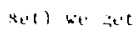

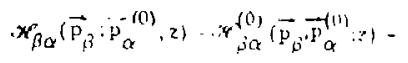

$$
\begin{aligned}
& \left.-\sum_{\gamma \neq \beta} \int d^{3} \vec{p}_{\gamma}^{\prime} \gamma+\vec{p}_{\gamma} ; \vec{p}_{\gamma}^{\prime}\right) \frac{1}{\vec{p}_{\gamma}^{\prime 2}-\kappa_{\gamma}^{2}-z} x_{\gamma \alpha}\left(\vec{p}_{\gamma}^{\prime}: \vec{p}_{\alpha}^{(0)}: z\right)-
\end{aligned}
$$

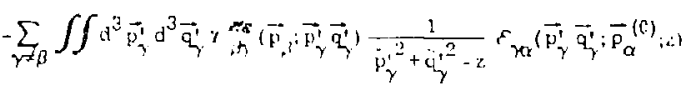

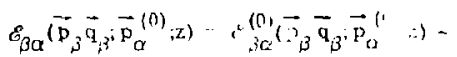

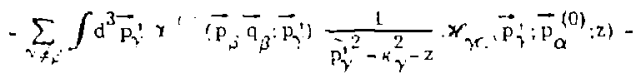

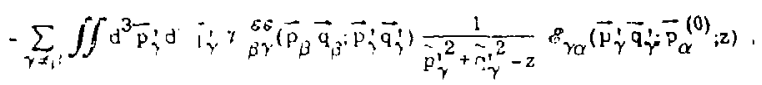

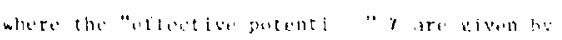

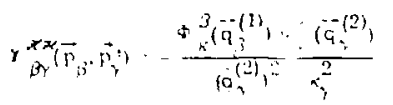

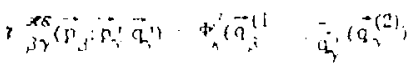

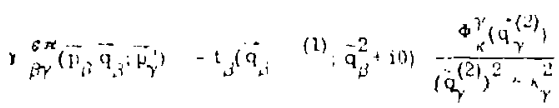

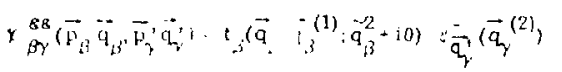

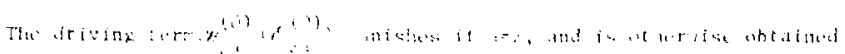

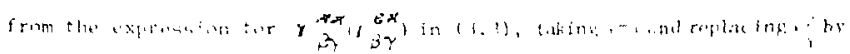

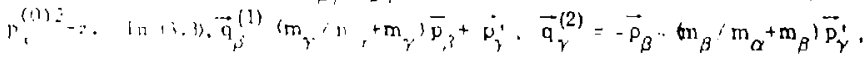


and $\phi^{B}$ is the two-body bound state vertex function, drfined as $\phi_{\kappa}^{\beta}\left(\vec{q}_{\beta}\right)=-\left(\tilde{q}_{\beta}^{2}+\alpha_{\beta}^{2}\right) \phi_{\kappa}^{\beta}\left(\vec{q}_{\beta}\right)$

As was mentioned before, we can see in $(3.2)$ and $(3.3)$, now the formulation of the three-body cheory gets slmplifted when it is expressed in terms of the new pait of amplitudes. $\mathscr{H}^{\prime}$ and $f$. In fact. Eqs. (3.2) have the following features:

(i) The effective potentials are all independent of the energy parameter $z$. This fact simplifies the structure of the aquations and has obvious computational acivantages.

(i1) The input consists solely of two-body bound state wavefunctions and half-off-shell transition amplitudes. The completely off-shell amplitudes - in partirular for arbitrarily large negative energies occuring in the usual treatments of the Fandepv equations, are therefore completely eliminated.

Addtional conventent features hesome evident aftor un angular momencurn decom :iltion of Eqs. (3.2) 1s carried out. Th1s is discussed in derail in the next section.

\section{Angular Momentum Decomposttion}

In this section we tunsider the angular numuntua derompusition of Eqs. (3.2). Stnce the propertics we want to discust are present in all cerms of such a decomposticn, we nuly consilur the simpluse situation. i.e., the S-wave case: Wa assume that th: total anqualar monentum $J$ is zero, and that only s-wave two-body inceractions are present.

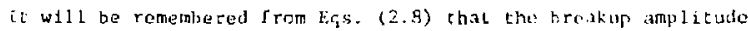
component $E_{B \text { ar }}$ ts ubtained by projectink to the list mo scottering

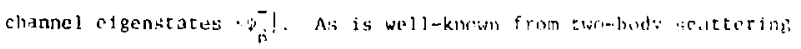
theory, ${ }^{24}$ the coordinate space cepressateltion of his solution can be expressed in the s-ratio calse an:

$$
\psi_{q_{1}}^{-}(r)=\frac{{ }^{q_{\beta}}{ }^{o} q_{\beta}(r)}{\mathscr{F}_{-}\left(\mathrm{q}_{\beta}\right)},
$$

where o ${ }_{g}(r)$ is the s-wave regatiar solution to the partial wilve Schrodinger equation (satistying wandary condittons at the arigit:

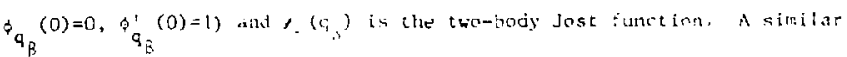
relation holds of coursu in every partial wave.

In this way, we see $f$ rivil $(4.1)$ that a Jost function factur $1 /$ sit can naturally be extracted fron oleh purtial wave componeme wi $c^{e}$ Redefining these amplitudes accoritingly,

$$
\varepsilon_{\beta \alpha}=\frac{1}{f_{\beta+}} \varepsilon_{\beta \alpha} .
$$

the new anplitudes $F_{4}$ are o!rtained in each partial wave by preje,ting. onto the regular sulutions racher than onto the scattering solutilinis. The resulting equations for the amplttutes $\mathcal{X}_{b a}$ and $r_{3,1}$ in the S-hisut ast. are:

$$
\begin{aligned}
& \mathscr{P P}_{\beta \alpha}\left(p_{\beta} ; F_{\alpha}^{(0)} ; z\right)=\mathscr{X}_{\beta \alpha}^{(0)}\left(p_{\beta}: p_{\alpha}^{(0)} ; z !\right.
\end{aligned}
$$

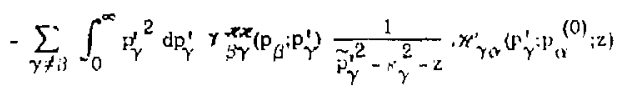

$$
\begin{aligned}
& -\sum_{\gamma \neq \beta} \int_{0}^{\infty} \int_{0}^{\infty} p_{\gamma}^{\prime 2} d p_{\gamma}^{\prime} q_{\gamma}^{\prime 2} d q_{\gamma}^{\prime} \gamma_{\beta \gamma}^{\infty}\left(p_{\beta}: p_{\gamma}^{\prime}, q_{\gamma}^{\prime}\right)
\end{aligned}
$$

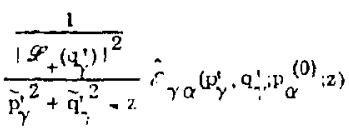

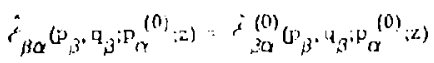

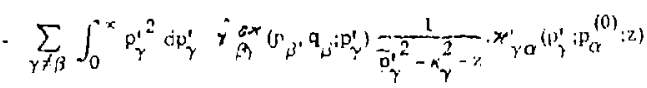

$$
\begin{aligned}
& -, 4-
\end{aligned}
$$




$$
\begin{aligned}
& -\sum_{\gamma \neq \beta} \int_{0}^{\infty} \int_{0}^{\infty} p_{\gamma}^{\alpha^{2}} \mathrm{dp}_{\gamma}^{\prime} \mathrm{q}_{\gamma}^{2} \mathrm{dq} \mathrm{q}_{\gamma}^{\prime} \gamma_{\beta \gamma}^{\sigma \alpha}\left(\mathrm{p}_{\beta^{\prime}}, \mathrm{q}_{\beta^{\prime}} \mathrm{p}_{\gamma}^{\prime}, \mathrm{q}_{\gamma}^{\prime}\right) \\
& \frac{\frac{1}{\left|\mathscr{L}_{+}\left(q_{\gamma}^{\prime}\right)\right|^{2}}}{{\tilde{p_{\gamma}}}_{\gamma}^{\mathbf{2}^{2}}+{\widetilde{q_{\gamma}^{\prime}}}^{2}-z} \tilde{\delta}_{\gamma \alpha}\left(p_{\gamma}^{\prime} q_{\gamma}^{\prime} ; P_{\alpha}^{(0)} ; z\right)
\end{aligned}
$$

The partial wave components of the effective potentials of the origtnal equatious are redefined accordingly, and the resulting putantals 1n (4.3) are:

$$
\begin{aligned}
& \nu_{\beta \gamma}^{* x}\left(p_{\beta} ; p_{\gamma}^{1}\right)=-\frac{1}{2} \int_{-1}^{1} \mathrm{~d}\left(\cos s_{\beta \gamma}\right) \frac{\Phi_{K}^{\beta}\left(\mathrm{q}_{\beta}^{(1)}\right) \Phi_{\mu}^{\gamma}\left(\mathrm{q}_{\gamma}^{(2)}\right)}{\tilde{q}_{\gamma}^{(2))^{2}+\kappa_{\gamma}^{2}}}
\end{aligned}
$$

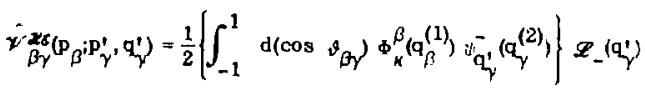

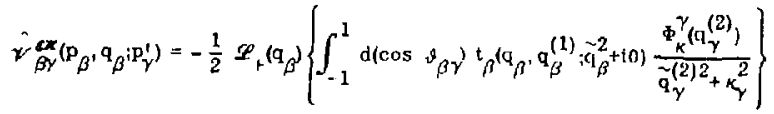

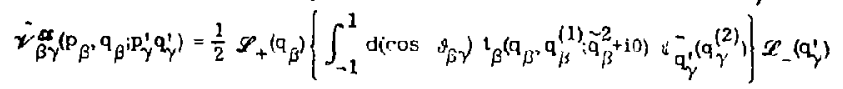

where

$$
\begin{aligned}
& q_{\beta}^{(1)}=\sqrt{\left(\frac{\mu_{\beta}}{m_{\alpha}} p_{\beta}\right)^{2}+p_{\gamma}^{\prime 2}+2 \frac{\mu_{\beta}}{m_{\alpha}} p_{\beta} p_{\gamma}^{\prime} \cos s_{\beta \gamma}^{4}} \\
& q_{\gamma}^{(2)}=\sqrt{p_{\beta}^{2}+\left(\frac{\mu_{\gamma}}{m_{\alpha}} p_{\gamma}^{\prime}\right)^{2}+2 \frac{\mu_{\gamma}}{m_{\alpha}} p_{\beta} p_{\gamma}^{\prime} \cos s_{\beta \gamma}} .
\end{aligned}
$$

This redefinition of the rimplitudes has the following advantages: first, the phase of the Jost function 1s precisely the two-body phase- strift, i.e.,

$$
\mathscr{P}_{ \pm}\left(\mathrm{q}_{\beta}\right)=\left|\mathscr{P}_{ \pm}\left(\mathrm{q}_{\beta}\right)\right| \mathrm{e}^{\mp 1 \delta\left(\mathrm{q}_{\beta}\right)}
$$

Since the same phase is carrled by the two-body half-on-shell t-matrix and two-body scattered wave function, we see that all these phases cancel out in the expression for the potentials. That is to say, the potentials $(4.4)$ in the equations for $\dot{f}$ and $\mathscr{X}$ are not only $z$-independent, but also real. In addition to the computational simplifications entadled by such a situation, problems related to unftarity (such as the construction of unitaxy approximatfon schemes) become easter to handle.

Obviously, to obtaln real potentials it is only necessary to factor out the phase of the Jost function from the original fo amplitude. However, we believe it is useful to factor out also the modulus of the Jost $f$ unction, as we have done above. The reason 1s that the regular solution $\phi_{q_{B}}(x)$ of $(4.1)$ is analytic everywhere in the complex a plane, 1.e., It has no bound state or resonance poles, nor any branch points. Instead, this structure of the two-body scartering vave function is carried by the Jost Eunction denominator. Thus, the amplifudes $\hat{f}_{B \mathrm{~B}}$ are more sraoothly-varying functions of $q_{B}$ that the corresponding $f_{B a}{ }^{-}$ amplicudes.

The same two-body structure is also absent from the potentials in (4.4), since they carry factors $\mathscr{H}_{+}$and $\psi^{-} \mathscr{S}_{-}$. In this mannct, the twoboty bound state and resonance singularitles are predominantly carried out by the fact. $\frac{1}{\sqrt[1]{12}}$ in Eq. $(4.3)$.

We conclude by witing the expression for the breakup amplttude in terms of the new amplitudes $\hat{b}_{B a}$ in the S-wave case: 


$$
B_{0 \alpha}=\sum_{\beta} \frac{1}{\mathscr{P}_{\beta+}} \dot{E}_{\beta \alpha}
$$

We see in (4.7) that $\hat{r}_{B u}$ differs from: the corresponding, breakup amplitude component by a Hatson finul state interaction factor.

$$
\text { v. The } 3-3 \text { and 3-2 implitudes }
$$

For the sake of completeness, we ronsider in this section the amplitudes for processes starting from three free particles. For this purpose we recall expression (2.8) for the amplitudes corresponding to prucesses starting from a bound state and a third free partfcle, 1.e.,

$$
\begin{aligned}
& 2-2: \quad x_{\beta \alpha}=\left\langle\overrightarrow{\mathrm{p}}_{\beta} \phi_{\kappa}^{\beta}\left|v_{\beta} G_{0} v_{\beta \alpha} G_{0} v_{\alpha}\right| \overrightarrow{\mathrm{p}}_{\alpha}^{(0)} \phi_{\alpha}^{\alpha}\right\rangle \\
& 2 \rightarrow 3: \quad \mathscr{E}_{\beta \alpha}=\left\langle\overrightarrow{\mathrm{p}}_{\beta} \psi_{\overrightarrow{\mathrm{q}}_{\beta}}^{-}\left|\mathrm{V}_{\beta} \mathrm{G}_{0} \mathrm{U}_{\beta \alpha} \mathrm{G}_{0} \mathrm{~V}_{\alpha}\right| \overrightarrow{\mathrm{p}}_{\alpha}{ }^{(0)} \phi_{\kappa}^{\alpha}\right\rangle
\end{aligned}
$$

The romaining amplitudes are now defincd as

$$
\begin{aligned}
& 3 \rightarrow 2: \quad \tilde{E}_{\beta \alpha}=\left\langle\overrightarrow{\mathrm{p}}_{\beta} \phi_{\kappa}^{\beta}\left|\mathrm{V}_{\beta} \mathrm{G}_{0} \mathrm{U}_{\beta \alpha} \mathrm{G}_{0} \mathrm{~V}_{\alpha}\right| \overrightarrow{\mathrm{p}}_{\alpha}^{(0)} \psi_{\overrightarrow{\mathrm{q}}_{\alpha}^{(0)}}^{+}\right\rangle
\end{aligned}
$$

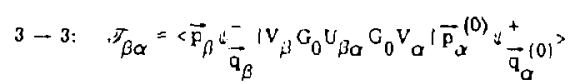

That the 3-3 amplitude of (5.2) directly ylelds the connerted part of the 3-3 cransition implitude an be seen at follows: in Faddecu's treatment, this 3-j amplteude is obtained by caking the fully-orshed

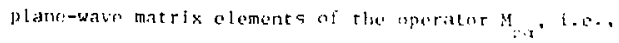

$$
T=\sum_{\beta \alpha}\left\langle\vec{p}_{\beta} \vec{q}_{\beta}\left|M_{\beta \alpha}\{E+j 0)\right| \vec{p}_{\alpha}^{(0)} \vec{q}_{\alpha}^{(0)}\right\rangle
$$

wherc $\quad \tilde{\mathrm{p}}_{\beta}^{2}+\widetilde{\mathrm{q}}_{\beta}^{2}=\tilde{\mathrm{p}}_{\alpha}^{(0) 2}+\widetilde{\mathrm{q}}_{\alpha}^{(0) 2}$.

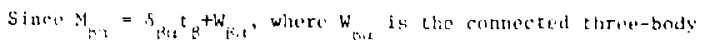

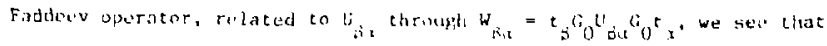

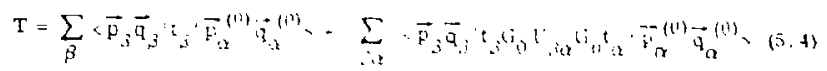

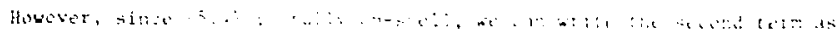

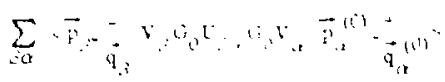

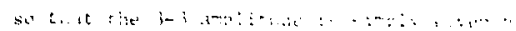

$$
\text { T } \sum_{j i x} i_{i 0}+\sum_{i} t:
$$

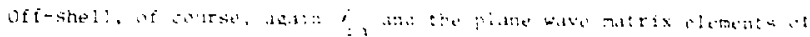
Hiatiot.

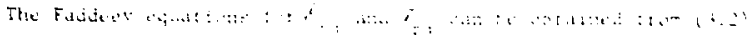

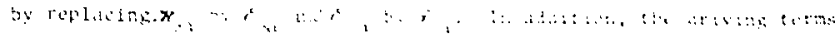

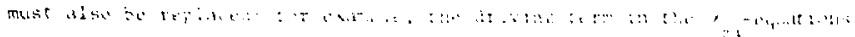
is given in

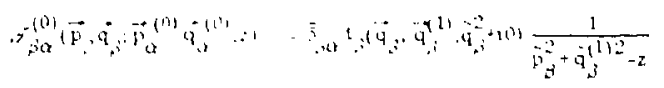

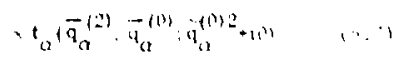

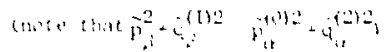

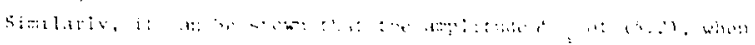

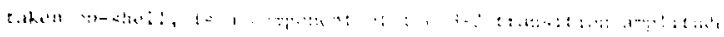

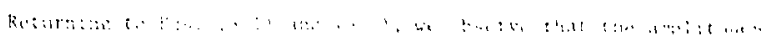

tw 116 ;

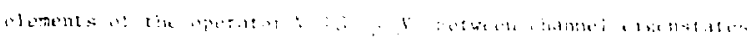

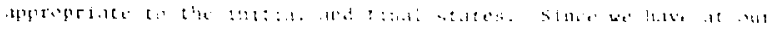

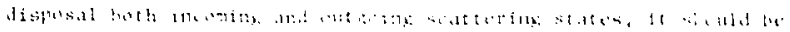

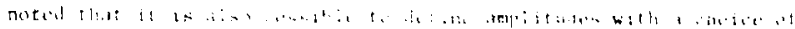

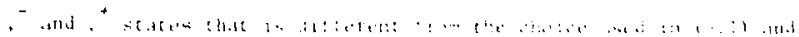


(5.2). However, such amplitudes are not as simply related to the physical transition amplitudes. The physical reason for thys ts that the three-body S-matrix involves inner products of incoming and outgoing three-body scattering states in the same order as they are expanded in (5.1) and (5.2).

\section{APPENDIX}

Hete we give an outline of the proof of the fact that the new amplitudes $c_{h a}$ are Eree fxom primary singularictes. ${ }^{9}$ Similar proofs can be obtained for the remaining new amplitudes ${ }_{\text {fhix }}$ and $z_{B: \text {. }}$.

we start by noting that the amplitudes, $\mathscr{P}$ and $f$ in terms of which Faddeev carries out the singularity analysis of the three-body wavefunction are defined by the first of Eq. (2.8) and

$$
\mathscr{E}_{\beta \alpha}\left(\overrightarrow{\mathrm{p}}_{\beta} \overrightarrow{\mathrm{q}}_{\beta} ; \overrightarrow{\mathrm{p}}_{\alpha}^{(0)} ; \mathrm{z}\right)=-\left\langle\overrightarrow{\mathrm{p}}_{\beta} \overrightarrow{\mathrm{q}}_{\beta}\right) \vec{i}_{\beta}(\mathrm{z}) \mathrm{G}_{0}(\mathrm{z}) \mathrm{U}_{\beta \alpha}(\mathrm{z}) \mathrm{G}_{0}(\mathrm{z}) \mathrm{V}_{\alpha}\left(\overrightarrow{\mathrm{p}}_{\alpha}^{(0)} \phi_{\kappa}^{\alpha}\right\rangle \quad \text { (A.1) }
$$
where $\hat{t}_{B}$ is abtalned by splitting the two-body transtion operator $t_{B}$ into a term $t_{B}^{p}$ containing the bound state pole and a remainder $\dot{t}_{B}$. The representation of the three-body wavefunction component in terms of $\mathscr{H}$ and $f$ can be obtalned from (2.5) and the relations $G_{0} K_{\beta \alpha}=-G_{0} t_{\beta} G_{0} U_{\beta \alpha}$ ' $\mathrm{t}_{\beta}=\mathrm{t}_{\beta}^{\mathrm{p}}+\hat{\mathrm{t}}_{\beta}$, with the result

$$
\begin{aligned}
\left\langle\overrightarrow{\mathrm{p}}_{\beta} \overrightarrow{\mathrm{q}}_{\beta} \mid \psi_{\beta}^{(\alpha)}\right\rangle= & \left.\delta_{\beta \alpha} \delta^{3}\left(\overrightarrow{\mathrm{p}}_{\alpha}-\overrightarrow{\mathrm{p}}_{\alpha}^{(0)}\right) \phi_{\alpha}^{\alpha} ; \overrightarrow{\mathrm{q}}_{\alpha}\right) \\
& -\frac{1}{\overrightarrow{\mathrm{p}}_{\beta}^{2}+\tilde{\mathrm{q}}_{\beta}^{2}-\mathrm{E}_{\alpha}-\mathrm{i} 0} \frac{\left(\tilde{\mathrm{q}}_{\beta}^{2}+\kappa_{\beta}^{2}\right) \phi_{\alpha}^{\beta}\left(\overrightarrow{\mathrm{q}}_{\beta}\right)}{\overrightarrow{\mathrm{p}}_{\beta}^{2}-\kappa_{\beta}^{2}-\mathrm{E}_{-\mathrm{i} 0}}, \mathscr{H}_{\beta \alpha}\left(\overrightarrow{\mathrm{p}}_{\beta} ; \overrightarrow{\mathrm{p}}_{\alpha}^{(0)} ; E_{\alpha}+i(0)\right. \\
& +\frac{1}{\overrightarrow{\mathrm{p}}_{\beta}^{2}+\tilde{\mathrm{q}}_{\beta}^{2}-\mathrm{E}_{\alpha}-\mathrm{i} 0} \mathcal{G}_{\beta \alpha}\left(\overrightarrow{\mathrm{p}}_{\beta} \overrightarrow{\mathrm{q}}_{\beta} ; \overrightarrow{\mathrm{p}}_{\alpha}^{(0)} ; \mathrm{E}_{\alpha}+\mathrm{i} 0\right)
\end{aligned}
$$

By comparing (A.2) with (2.4), it can be seen how the choice of the

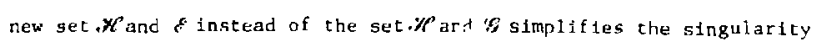
structure of the expanston.

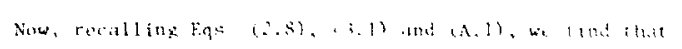

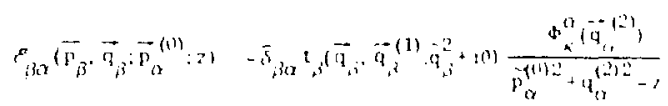

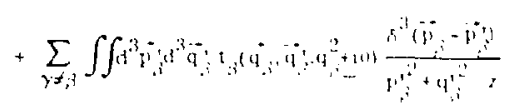

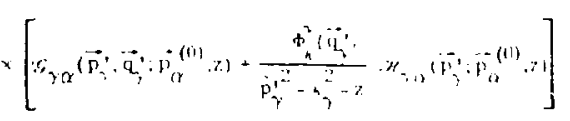

(A. 3 )

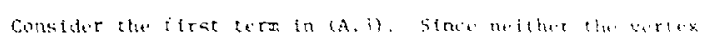

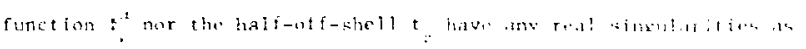

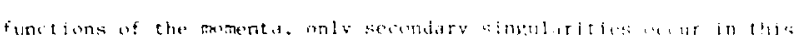

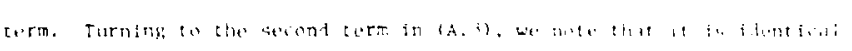

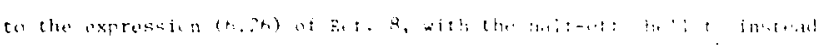

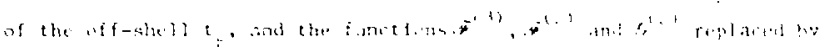

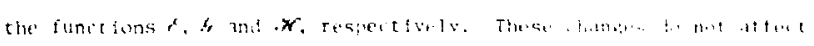

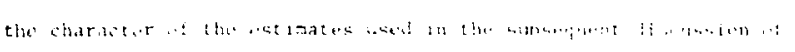

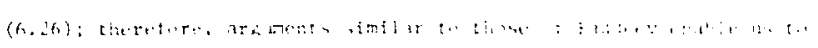

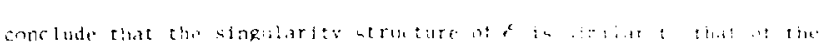

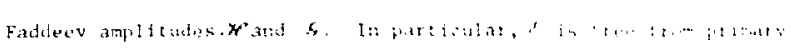
singulartien. 
Ghinger $\because i$

THREF-HODY NOTARITY

I. Int $\cdots, \ldots$ in:

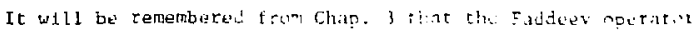

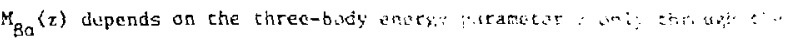
three-body Green's function $G(: i, i, \ldots$

$$
M_{B \alpha}(z)=\delta_{B \alpha} Y_{-} \cdots v_{c} C(z) v_{i:} .
$$

It is thus straightforward to show that $Y_{3 a}$, as well dis tie an: litudes arising from taking plane-widy. matrix el ments of $y_{p}$, whey ine

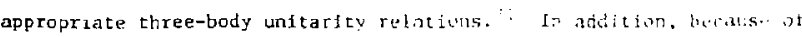
the symetry involved in the detillitinn $(1.1)$, the piane-wave ratrix elements of $M_{B a}$ are simply refated to the time-reversed amplitudes; i.e., (recall that $G^{+}(z)=G\left(z^{\star}\right)$ ),

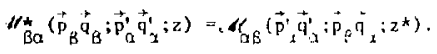

In this chapter we proced to the witgate the rastespendine

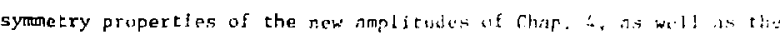
three-body unitarlty relations they sar it: ry.

\section{Symmetry pernertics}

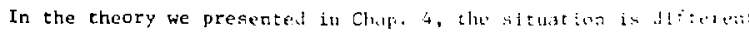

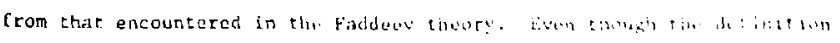
of our three-budy operator $T_{i, 2}$, 1 , e'.

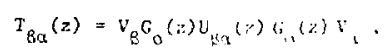

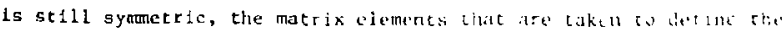

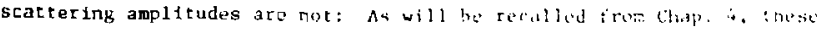
amplitudes are (Im $z ; 0)$

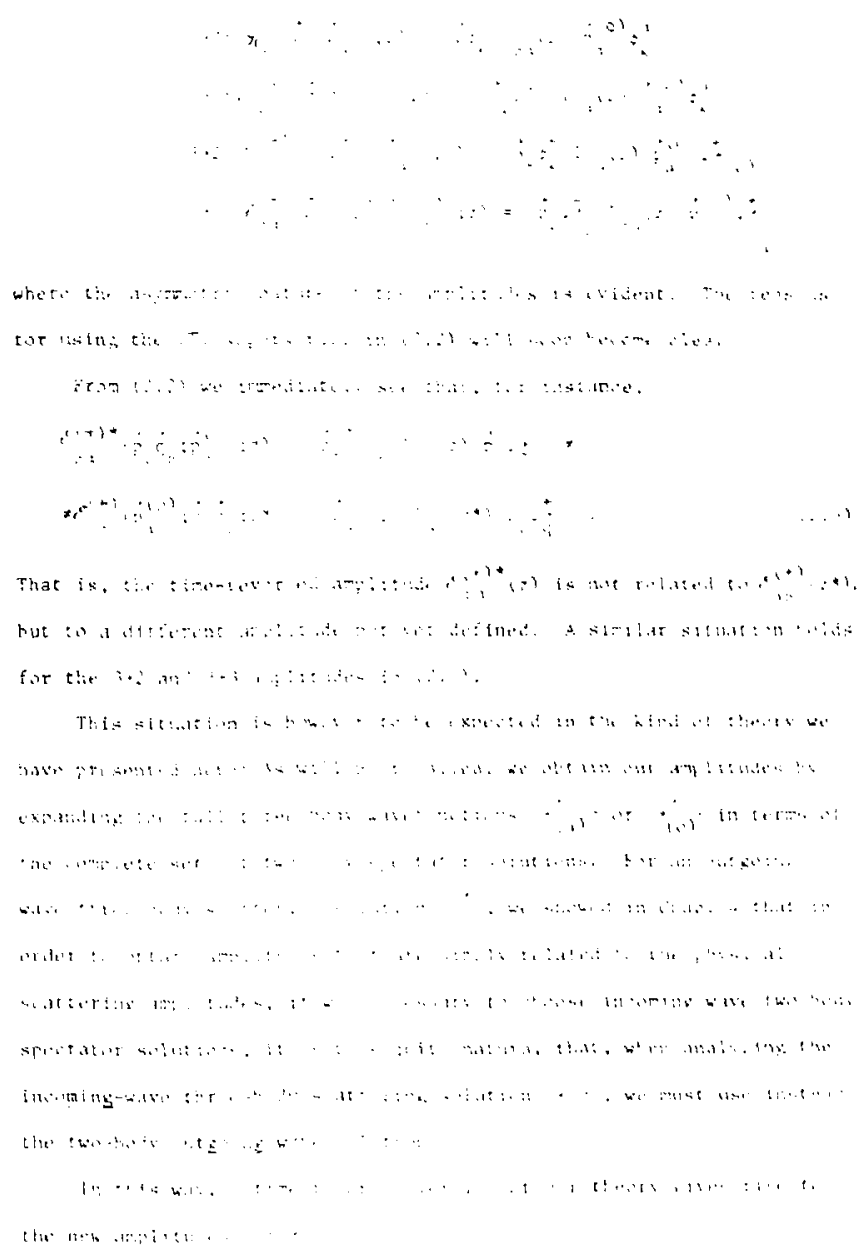

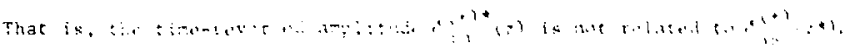
put 0 a d1 a

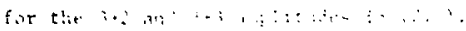

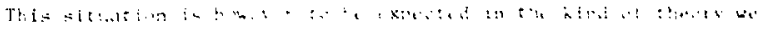

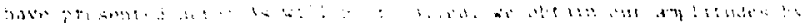
(4)

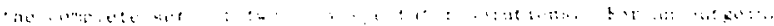

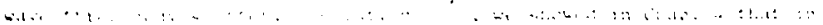

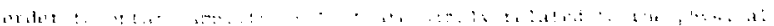

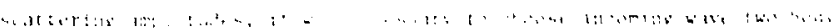

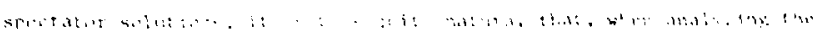

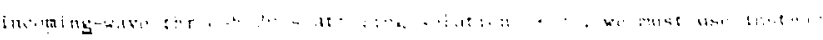

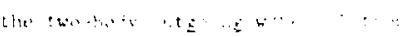

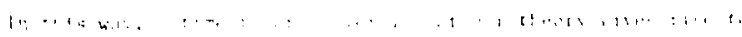

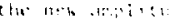




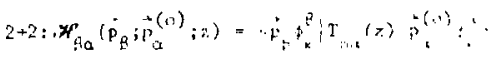

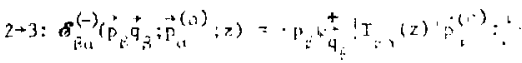

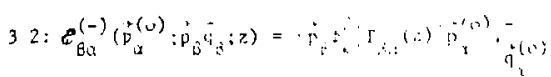

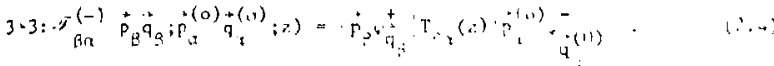

In terms of both linds of ampldtudes (2.2) and (2.2), we witain 1 s expected the relations $(\operatorname{Im} z>0)$

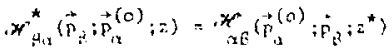

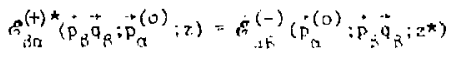

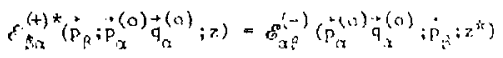

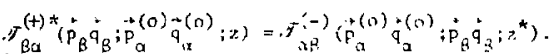

That $1 \mathrm{~s}$, when considering the elme-reversed version of aur theory, we are led to amplitudes that are different from the onos used in Chip. : (with the exception of the clastic/ecarranfement amplitucie. $\mathscr{H}_{3}$, which is the same in both).

In the next section we will obcaln our three-budy mitarity relations by defining the three-body S-matrix components in turms of the amplitudes of Chap. 4 , and then requiring that such s-matrix components be unitary. Because of the reasons outlned ahove, howiver, boch kinds of amplitudes will he lnvolved in the oxpressions wo ohtaln

Before proceeding, however, we will simplify nur task by redrfining one of our amplitudes. As will be remembered, we proved in char. i that all our amplitudes are free from peimary singularitieg. For this to be true also in the case of the $7 \cdot 3$ anplitude, it was nrcessary to diftno

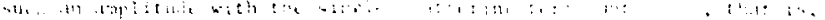

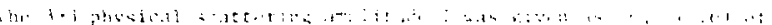
$(i n+.) \cdot 9$

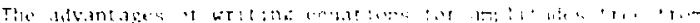
primary a

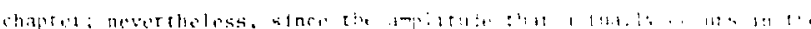

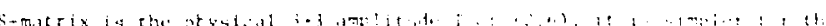

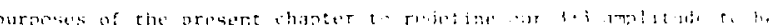

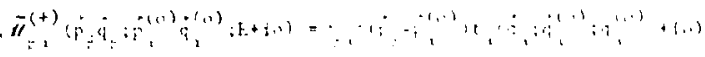

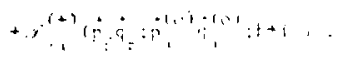

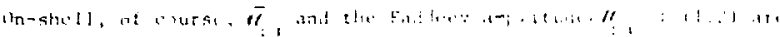

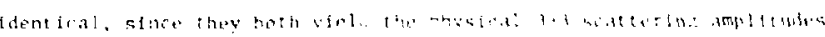

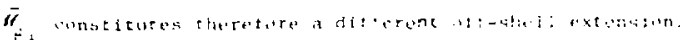

$$
\text { [1] Ihe Then }
$$

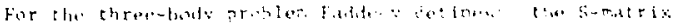

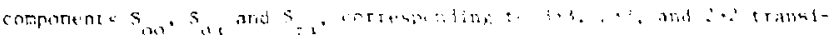

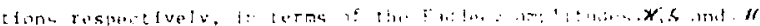

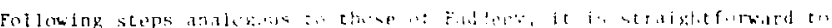

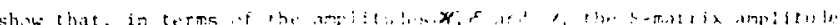
components can be written

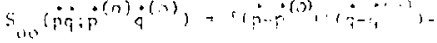

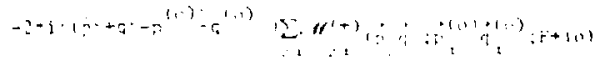




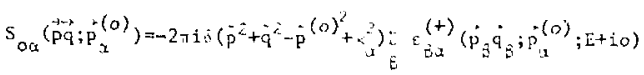

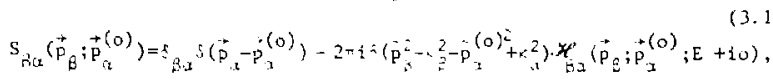

$$
\begin{aligned}
& \text { w1th } E_{a}=\dot{p}^{(0)^{2}}+\dot{q}^{(0)^{2}}, E_{i z}=\dot{p}_{a}^{(0)^{2}}-\alpha_{a}^{2} \text {. }
\end{aligned}
$$

The requirement that the three-body S-matrix be unitary is of course that

$$
\mathrm{s}^{+} \mathrm{S}=\mathrm{SS}^{+}=1,
$$

which in terms of s-matrix components takes the form ${ }^{3}$

$$
\sum_{\gamma=0}^{3} s_{z \gamma}^{+} s_{Y, X}=s_{s, t} .
$$

When the $S$-matrix components are expressed in terms of the amplitudes $\mathscr{X}, \mathscr{G}$ and. $\mathscr{H}$, Faddcev proves that the unitarity requirement (3.3) does indeed hold, so that the faddeev amplitudes are shown to yicld the correct scatering amplicudes for all three-body processes. next section we proceed to show that the S-macrix components (3.1)

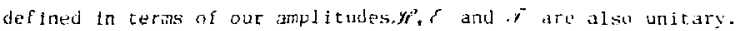

We conclude tilis section be writing down the condition our amplitudes must satisfy to tulfill the requirements (3.3). For simplicity, ve consider first the casc of two-bojy interactions that support no two-body states. As we will see in the next section, the operatur relations we are led to in this way are also valld for the rase of interactions with two-hody states, so chis restriction produces no loss of generality.

For such a situation, (3.3) reduces to the condition $\mathrm{s}^{+} \mathrm{S} \mathrm{Son}^{-1}=1$, ar in terins of the amplitudes (3.1)

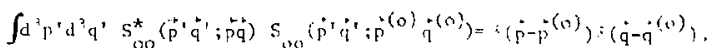

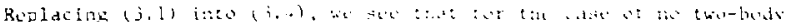

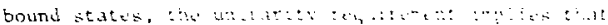

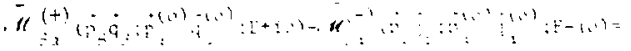

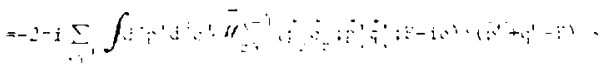

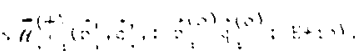

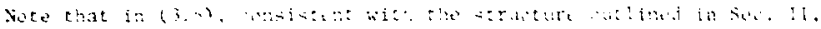

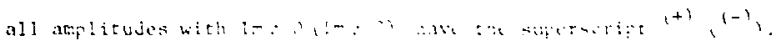

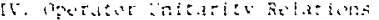

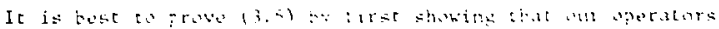

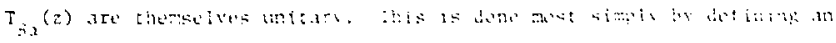

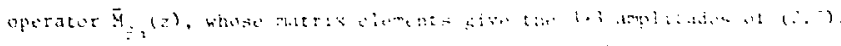

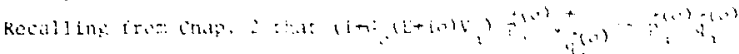

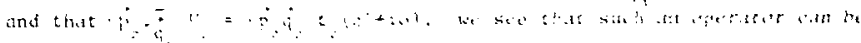
defillod is

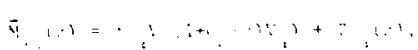

\&ncil bien

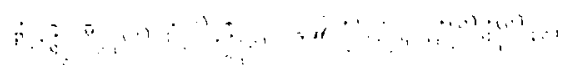

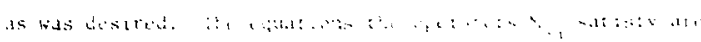

$$
\begin{aligned}
& \bar{y}, \cdots(2+\cdots), \quad \because y^{2},
\end{aligned}
$$

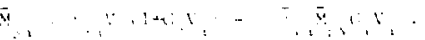

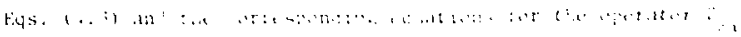

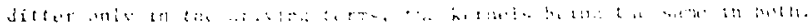

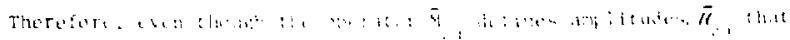


have primary singulartes (as opposed to $\bar{y}_{2}$ ), tho cquations arising from (4.3) still retain. 11 other conventent fartures of the colations of Chap. 4, anit we have introduced ne formal complications.

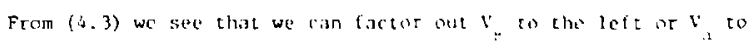

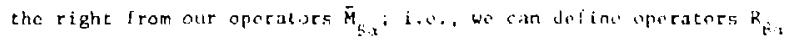
and $L_{t a}$ through

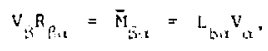

where

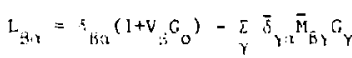

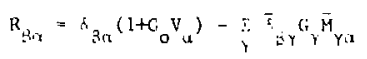

The operacors $L_{p}$, and $R_{p \times x}$ will he extremely useful th our pronf of operator unitarity, as will be seen beluw.

Returning to the enerator $\vec{x}_{R i x}$, with the definitions (4.1) and (4.2) we can now write an pperator version of the unitariey relation (3.5), i.e.

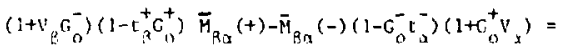

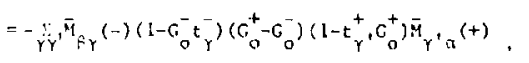

where for convenience we have used the shorthand notation $\overline{\mathrm{M}}_{B, \alpha}(t)=\overline{\mathrm{M}}_{\beta_{0}}(E+i 0), C_{0}^{\prime}=\mathrm{G}_{0}(E+i 0)$, ete.

Taking matrix elements of (4.6) betwcen outgolng-wave scattering

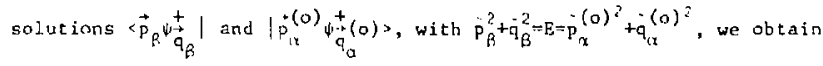
expression (3.5) drectly. That 15. Eq. (3.5) is the on-shell amplicude verston of the general operator unitartty relation (4.6). This resule can be seen as follows: It wall be recalled that

$$
\frac{1}{\bar{p}^{2}+\bar{q}^{2}-\mathrm{E}^{-}+10}=: \frac{1}{\bar{p}^{-2}+\bar{q}^{-2}-\mathrm{E}} \pm 1 \pi d\left(\bar{p}^{2}+\ddot{q}^{2}-\mathrm{E}\right)
$$

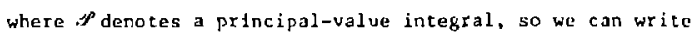

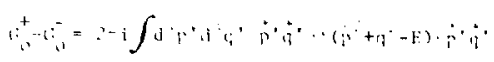

and thise

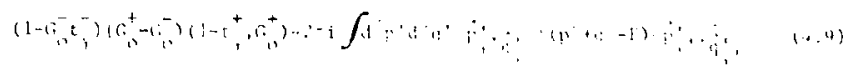

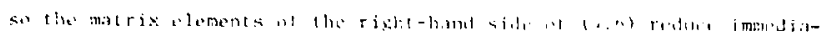

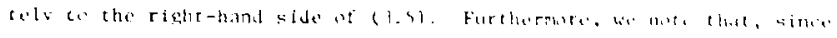
the bras and ketes we lise are on-shell, we haw

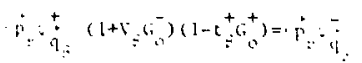

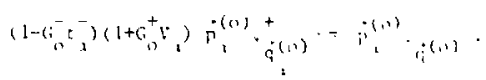

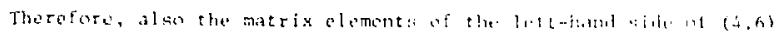
reduce to the lefthand ide of $(3, h)$.

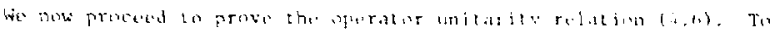

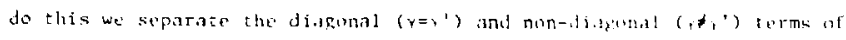

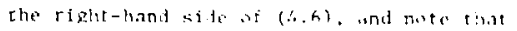

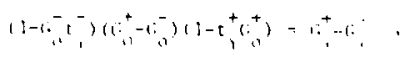

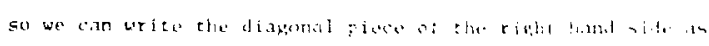

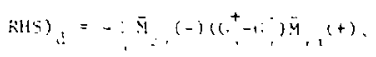

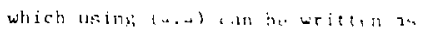

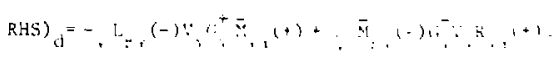

We now add and whbtract the ter.

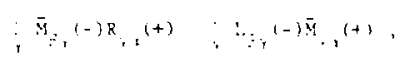

nhtaining

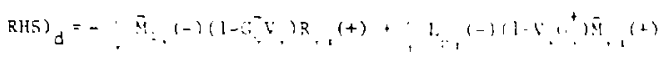




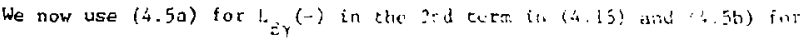
$R_{\gamma \mathrm{a}}(+)$ in the first, obtaining

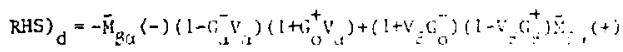

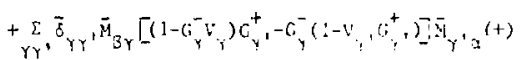

But the factor in square brackets in the $2 \pi$ term in $(4.16)$ is equal to $\left(1-C_{0}^{-} t_{y}^{-}\right)\left(C_{0}^{+}-C_{0}^{-}\right)\left(1-c_{1}^{+}, C_{0}^{+}\right)$, so that we recognize this 2 nd tern to be exactly equal to the non-diagonal plece of (4.6), with opposice sign. Thus the survivtng lerms become identicjal to the leit-hand side of (4.6), and we have completed the proni.

\section{v. Unitarity Relations for the Amplitudes}

We now complete aur disctission by allowing (wo-bady bourd states to be present. He first note thar the proof the nelalur unitarity relation (4.6) given in the last sertinn is completuly guverial, and holds whether the twi-body inters. iling an suppert hund states or wol.

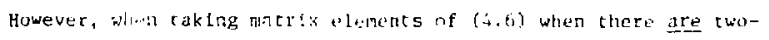

body bound scaces, we are noe liet te (5.5), but th a differont

expression. The reason for this is that when there are bound states.

the two-body tomatrices in the hatur: $\left.11-G_{0}^{-} t_{r}^{+}\right)$and $\left(1-E_{1}^{+}, C_{0}^{+}\right)$have is

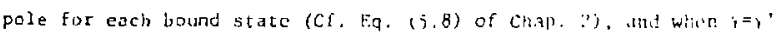
these poles combtne with the facror $\left(: 0_{0}^{+}-C_{0}^{-}\right.$to yilld a tinitu extra term lnvolving the two-buty bouril-stat: wilvetunctions.

A drect way to seo this expliciote is to birst write, using (4. 19 ),

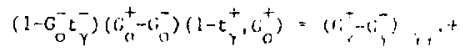

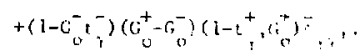

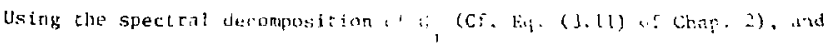

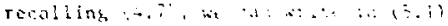

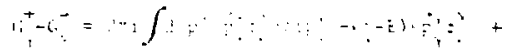

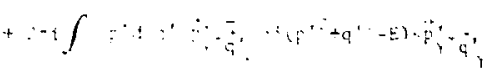

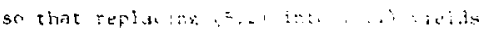

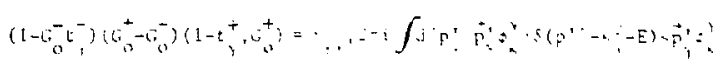

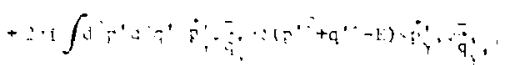

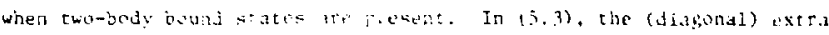

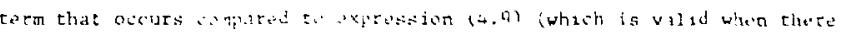

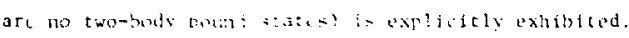

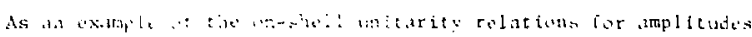

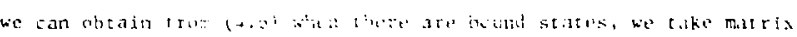

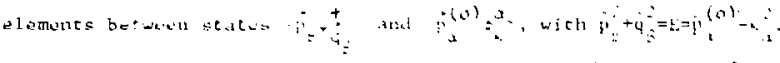

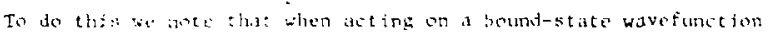

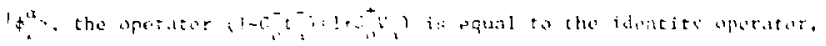
i. i. .

$$
11-1 \div \div 1+2 \div 1: \div \quad: 3
$$

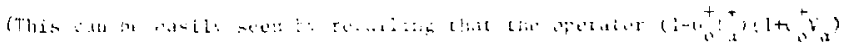

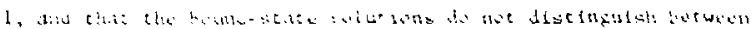

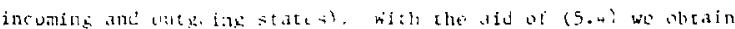

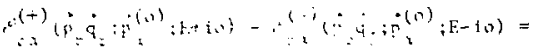

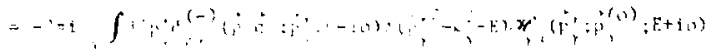

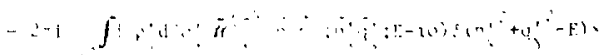

$$
\begin{aligned}
& -x^{2+1}+\cdots, \cdots+\cdots+1, \cdots
\end{aligned}
$$


As the on-shell amplifudes "adirectly yiatd the breakup scattering applitudes, Eq. (5.5), when summed over B, has the form one would expect froin physical grounds for the brenkup case. ${ }^{3}$ [hiplet six

FOKR-RODY EQTATLONS WITH ILLF-ON-SHELL INPLT

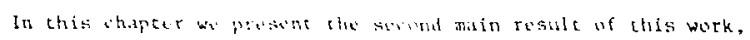

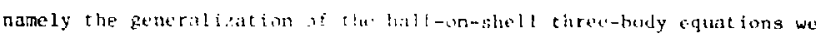

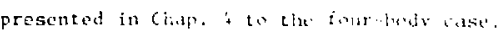

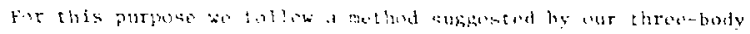

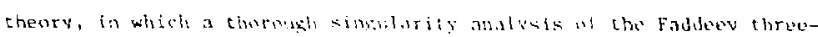

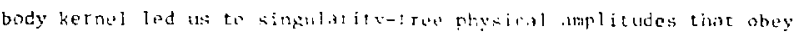

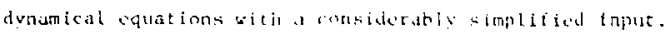

Hith hese resules in mind, we curry ant a wiritar singularity

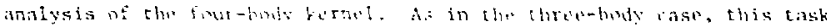

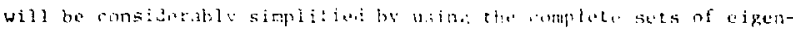
state's of the "hannel thimiltomilias.

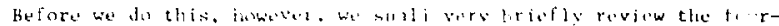

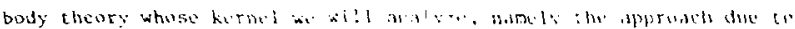
Faddeger and Yakuhurakij.

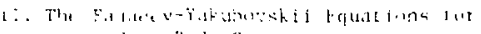

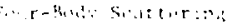

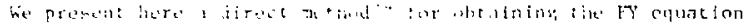

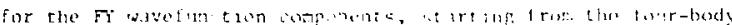

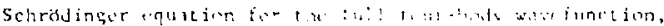

$$
\left(H_{0}+Y \cdot B+1\right)
$$

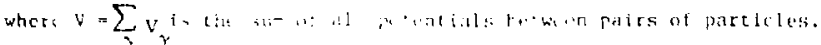

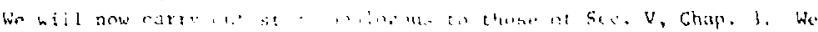
are now

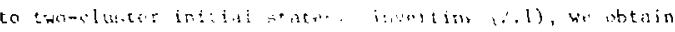

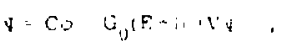


where $\phi$ is a solution of $\left(H_{0}-E\right) C=D$, and $C$ is a constant. Since we have chosen to consider only two-cluster cunfigurations as inftial states, $c=0$. As indicated in (2.2), all operators of this sectlon are to be taken at an energy corresponding to that of the initiai statc.

As in Chap. 3, Faddeev components of the four-body wavefunctions are defined through

$$
\psi_{\beta}=-G_{0} v_{\beta} \Psi
$$

so that

$$
\Psi=\sum_{\beta} \Psi_{\beta}
$$

where $B$ is a label corresponding to a splitting of the four particles into three groups, 1.e. so that only a single pair (s) is interacting. Again as in Sec. V, Chap. 3, we apply the Faddece procedure of removing two body disconnected pleces from the kirncl of (2.3), obtaining

$$
\left(1+G_{0} v_{\beta}\right)_{\beta}=-G_{0} v_{\beta} \sum_{\gamma} \bar{\delta}_{\beta \gamma} \Psi_{\gamma} \text {. }
$$

Operating on (2.5) with $\left(1-G_{0} t_{B}\right)$, we get

$$
\Psi_{\beta}=C \phi_{\beta}-G_{0} t_{\beta} \sum_{\gamma} \bar{\delta}_{\beta \gamma} \Psi_{\gamma},
$$

where $\Phi_{B}$ satisfies $\left(1+\sigma_{0} V_{P}\right) r_{B}=0$. Again, due to bur choloe of inirial state, $C=0$.

For the Eour-hody case, the kernel of (2.6) must he further modified, since it still tentians disconnected pioces corrisponding to two non-inceracting clusters - i.e. Lo r lwites of the type $1+3$ and it?

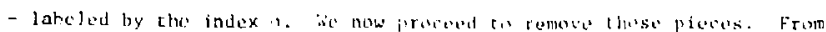
(2.6) we define the eomponetits

$$
\Psi_{B}^{\sigma} \quad-G_{0}{ }_{\beta} \sum_{\gamma \in \sigma} \bar{\delta}_{\beta \gamma} \Psi_{\gamma} .
$$

wherc $\sigma \supset \beta$, and such that

$$
\Psi_{\beta} \sum_{\sigma \supset j} \Psi_{\beta}^{\sigma}
$$

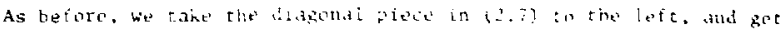

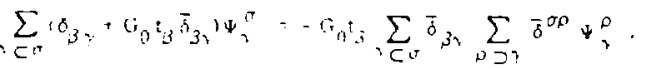

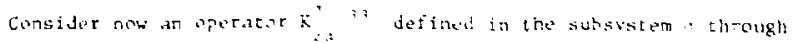
che equation

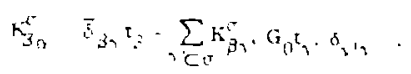

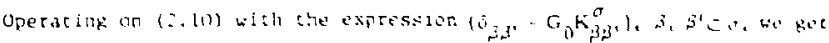

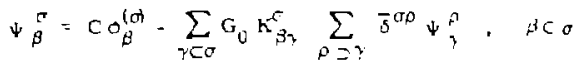

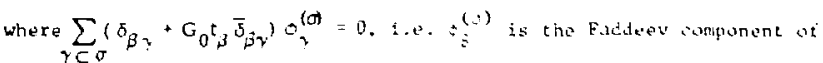
che wavefunction corresponting bo a bound state in the subsystem $\rightarrow$.

With our choice of intial state, $c=c$ and we abtain the four-boly Faddeov-Yakuboviki ( $\mathrm{Fr}$ ) equat inns."

The ke'rnel of $(2,11)$ is now more sonnected than that of (2.6), in the sense that its thitd (or higher) power does not cuntain discontueded pleces corresponding to twi non-interating elusters. The kernel ot (2.11) is sald to be four-body annereted (atter two itorations).

ItI. Cieneralizat ion the the Four-Body chase: Proliminary Lonsiderations

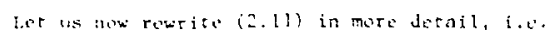

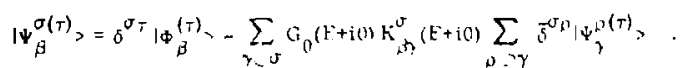

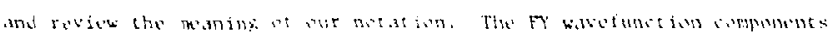

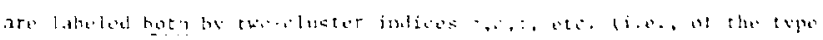

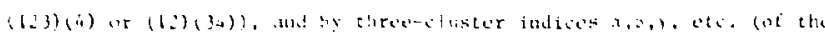
type $(12)(3)(4)$, i.e. piar indices). The decomponsition is such that $\sum_{\sigma} \sum_{\beta C \sigma} \Psi_{\beta}^{\sigma(\tau)}$ is the tuil fintr-indy wavefunction. A three-clujer inder

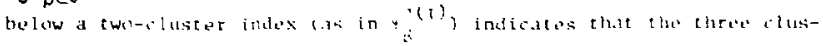

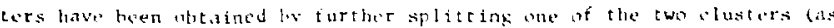


in $\alpha=(123)(4) \cdot(12)(3)(4)=\beta)$ ?" This is alse described by uriting $\beta(-\sigma$.

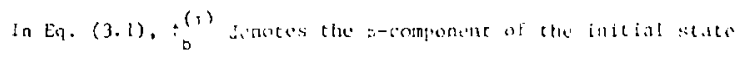

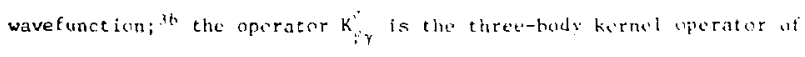

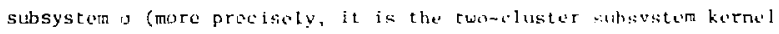

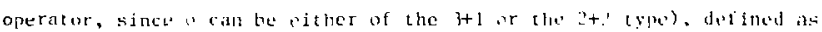

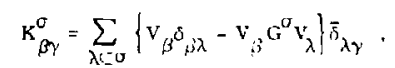

where $G^{U}=\left(H^{U}-E-i 0\right)^{-1}=\left(H_{0}+\sum_{\gamma-v} v_{\gamma}-E_{-i}-\right)^{-1}$.

In order to proceed with our treatment of the four-borly anse, we need to define the apropriate complete sets oi uigustates at the channel Handlemnians $\|^{\prime}$. For " of the $3+1$ type, the entaplete set ol

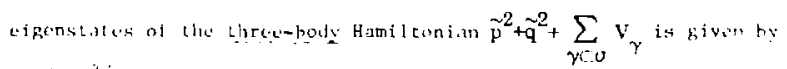
Fadderey" is beint

$$
\left.\left\{|\Phi\rangle,\left|\Psi_{\langle\rho) \vec{p}}^{ \pm},\right| \vec{p} \vec{q}\right\rangle\right\}, \quad \text { all } \delta<\sigma
$$

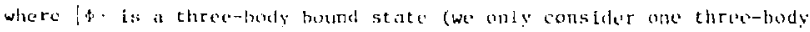
hound state per (hationel) of anerge $-1^{+}$(c)p is the (nutgoing wave)

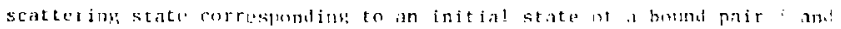

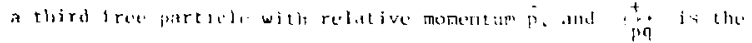

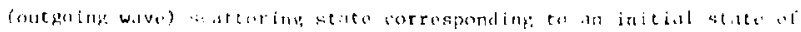

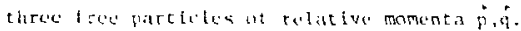

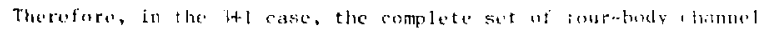
Digenstates can bu writen as

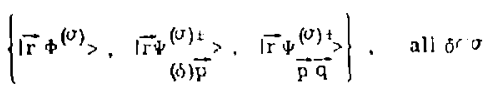

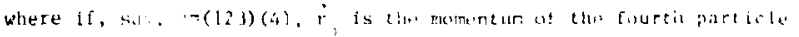

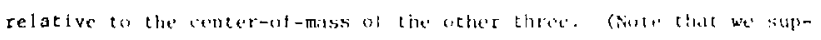
press the channel indices of all variablese?

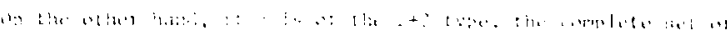

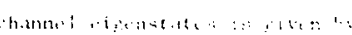

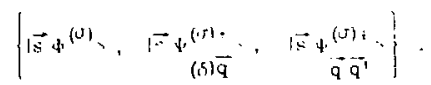

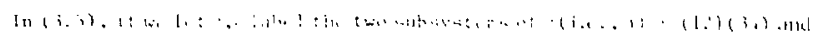

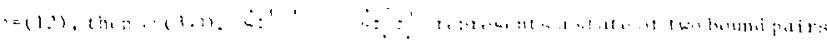

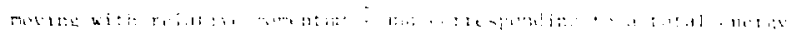

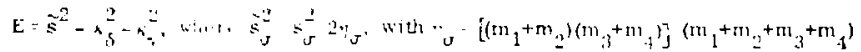

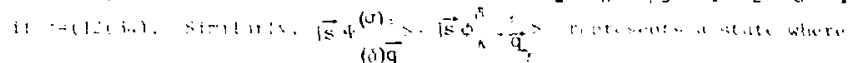

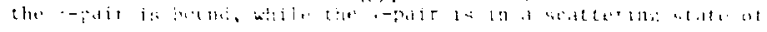

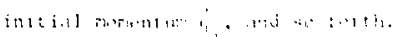

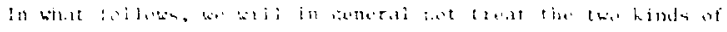

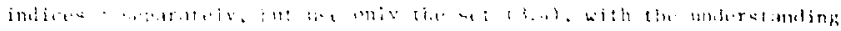

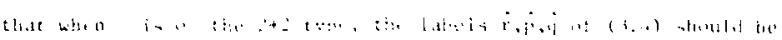

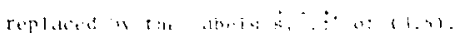

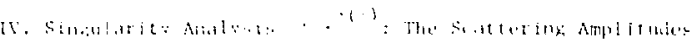

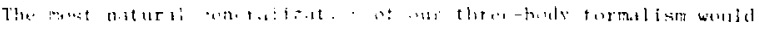

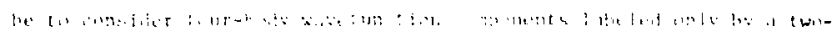

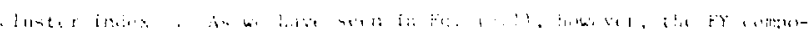

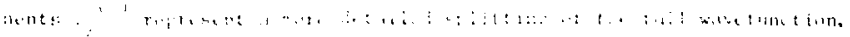

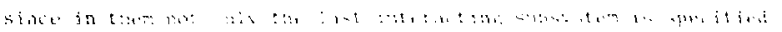

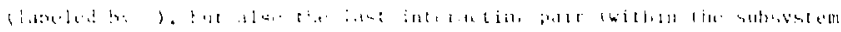

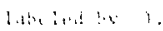

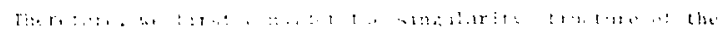

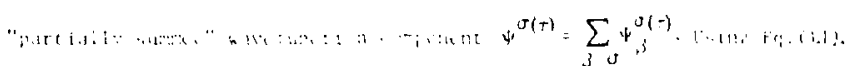
Lie $1 \mathrm{i}$ is:

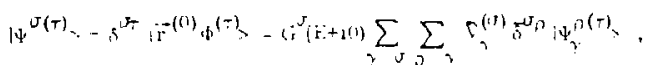


where $\nabla_{\gamma}^{(\sigma)}=\sum_{\lambda \subset \sigma} V_{\lambda} \vec{E}_{\lambda \gamma}$ (it is understood that $\gamma(\sigma)$, and we have used the relation

$$
G_{0} \sum_{\beta} K_{B \gamma}^{\sigma}=g^{\sigma} q_{\gamma}^{(\sigma)}
$$

which follows irom (3.2).

With the explicit appearance of the channel freen's function $G^{3}$ in (4.1), the singularicy analysis of $i^{0(1)}$ becumes straightforuard. Using the conplete set of channel eigensrates (3.4) or (3.5), we obtatn

$$
\begin{aligned}
& G^{u}(E+10)=\int \vec{r} \phi^{(U)}>\frac{d \vec{r}}{\vec{r}^{2}-\kappa_{\sigma}^{2}-E-10}<\vec{r} \phi^{(\vec{r})} \mid \\
& +\sum_{\delta \subset \sigma} \int\left|\vec{r} \Psi_{(\delta) \vec{p}}^{(\sigma)-}>\frac{d \vec{r} d \vec{p}}{\vec{r}^{2}+\vec{p}^{2}-\kappa_{\delta}^{2}-E-i 0}<\vec{r} \Psi_{(\delta) \vec{p}}^{(\sigma)-}\right| \\
& +\int \vec{r} \Psi_{\vec{p} \vec{q}}^{(\sigma)-}>\frac{d \vec{r} d \vec{p} d \vec{q}}{\vec{r}^{2}+\vec{p}^{2}+\vec{q}^{2}-E-i 0}<\vec{r} \Psi_{\vec{p} \vec{q}}^{(\sigma)-} \mid .
\end{aligned}
$$

where $\ddot{p}^{2}$ and $\dot{q}^{2}$ are defined in Section II, and $\dot{r}_{0}=\dot{r}^{2} / 2 n$, with $n_{0}{ }\left[m_{4}\left(m_{1}+m_{2}+m_{3}\right)\right]\left(m_{1}+m_{2}+m_{3}+m_{4}\right)$ 1f $g=(123)(4)$. With the aid of Eq. (4.3), (4.1) can nuw be wrtten ds

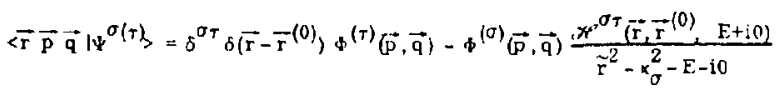

$$
\begin{aligned}
& -\sum_{\delta \subset \sigma} \int_{(\delta) \overrightarrow{\mathrm{p}}^{1}}^{(\sigma)-}(\overrightarrow{\mathrm{p}} \overrightarrow{\mathrm{q}}) \frac{d \overrightarrow{\mathrm{p}^{\prime}}}{\overrightarrow{\mathrm{r}}^{2}+\tilde{\mathrm{p}}^{\prime 2}-\kappa_{\delta}^{2}-\mathrm{E}-\mathrm{i} 0} \cdot \vec{F}_{(\delta)}^{U \tau}\left(\overrightarrow{\mathrm{r}}, \overrightarrow{\mathrm{p}^{1}} ; \overrightarrow{\mathrm{r}}^{(0)}: E+\mathrm{i} 0\right)
\end{aligned}
$$

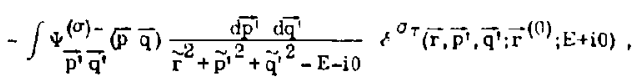

where

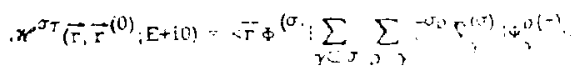

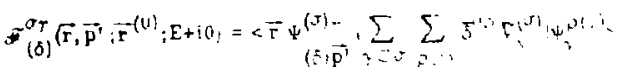

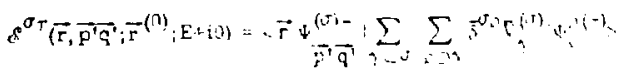

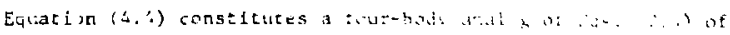

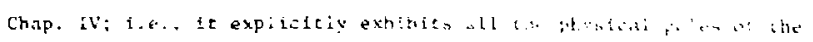

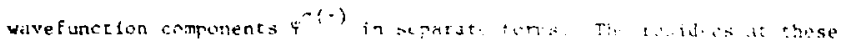

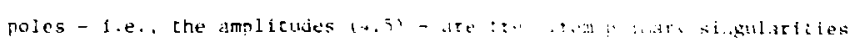

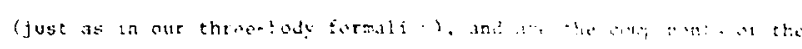

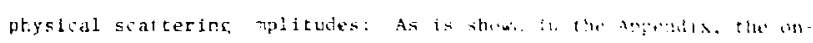

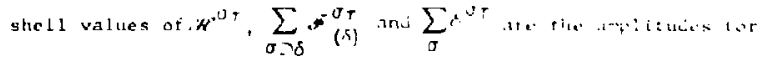

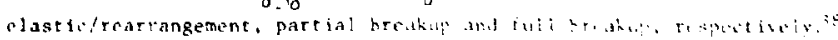

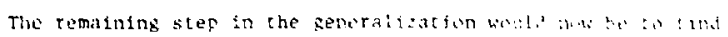

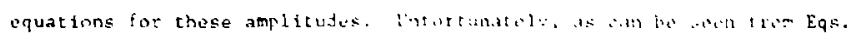

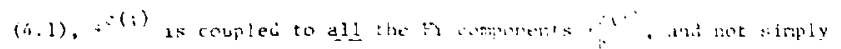

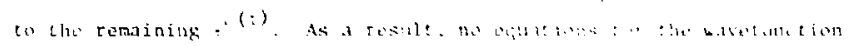

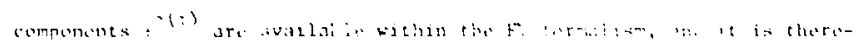

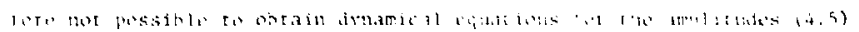
at thes stater.

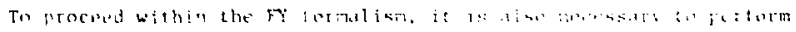

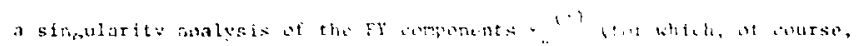

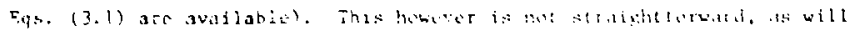

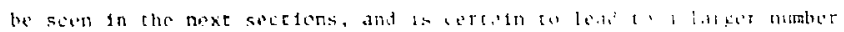

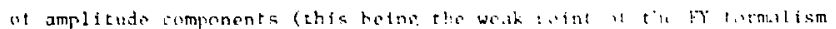
an min.rat). 


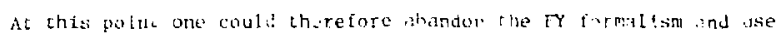
wher Bynamical equations for the components, (i), for coxample those discussal in Refs. 18 and 99 . Hiwever. all such alternatives wi dre

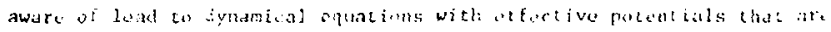
not only energy dependent, hat also require fully-off-siell sulsystem input. In additian, these alcernative aquations may posetaly admit spurious solutions. For lase reasuat, we choose to remaln within the FY formalism for the present writk.

\section{v. Sinpulartiy Analysis of the FY Components}

Recallins: fics. (j.1) and (3.2), we see that the kermel (hat must

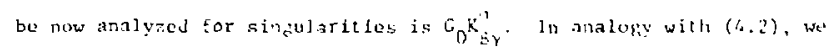
write

$$
G_{0} K_{\beta \gamma}^{\sigma}=\sum_{\lambda \subset \sigma} G_{\beta \lambda}^{\sigma} v_{\lambda} \tilde{\delta}_{\lambda \gamma}
$$

where

$$
\mathrm{G}_{\beta \lambda}^{\sigma}=\delta_{\beta \lambda} \mathrm{G}_{0}-\mathrm{G}_{0} \mathrm{v}_{\beta} \mathrm{G}^{\sigma}
$$

is: the Faddew somponent of the Green's funition $C^{\prime \prime}$, with the nesperty that $\sum_{\beta} G_{\beta \lambda}^{\sigma}=C^{0}$. Therefore, we see that for the pole decomposiction of

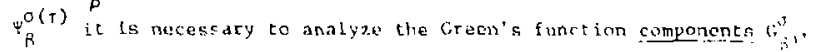
racher than $G^{3}$ 1tself. As is evitent from (5.2), use wi the simetral decomposition uf $6^{\circ}$ (Fq. (4.3)) is not sufficient, sunce there is also a pole in : $_{0}$. This pole is acrounted for in the folluwing way In wach term that results irom applying the spectral decomposition (a) in to the product $G_{0}(E+i 0) V_{B} G^{0}(E+i n)$ of $(5,2)$ we use the resolvent bent it

$$
\mathrm{G}_{0}(E+1 \epsilon)=\mathrm{G}_{0}\left(z^{\prime}\right)+\left(E+\mathrm{i} \epsilon-z^{\prime}\right) \mathrm{G}_{0}\langle E+\mathrm{i} \epsilon\} G_{0}\left(z^{\prime}\right) \text {. }
$$

with $z$ ' equal to the energy of the corresponding channe? elgristiate wath an imaginary part " that is always understoud to go aer before, ), aris ind $\therefore$,

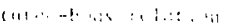

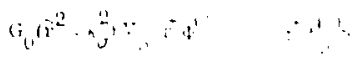

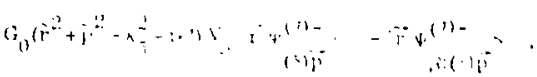

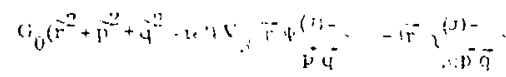

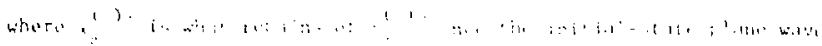

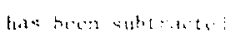

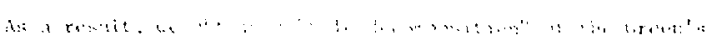

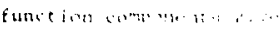

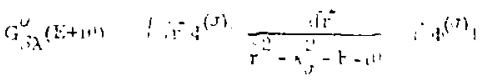

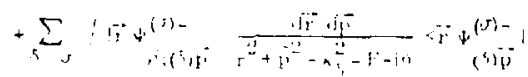

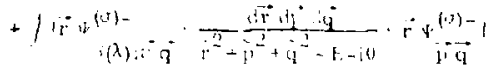

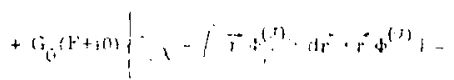

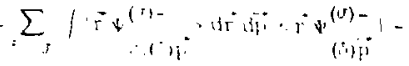

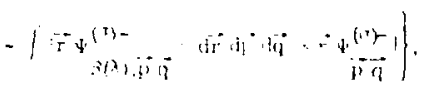

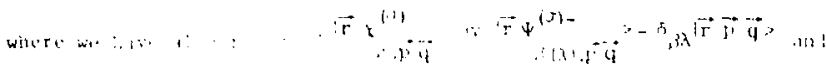

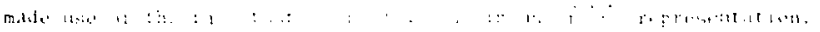

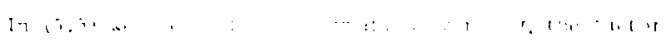

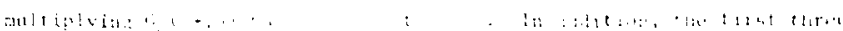


terms become cqual to the cxpression (4, 3) for $\mathrm{C}^{\prime}$, ince the Faddeey

onents of (5.5) ald ur to the furl channel digenstates.

Using (5.5), we finally obtain the stoughtit -tor pole decomposition c. the FY kernel $(5,1)$, and also of the FY wavefunction couponerits (3, 1): $<\overrightarrow{\mathrm{r} p} \overrightarrow{\mathrm{q}}\left|\Psi_{\beta}^{\sigma(\tau)}\right\rangle=\delta_{\delta \tau}^{\sigma_{\tau}}\left(\overrightarrow{\mathrm{r}}-\overrightarrow{\mathrm{r}}^{(0)}\right) \phi_{\beta}^{(\tau)}(\overrightarrow{\mathrm{p}} \overrightarrow{\mathrm{q}})$

$$
\begin{aligned}
& -\frac{\Phi_{\beta}^{(\sigma)}(\overrightarrow{\mathrm{p}} \overrightarrow{\mathrm{q}})}{\overrightarrow{\mathbf{r}}^{2}-\kappa_{\sigma}^{2}-\mathrm{E}-\mathrm{i} 0}, \%^{\sigma,}\left(\overrightarrow{\mathrm{r}}, \overrightarrow{\mathrm{r}}^{(0)} ; E+\mathrm{i} 0\right)
\end{aligned}
$$

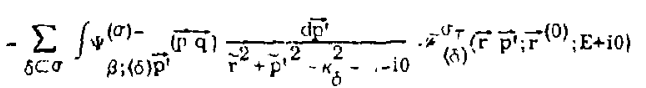

$$
\begin{aligned}
& -\sum_{\lambda \subset \sigma} \int_{\beta(\lambda) ; \overrightarrow{p^{\prime}} \vec{q}^{(\sigma)}}^{(\overrightarrow{p q})} \frac{d \overrightarrow{p^{\prime}} d \overrightarrow{q^{\prime}}}{\vec{r}^{2}+\vec{p}^{\prime 2}+\vec{q}^{2}-E-i 0} \delta_{\lambda}^{(\sigma+}\left(\vec{r} \overrightarrow{p^{\prime}} \vec{q}^{\prime} ; \vec{r}^{(0)} ; E+i 0\right) \\
& -\frac{1}{\vec{r}^{2}+\hat{p}^{2}+\tilde{q}^{2}-E-i 0} \cdot{ }_{\beta}^{\sigma_{T}}\left(\vec{r} \overrightarrow{p q} ; \vec{r}^{(0)} ; E+i 0\right) \text {, }
\end{aligned}
$$

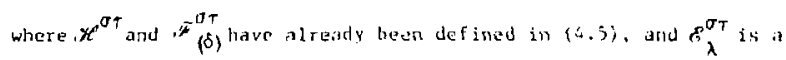
decomposition of the amplitude ${ }^{3}$ of (i. 5 ), i.e.

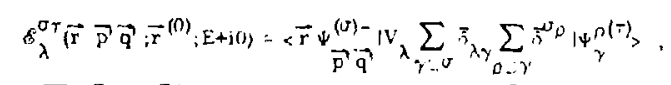

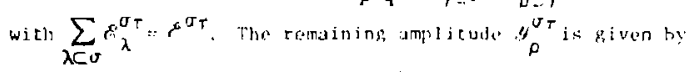

$$
\begin{aligned}
& \left.3_{\beta}^{\sigma \tau} \mid \overrightarrow{\mathrm{r}} \overrightarrow{\mathrm{p}} \overrightarrow{\mathrm{q}}_{i} \overrightarrow{\mathrm{r}}^{(0)} ; \mathrm{E}+\mathrm{i} 0\right)-\overrightarrow{\mathrm{r}} \overrightarrow{\mathrm{p} q}\left|\sum_{\lambda \subset \sigma}\right|{ }_{\beta \lambda}-
\end{aligned}
$$

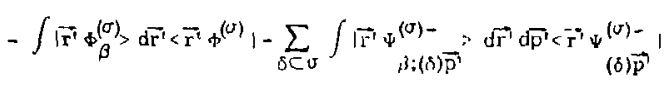

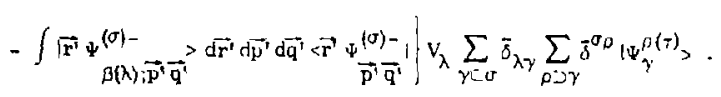

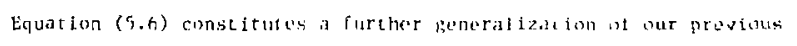

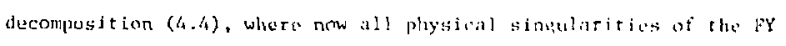

$$
-71-
$$

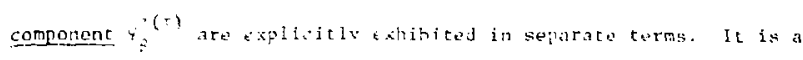

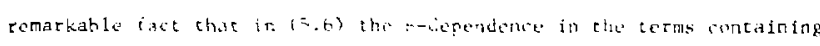
F'and factoriacs, so that these scatering amplitudes still depend only on the two-duster index: at tie wavetunction. In other words.

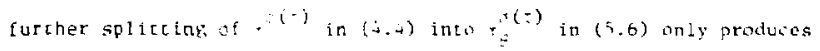
a spliting of the amplitude $x$.

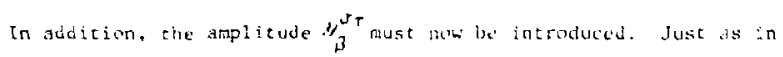

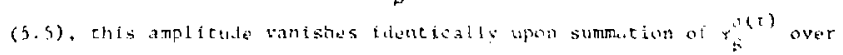

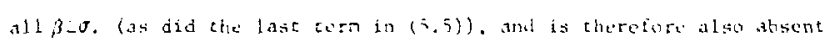

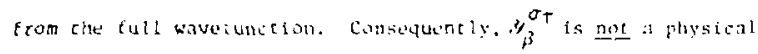
scatering amplituda.

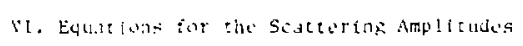

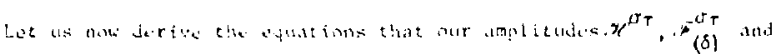
$\sum_{\beta}^{\sigma T}$ intistis.

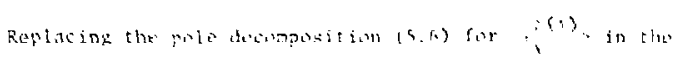

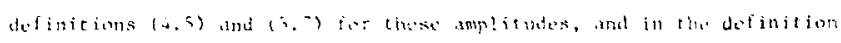

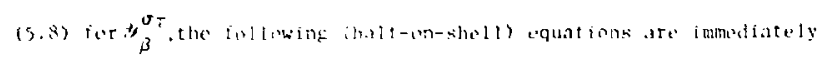
othiained:

$\mathscr{H}^{\mathrm{\sigma} \tau}\left(\vec{r} ; \overrightarrow{\mathrm{T}}^{-(0)} ; \mathrm{E}+\mathrm{i} 0\right)-\overrightarrow{\mathrm{H}}^{-\mathrm{U}-},\left(\mathrm{r} \times \mathrm{U}+\overrightarrow{\mathrm{r}} ; \mathrm{r}^{(1)}\right)$

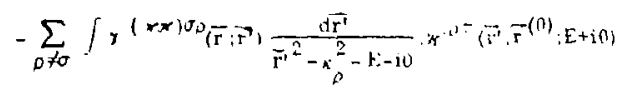

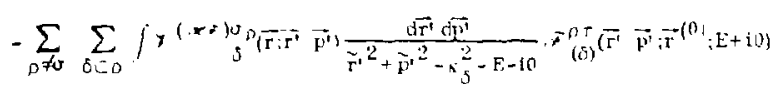

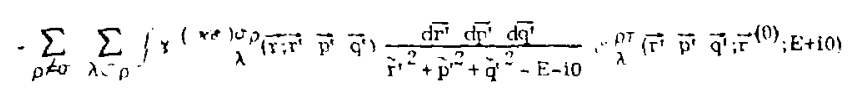

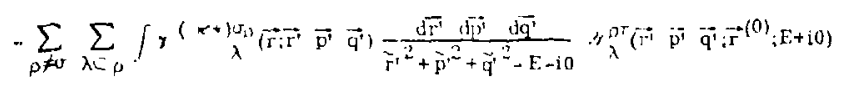




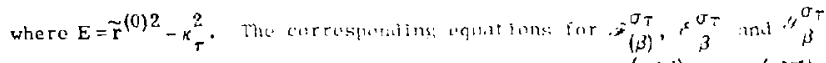
are ohcained from $(6,1)$ by replating, respetively, $f(x)$ by $x(x)$, $y(x, x)$ and $y(3 x)$, and sal an.

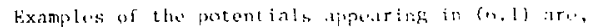

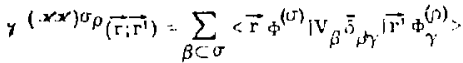

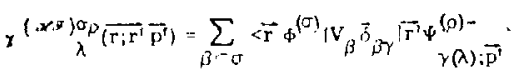

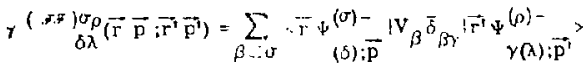

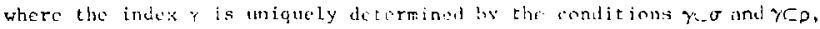
(ofo). (Note that when bothe and, are of the $2+2$ type on $\rho \equiv 0$, so the

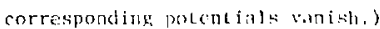

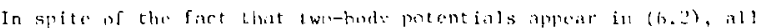
effective notenti:is in $(6,1)$ san he expressude in corms of halt-on-shell

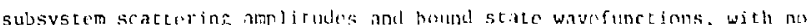
two-buly potentials rumaining axplicitly. Far axample, $f(x, 4)$ in (6.2) can be writton at:

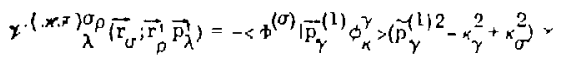

$$
\times\left\{\delta_{\gamma \lambda} \delta\left(\vec{p}_{\lambda}^{(2)}-\vec{p}_{\lambda}^{\prime}\right)-\frac{\left.\psi_{\gamma \lambda}^{p} \vec{p}_{\gamma}^{(2)}, \vec{p}_{\lambda}^{\prime} ; \tilde{p}_{\lambda}^{2}-\kappa_{\lambda}^{2}-10\right)}{\vec{p}_{\gamma}^{(2) 2}-\kappa_{\gamma}^{2}-\vec{p}_{\lambda}^{\prime 2}+\kappa_{\lambda}^{2}+i 0}\right\}
$$

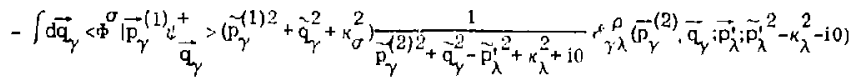

where, as in (6.2), $\gamma=\sigma \cap_{p}$ is uni gruely determined by and u(nti). Aiso,

$$
\overrightarrow{\mathbf{p}}_{\gamma}^{(1)}=\frac{\mathrm{M}_{\rho}}{\mathrm{M}_{\gamma}+\mathrm{M}_{\rho}} \overrightarrow{\mathrm{r}}_{\sigma}+\overrightarrow{\mathbf{r}}_{\rho}^{\prime} \quad \text { and } \quad \overrightarrow{\mathrm{p}}_{\gamma}^{(2)}=\overrightarrow{\mathrm{r}}_{\sigma}+\frac{\mathrm{M}_{\sigma}}{\mathrm{M}_{\gamma}+\mathrm{M}_{\sigma}} \overrightarrow{\mathrm{r}}_{\rho}^{\prime \prime} \text {. }
$$

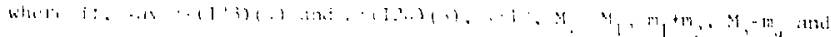

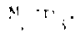

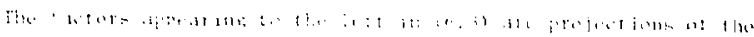

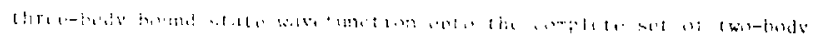

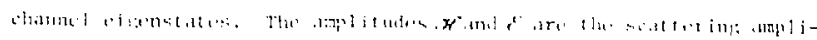

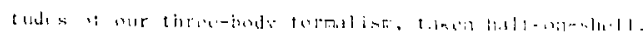

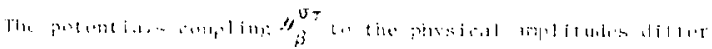

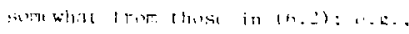

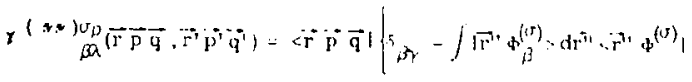

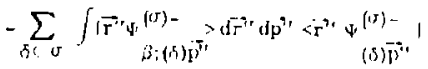

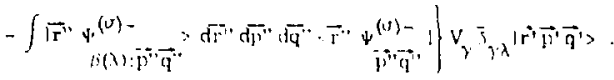

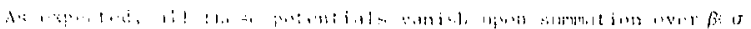

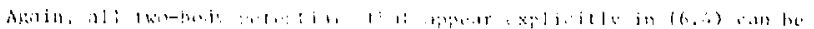

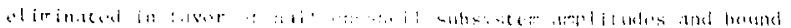

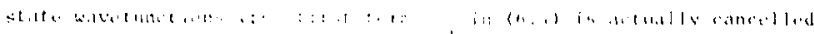

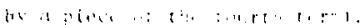

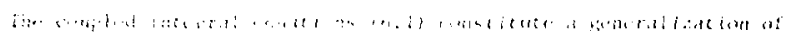

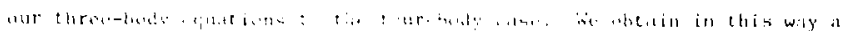

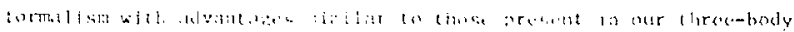

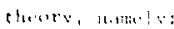

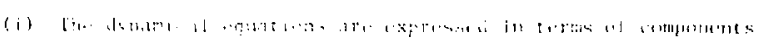

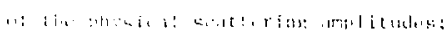

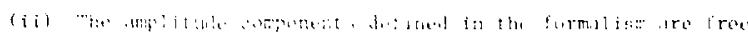

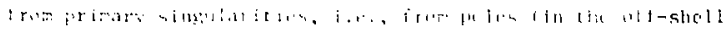

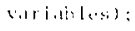


(i1i) The equations have the structure of a multtchenncl lippmannSchwinger formulation, with effectlve potentels that are independent of the four-body energy.

(iv) The equations require as input only half-ou-shell subsysten transicion amplitudes and bound scace wayefunctions.

As poinced out before, however, the equations also include a nonphysical amplitude $z_{\beta}^{\sigma \tau}$ and our goal is therefore not fully achieved. The presence of this nonphystcal amplitude can be understood as follows:

The FY equations are obcained from the four-body Lippmann-Schwinger equations by means of a t2o-step procedure $^{\text {th }}$ : the cwo-body disconnected pleces are first removed from the kernel, and only then are three-body disconnected pleces removed. (Thls is done in such a way that the resulting FY kernel connects three particles after one iteration and all four particles after two iteratir..; $3 \%$ ) As a consequence, the full wavefunction is split first accordin? to three-c! uster indices, and then split filtiner according to two-cluster indices.

on the other hand, as wh have seen, the sinputaricy structure of the full wavefunction is most naturatly exhibited by considering the wavefunction tomponents $f^{u(1)}$. sille miy according to the two-cluster index 0 . The (prior) additional splitting according to three-cluster indtces requtred by the FY formalism (In order to achteve connectedness of the kernel) appears thus far Jess nacural from the point of viow of the singularitic" of the kerned (ar from the point of view of asymptatil channels).

The fy formalism nevertheless require: lhat we ferform the more compleated singularity analysis of the fully-split wavefunction components $\psi_{g}^{a(r)}$, 1.e., that we retain the full index context of the Fr equattons. In choosing to reinaln witlit; the $r$ formel $\mathrm{ism}$, and insisting on energy-dependent helf-on-shell input, we are ant an? required co split the breakup amplitude $\varepsilon^{\sigma_{T}}$ iurther inis anpinnent: $i_{j}^{\sigma_{T}}$ (an expected copplication) but also to introduce the nunphysical amplicucies

VII. Generalization to the Fully-off-Shell cise

In the previous sections we constructed aur four-boly formadisn keeptre the use of four-body operators and wirater robitionti to a mintmum; 1.e., staytng essentally withto che wavefunction approach. It is Lllustrative however to consider how our formulation relatos to the

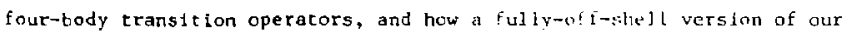
amplitudes car be obtained fron these operiturs.

To do so, we first recall fron Chap, 5 that an wir turee-hodv formalism the fully-off-shell amplitudes are delined us ing the threebo:ly operatoris

$$
T_{\beta \alpha}(z)=v_{\beta} G_{0}(z) U_{\beta \alpha}(z) G_{0}(z) v_{\alpha} .
$$

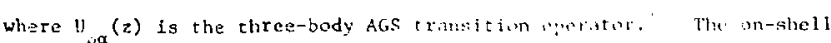

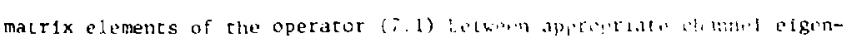

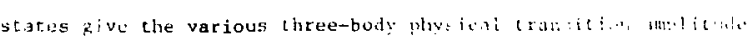
innwhents.

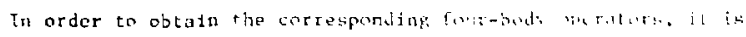

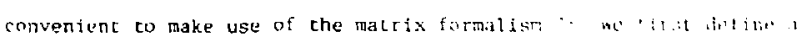

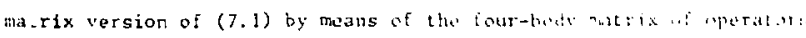
$\hat{\mathrm{T}}^{\sigma_{\tau}}=\left\{\hat{\mathrm{T}}_{\beta \alpha \alpha}^{\sigma_{\tau}}\right\}$, according to

$$
\hat{\mathbf{T}}^{\sigma \tau}=V^{(\sigma)} G_{0}^{(\sigma)} T^{(\tau)} G_{j}^{(\tau)} V^{(i)}
$$

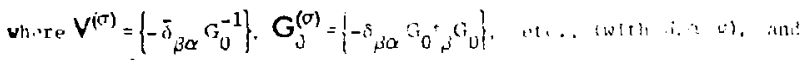

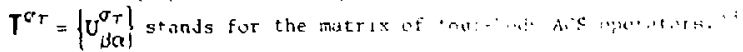


Next, al: in ( 7.11 , we sertme

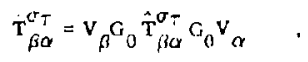

or, mure lexplicitl\%.

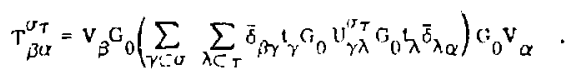

The equations these aperators satisfy and castly obtained using the

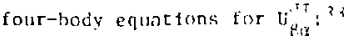

$$
\begin{aligned}
& \tau_{\beta \alpha}^{\sigma \tau}(z)=\tilde{\delta}^{\sigma \tau} \vec{\delta}_{\beta \gamma} \mathrm{V}_{\beta} \mathrm{G}_{0}(z) \mathrm{t}_{\gamma}(\mathrm{z}) \mathrm{i}_{0}(z) \mathrm{V}_{\alpha} \ddot{\delta}_{\gamma \alpha}
\end{aligned}
$$

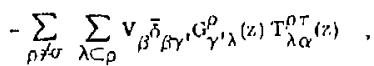

where $C_{Y}^{\prime}$, las beer detined in (5.2) (recall also (5.1)), end $Y \cdot y^{\prime}$ are

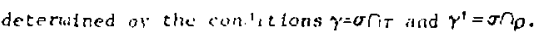

By analogy with the three-bndy case, we expect matrix elements of the mprators (7.3) (rather than matrix elemento of just $L_{B \alpha}^{i j}$ ) to be clusely related to the arititudes of the previuus sections. Indeed, by

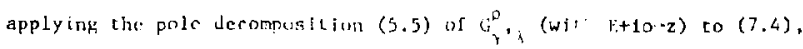

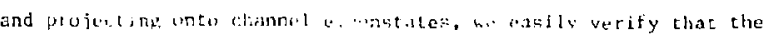

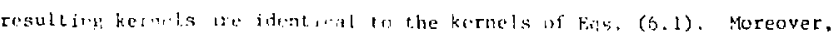

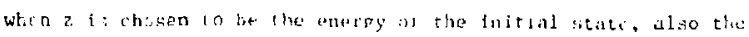

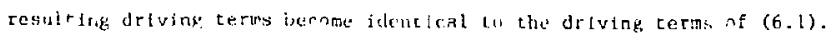

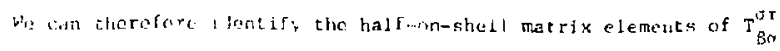
betwern appopriate initiul and final states with air greviously

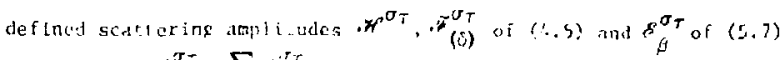

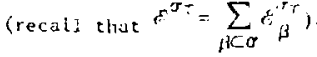

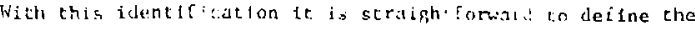

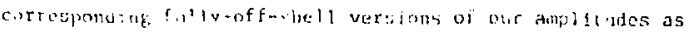

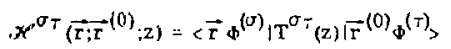

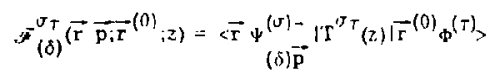

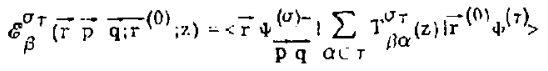

where

$$
T^{U T}=\sum_{\beta \leqslant U} \sum_{\alpha C T} T_{j i O}^{U T}
$$

It is important to note that it is frow the Appropriately "dressed"

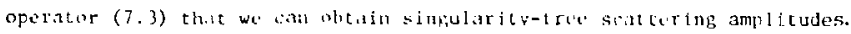
This is in analogy with the threw-iody cise, where the fiactor $v_{0} c_{0}$ in

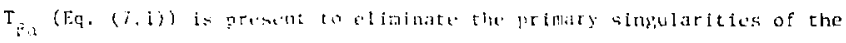

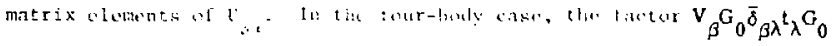

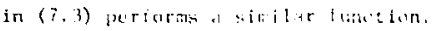

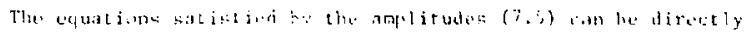

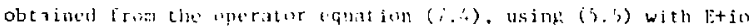
replaced by 2. The effertive antentials in the resulting cquations are

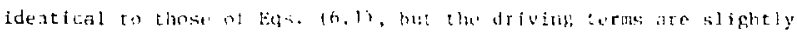
i) iturent.

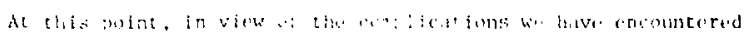

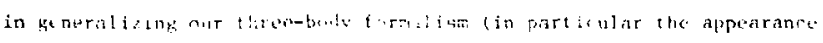

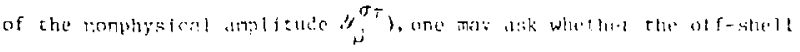

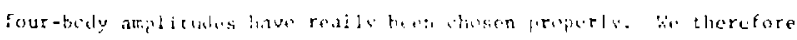

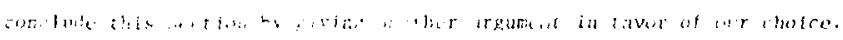

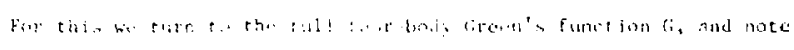

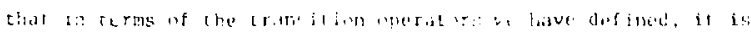
itraigleferingel te writ 


$$
G=G_{0}-G_{0} T G_{0}=
$$

$$
=G_{0}-\sum_{\gamma} G_{0}{ }^{t} G_{0}-\sum_{\sigma} \sum_{\beta \in \sigma} G_{\beta} T_{\beta \alpha}^{(\sigma)} G_{\alpha}-\sum_{\sigma, \tau} G^{\sigma} T^{\sigma_{T}} G^{T},
$$

where $T_{B a}^{(\sigma)}$ is che three-body (1.e., cwo-cluscer) transition bperator Eq. (7.1)), and $T^{\nabla \tau}$ has been defined in $(7.6)$.

In (7.7) we observe that the four-, three- and two-eluster disconnected pleces of $G$ have been separated from the true one-cluster $(i . i$. four-body connected) plece in a very natural manner. In addition, it $1 \mathrm{~s}$ easy to verify that the four-body connected pieces of $C$ can be written

$$
\mathrm{G}^{\sigma} \mathrm{T}^{\sigma \tau} \mathrm{G}^{\top}=\sum_{\substack{\beta \subset \sigma \alpha \\ \gamma \subset \alpha}} G_{\beta \gamma \gamma}^{\sigma} \mathrm{T}_{\gamma \lambda}^{\sigma_{T}} \widetilde{\mathrm{G}}_{\lambda \alpha}^{\top},
$$

where $G_{B Y}^{O}$ is the "left-hand" splitting of $G^{0}$ as defined in (5.2), and $G_{\lambda \alpha}^{T}=\delta_{\lambda \alpha} G_{0}-G^{T} v_{\alpha} G_{0}$ is the corresponding "Iight-hand" splitting of $G^{\Gamma}$.

we thus see that both the operators $T^{0 T}$ of $(7,6)$ and $T_{3 x}^{C}$ of $(7, h)$ appear tn the cluster decomposition of che four-body Green's function in a very natural manner, suggesting that they are indeed the proper ihilice of transition operators in this formalism.

\section{(1): : :}

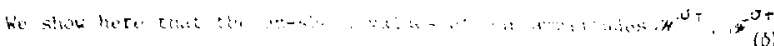

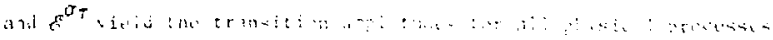

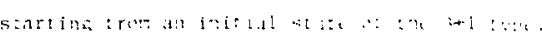

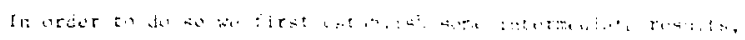

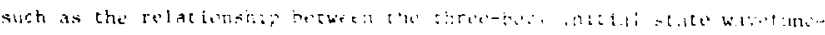

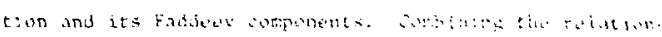

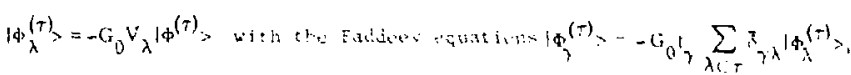
we get

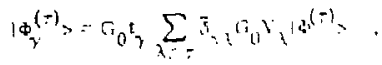

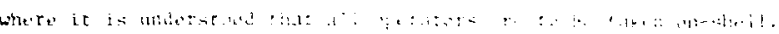

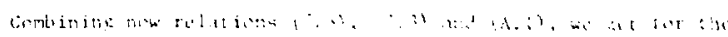

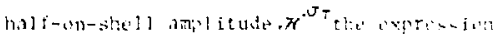

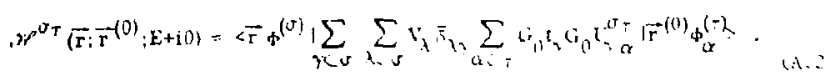

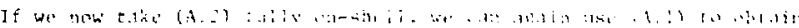

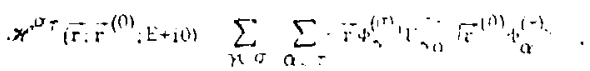

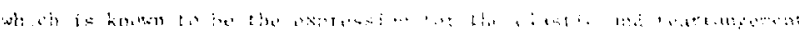

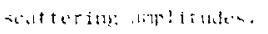

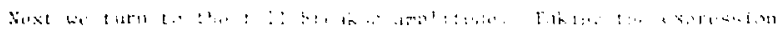

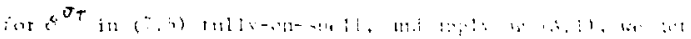

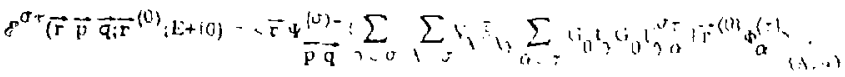

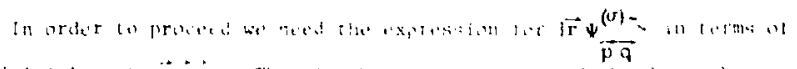

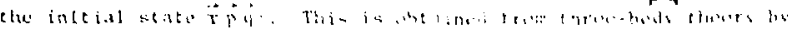
recalling that 


$$
\underset{\beta ; \vec{p} \vec{q}}{(\sigma)-}-G_{0}(E-10\rangle \sum_{\lambda C \sigma} M_{\beta \lambda \lambda}^{\sigma}\{E-10)|\overrightarrow{p q}\rangle
$$

where $\mathrm{M}_{\beta \lambda}^{\sigma}=\mathrm{V}_{\beta} \delta_{\beta \lambda}-\mathrm{V}_{\beta} \mathrm{G}^{\sigma} \mathrm{V}_{\lambda}$ is the three-body Faddew operator in subsesstem o. Combining (A.5) with the last of Eqs. (5.4) we obtain

$$
\mathrm{G}_{0}(\mathrm{E}-\mathrm{i} 0) v_{\gamma} \vec{\Gamma} \underset{\overrightarrow{\mathrm{p}} \overrightarrow{\mathrm{q}}}{(\sigma)-\mathrm{s}}=\mathrm{G}_{0}(\mathrm{E}-\mathrm{i} 0) \sum_{\lambda \subset U} \mathrm{M}_{\gamma \lambda}^{U}(\mathrm{E}-10)|\overrightarrow{\mathrm{p}} \overrightarrow{\mathrm{q}}\rangle .
$$

With (A.6), the on-shell amplitude $\varepsilon^{\sigma_{T}}$ can be writton (recall that $\mathrm{o}_{0}^{+}(\mathrm{E}-\mathrm{io})=\mathrm{o}_{0}\left(\mathrm{k}+\mathrm{io}_{0}\right)$, etr. $)$.

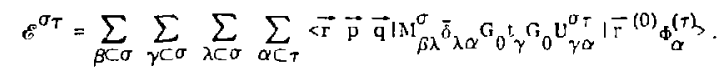

To simplify this expression we recall from the matrix nutartom"

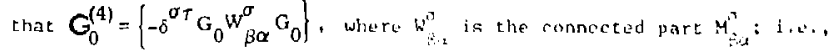

$$
w_{\beta \alpha}^{\sigma}=y_{\beta \alpha}^{\sigma}-\delta_{\beta \alpha} t_{\beta}=-\sum_{\gamma \subset \sigma} M_{\beta \gamma}^{\sigma} \bar{\delta}_{\gamma \alpha} \sigma_{0}^{t}{ }_{\alpha} \text {. }
$$

Using the fact that $G_{0}^{(4)} T^{(4)}=N^{(4)}=\left\{G_{0} K_{j \alpha}^{U T}\right\}$, where $k_{B}^{\prime \prime \prime}$, is the fourbody kernel operatur, we lan now berite instead of (A.)),

$$
\left.\mathscr{E}^{\sigma \tau}=\sum_{\lambda \subset \sigma} \sum_{\alpha \succeq T} \overrightarrow{\tau \tau} \vec{p} \vec{q}\left|K_{\lambda \alpha}^{\sigma \tau}\right| \vec{\Gamma}{ }^{(0)} \phi_{\alpha}^{(\tau)}\right\rangle .
$$

When summus uver 1. (A.9) hecomes identical th the expression for the full hreakiti seatetering amplitule pivert in kef. 14

We conclute by considering the partial breakun amplitude. We proceed as before, and taki axpression (7.5) for of $\sigma_{T}^{\sigma_{T}}$ fully an-she11,

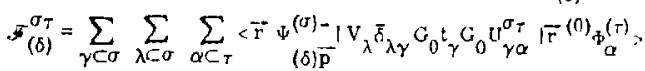

again using (A.I). Further, we recall from threatholy theory that

$$
|\Psi \underset{\beta ;(\hat{\delta}) \overrightarrow{\mathrm{p}}}{(\sigma)-}\rangle=\left(\delta_{\beta \delta}-\mathrm{G}_{0}(\mathrm{E}-\mathrm{i} 0) \mathrm{K}_{\beta \delta}^{J}(\mathrm{E}-\mathrm{i} 0)\right)\left|\overrightarrow{\mathrm{p}} \phi_{\mu}^{\delta}\right\rangle
$$

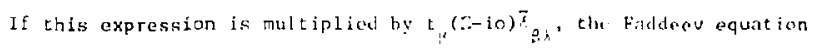
for $k_{B \delta}^{\sigma}$ wan be used to simplify the ripht-liand side. Using in addition

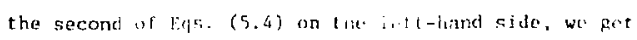

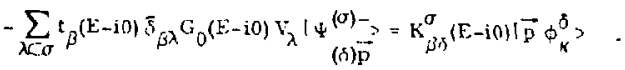

Finallv, with the relation $\mathrm{k}_{\beta \delta}^{\sigma}=-t_{B} \mathrm{C}_{0} \mathrm{U}_{\beta \delta}^{\sigma}$ we got for the on-shell valut of $(A .10)$,

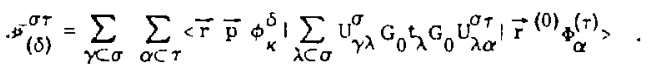

Wo compare thls with the expression olatained in Rot. Iis for the p.artiall britakul anrlitude, i.e. with

$$
\sum_{\mathrm{b}_{2}}\left\langle\phi^{\left[\mathrm{b}_{3}\right]} \mid \mathrm{B}^{(3,2)} 1 \phi^{\left[\mathrm{a}_{2}\right]}\right\rangle \text {; }
$$

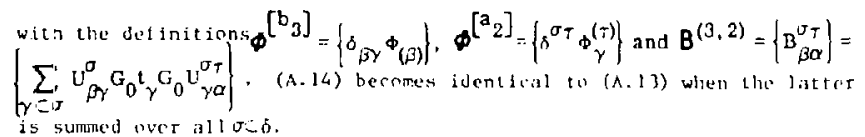




\section{Chapter Seven}

CONCLUSLONS

Within the context of non-relativistic quanturi mechanics and the tramework of a Humflonian scatcertny thenry, we have presented fit this vork new sets of dynamical equations for thrce- and four-body scatcerint expressed in terms of components of the physical scacterting amplizucus.

For the three-hody case, we have seen how the use of the complete sets of eigenstates of the channel Hamlitonians stgntficantly simplifies the formut tion of three-body scatering cheory. By using this representation we have ohtalned a new set of amplitudes for all thrce-body processes that crijicide m-shell with the phystcal transitfon amplitudes. We have further shown how these inplitudes satisfy integral equations that are simpler thon the usual Faddcev equations:

(1) The effective potentials are all independert of the theesbady inergy ;

(ii) The fiput consigts solely of two-body bound state wayefunctione and half-off-shell transition amplitudes;

(ili) Our cholce bi partial wave components ot the theno-bodv amplitudes satisfy equations with real effective potentials. In addition, the hreakip amplicudes explicitly exhihit a Watson fí factor.

Finally, we expect that hy the tature of the infuc to theise andutions, they will be particularly uscful in understanding the dependenco of three-body observables on the off-shell two-body input. In addition. the simplified structure of our equations suggests that the problein of constructing approximation schemes should now be reconsidered.

We have also carrled our a generalization of this metind to the

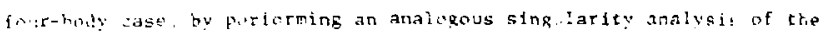

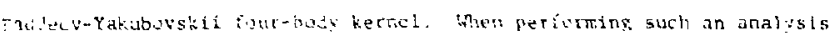
on the wavefullition component: (t) where. th a two-luster-fndex -

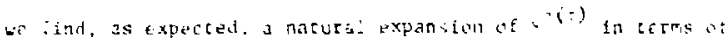

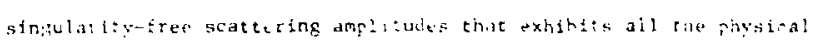

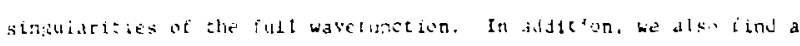
cortespolding natural separation of the four-t.ly reen's function into picics of iacreasirg degree of zonnectedness.

Howerer, silue this analysis is catried out on ohteces thit are

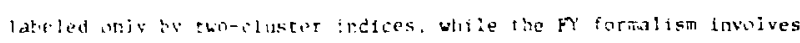

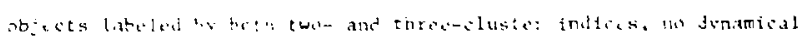

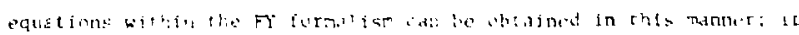
becises necessaty to curre wat a gore betailed and muth lese transparent sirgularly analysis of the $F$ components $4: 01$.

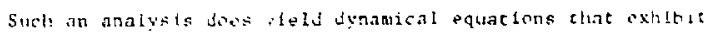

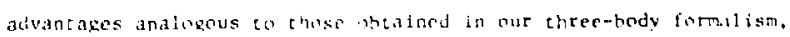
nameln,

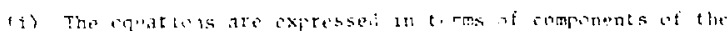

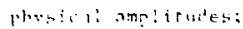

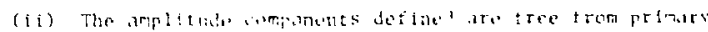

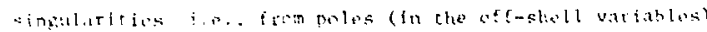

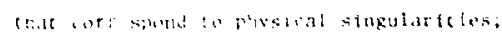

(1ii) The equations hive the structure at a multichaune leippmansiluinget tormulation. with effective potentials that aro inclefendent it the four-body anergy;

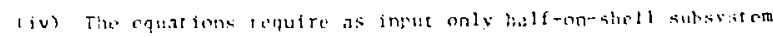
transithon amplitudes and buund state wavefunctoms. 


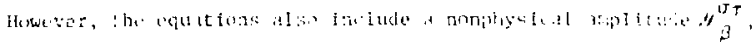

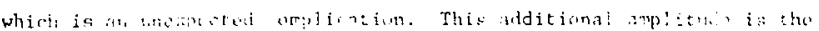

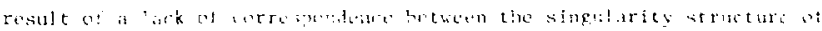

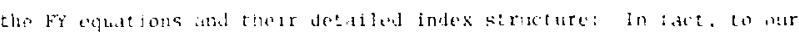
prosent understanding, tise connectosness of the (twice itarard) $\mathrm{kr}$

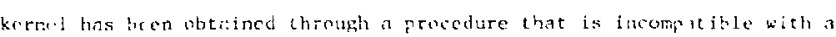

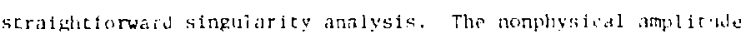
serves to conponinte tar tids incompatibility, in a way that allow the de-ired fuature (i) $\cdots$ (iv) wo be earricd over directly trom the

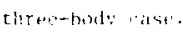

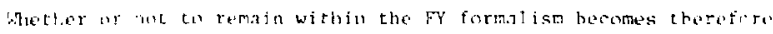

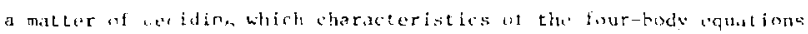

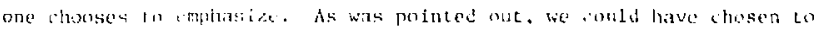

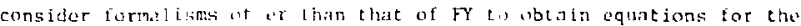
components: (i). Sime uf these formalists, however, are clearly free fecm spuriou:; solut 1.1:5; and, sare importantly for our present treatment, all the alternative fermalisms be are aware of lead to oquarions with an input thit $i$ i not only energy-dependnat, but also folly-off-shell. In kerping, with our an of obtaining a theory without such feacures, we have chosen far the presint wark to remiin within the ty sormalis. Nevertheless, furtiser work or, alternative formulations of the forar-body theory is clearls alled for.

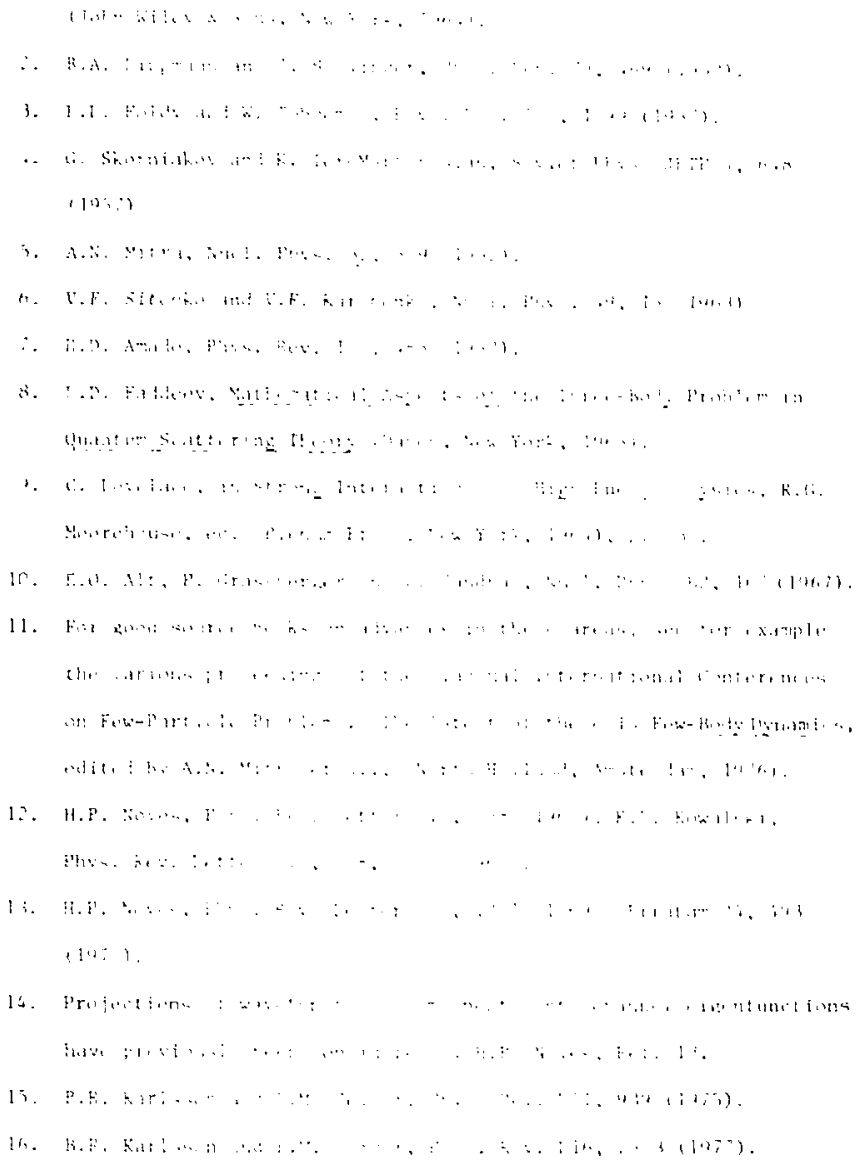


17. O.A. Yakubovskii, Yad, Fiz. 5, 1312 (1967) (Sov. J. Kucl. Phys. 5, 937 (1967)).

18. I. 4 Sloan, Phys. Rev. C6, 1945 (1972)

19. See Ref, 8. Primary singularicies (i,e. elastir, rearrangement or breakup poles) can be distinguished from secondary singularities by the fact that the former are present in all teriss of an iteracivo series of the amplitudes, while the latter get progressively weaker and disappear after a few itcrations.

20. A. Ya, Povzner, Matem. Stornik, 32, 109 (1953); Doklady Akadeni: Nauk SSSR, 104. (1955); T. Kato, Trans. Am. Marh. Soc., 70, 195 (1951).

21. See for example F. Snithies, Integral Equations (Cambridge Lniversity Press, New York, 1958). More details on the the'wry of integral equations will be given in Chap. 3 .

22. Ser Ref. 21, and also: F. Riesz and B. Sz-Nagy, Funcitunal Analysis (Frederich Ungar Publishing Co., New York, 19i5); S. Wininberg, Phys. Rev, 130, $776(195,3)$ : Pliys, Reve, 13!, 441) (1963),

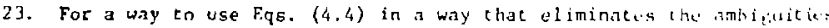

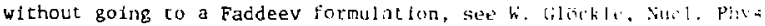
A. $141,620(1970)$

24. L.D. Faddeev, JFTP 39, 1459 (1960) (Sov. Phys. JETP $12,101.4(1+41)\}$

25. Rev. 8, Chap, 9

26. Lbid., Chap. 5.

27. T.A. Osborn and K.L. Kowalsk1, Ann. Phys. (ii.Y.) 68, 361, (19:1).

28. B.R. Karlsson and E.N. Zelger, in Few Particle Protelgens in the Nuclear Interaction, I. Slaus et al., eds., (North-hollind, Ansterdam, 1972), P, 330, and Repore No. SLAC-PIBB-1139, Scuniur.

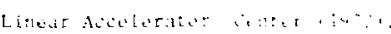

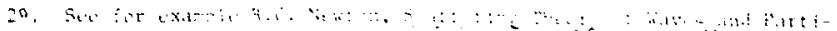

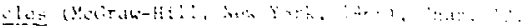

30. K.Y, hat $10 \div \div 1$

31. Ref, \&, G1\%, :

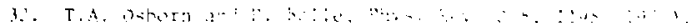

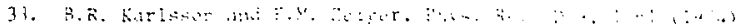

3. B. B.

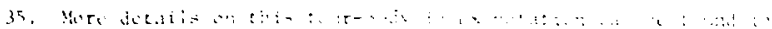

R.',$\quad$ i i

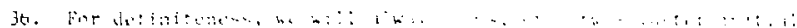

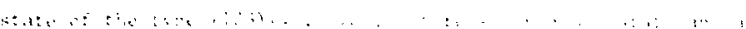

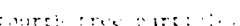

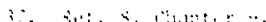

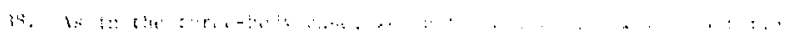

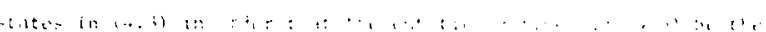

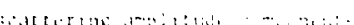

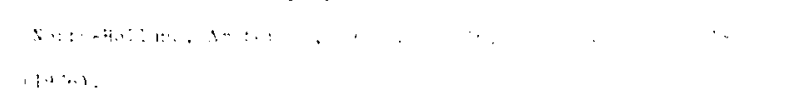

